Universidade de São Paulo

FFCLRP - Departamento de Física

Pós-graduação em Física Aplicada à Medicina e Biologia

\title{
Imagens acústicas geradas pela interação da radiação ultrassônica com o meio material
}

\author{
André Luis Baggio
}

Tese apresentada à Faculdade de Filosofia, Ciências e Letras de Ribeirão Preto da Universidade de São Paulo, como parte das exigências para a obtenção do título de Doutor em Ciências. Área: Física Aplicada à Medicina e Biologia.

Ribeirão Preto - SP

2011 


\section{ANDRÉ LUIS BAGGIO}

\section{Imagens acústicas geradas pela interação da radiação ultrassônica com o meio material}

Tese apresentada à Faculdade de Filosofia, Ciências e Letras de Ribeirão Preto da Universidade de São Paulo, como parte das exigências para a obtenção do título de Doutor em Ciências.

Área de Concentração:

Física Aplicada à Medicina e Biologia.

Orientador:

Prof. Dr. Antonio Adilton Oliveira Carneiro

Versão corrigida

Ribeirão Preto - SP

2011 
Autorizo a reprodução e divulgação total ou parcial deste trabalho, por qualquer meio convencional ou eletrônico, para fins de estudo e pesquisa, desde que citada a fonte.

\section{FICHA CATALOGRÁFICA}

Baggio, André Luis.

Imagens acústicas geradas pela interação da radiação ultrassônica com o meio material/ André Luis Baggio; orientador Prof. Dr. Antonio Adilton Oliveira Carneiro. Ribeirão Preto, 2011. 143 p.

Tese (Doutorado - Programa de Pós-Graduação em Física Aplicada à Medicina e Biologia) - Faculdade de Filosofia, Ciências e Letras de Ribeirão Preto da Universidade de São Paulo.

1. Ultrassom. 2. Propriedades Mecânicas. 3. Acústica. 4. Elastografia 5. Efeitos Não Lineares. 

Nome: Baggio, André Luis

Título: Imagens acústicas geradas pela interação da radiação ultrassônica com o meio material

Tese apresentada à Faculdade de Filosofia, Ciências e Letras de Ribeirão Preto da Universidade de São Paulo, como parte das exigências para a obtenção do título de Doutor em Ciências.

Aprovado em:

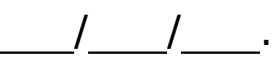

\section{Banca Examinadora}

Prof. Dr. :

Instituição:

Julgamento:

Assinatura:

Prof. Dr. :

Instituição:

Julgamento:

Assinatura:

Prof. Dr. :

Instituição:

Julgamento:

Assinatura:

Prof. Dr. :

Instituição:

Julgamento:

Assinatura:

Prof. Dr. :

Instituição:

Julgamento:

Assinatura: 


\section{Dedicatória}

Dedico este trabalho à minha mãe, aos meus irmãos, pelo apoio e carinho e ao meu pai (in memorian) e, é claro, à Jussara, minha esposa, por sua paciência nos meus vários momentos de ausência e introspecção e, principalmente, pela sua companhia e dedicação. Sem ela, esse trabalho não teria sido tão prazeroso'. 


\section{Agradecimentos}

- Para a realização deste trabalho tive que superar muitos obstáculos, ultrapassando o limite das minhas virtudes, isso só foi possível graças a Alguém que denomino Deus e aos demais que Ele colocou em minha vida

- Dedico primeiramente, uma enorme gratidão ao professor Dr. Antonio Adilton Oliveira Carneiro não só pela orientação mas também pelo apoio, dedicação, companheirismo e, principalmente pela confiança que depositou em mim, pois sempre me deu a liberdade para criar e ousar e se, as vezes, me senti meio a vontade, meio solto, eu hoje, dou o nome a isto de credibilidade, que com certeza fez-me amadurecer muito na vida acadêmica, e pra ser justo, na verdade, eu estava sempre sendo observado de perto por ele, me conduzindo, orientando, cobrando e insistentemente tentando colocar me no cronograma.

- Agradeço, sem dúvida, aos meus colegas de trabalho do grupo Giimus, os quais devo uma parte deste trabalho, principalmente pela troca de conhecimento, Destes, em especial não posso deixar de citar: Théo Z Pavan, Hermes A.S. Kamimura, Tenysson W. Lemos, Thiago W.J. Almeida, Alexandre C. Bruno, Raimundo N. A. Costa, Ebenézer $\mathrm{S}$. Cavalcanti pela grande ajuda nos experimentos e nas correções deste trabalho, Marden A. Fagundes e Rogério Bulha pelo grande apoio tecnológico, Larissa N. Gatto, Diego R. T. Sampaio, Marcelo L. A. Pádua, Gislaine Marini, Artur Menezes, Eduardo, Anderson, e outros tantos que por ali passaram. 
- Ao professor Dr. Luiz Otávio Murta Junior, por sua disponibilidade ao tirar muitas dúvidas de processamento de sinais.

- Ao Professor Dr.Emérito Sérgio Mascarenhas, pelos incentivos, as injeções de ânimo e por disponibilizar o seu precioso tempo comigo.

- Não poderia deixar de lembrar do amigo prof. Dr. Silvio Leão Vieira que, com muita disposição se prestou prontamente a discutir muitos pontos importantes que melhoraram e muito a discussão deste trabalho.

- Aos professores Drs. Carlos Ernesto Garrido Salmon, Oswaldo Baffa Filho e Antônio Carlos Shimano pelas importantes contribuições no processo de qualificação, e pelas dúvidas e esclarecimentos pelos corredores do departamento

- Um agradecimento especial ao professor Dr. Glauber J. F.T. Silva, pelas discussões científicas, sugestões e incentivo.

- Agradeço também aos técnicos do departamento de física que jamais deixaram de atender minhas solicitações prontamente, se não menos, os agradeço pelos ensinamentos técnicos que me proporcionaram. Em especial aos senhores Agnelo dos Santos Bastos Neto, Carlos Alberto Brunello, José Luiz Aziani, Sérgio Oliveira Bueno da Silva, Eldereis de Paula, Éucio Aparecido Navas,Lourenço Rocha e a senhora Nilza Marina Leone Marino.

- Ao professor louri Borissevitch que, como poucos, conseguia entender de primeira minhas perguntas mal formuladas sobre física básica.

- Aos meus amigos Eric Smaniotto e Jefersson Ferrari e Fabio Doro, pela colaboração nos conceitos de química e por aguentar um físico no território dos químicos. 
- Agradeço também aos autores do template em LaTex Erbe L. Pandini, Isaias J. A. Soares e Leandro Rizzi.

- E por último, agradecimentos especiais a toda minha família, e especialmente: ao meu tio Antonio Caliri por ser um segundo pai, pelo apoio e ensinamentos de conduta ética e um pouquinho da muita física que carrega na bagagem! e é claro, os livros que me emprestou que, acredito, nunca irei devolvê-los. Meu tio Mauricio e família pela acolhida em sua casa e pelo apoio financeiro e moral. Minha esposa Jussara, pelos conselhos, palpites, correções, apoio e muita paciência, a final aguentar um físico em vésperas de defesa é com muito amor mesmo! Ao meu Irmão Alessandro, porque eu nunca ouvi dele nenhuma palavra que não fosse de apoio, a grande ajuda, e por fazer valer a palavra irmão!! A minha Irmã Kelly que sempre se mostrou muito orgulhosa e feliz com meu caminho e pela torcida pra que desse tudo certo. Ao meu Pai, que mesmo não mais entre nós, deixou me de herança não dinheiro, mas os maiores valores que um homem pode ter, ética, honestidade, simplicidade e lealdade. Por último, agradeço imensamente minha mãe que foi também pai, amiga, pelo amor incondicional, por me confortar e me trazer até aqui, mesmo contra todas as adversidades, necessidades e por sempre me fazer acreditar que eu poderia chegar mais longe mesmo sobre a incredibilidade e pessimismo de muitos. Se alguém ficou de fora desta relação, peço desculpas e digo que estão guardados em algum lugar das minhas melhores lembranças. 
"There's really no secret about our approach. We keep moving forward, opening up new doors and doing new things, because we're curious... and curiosity keeps leading us down new paths. We're always exploring and experimenting."

\section{Walt Disney}

"If I had eight hours to chop down a tree, I'd spend six hours sharpening my ax."

Abraham Lincoln

"Reconheça o que está ao alcance dos seus olhos, e o que está oculto tornar-se-á claro para você." 


\section{Resumo}

Baggio, A.L. Imagens acústicas geradas pela interação da radiação ultrassônica com o meio material. 2011. Tese (Doutorado Programa de Pós-Graduação em Física Aplicada à Medicina e Biologia) - Faculdade de Filosofia, Ciências e Letras de Ribeirão Preto da Universidade de São Paulo. 2011.

Neste trabalho é apresentada uma nova modalidade de imagens elastográficas baseada na emissão acústica, quando um meio é submetido à radiação ultrassônica. Esta técnica está sendo denominada de Acustografia por Pulso/Emissão (APE). Características não-lineares da propagação acústica de ondas ultrassônicas, e a resposta mecânica vibracional, foram utilizadas como artifício para geração de imagens com frequências da ordem de quilohertz $(\mathrm{kHz})$, a partir da excitação com ondas ultrassônicas na ordem de megahertz. Para exemplificar a produção de imagens com essa nova modalidade, simuladores de tecido biológicos foram construídos com diferenças de rigidez localizadas, e submetidos a uma radiação ultrassônica focalizada ( $\mathrm{MHz}$ ). O som emitido devido a interação da onda ultrassônica com a região de interesse foi gravado e processado de modo a associar cada pequena porção do tecido a um valor relacionado a rigidez para a formação da imagem. Os resultados mostraram que o método pode produzir imagens associadas às alterações viscoelásticas das amostras. A resolução espacial mostrou-se fortemente ligada a morfologia do campo acústico de excitação, sendo possível detectar estruturas da ordem de $0,25 \mathrm{~mm}$ iso- 
xiv

ladamente. A técnica de aquisição desenvolvida e apresentada neste trabalho é similar a técnica de vibroacustografia, todavia, com uma instrumentação reduzida e com a possibilidade de obtenção de mais informações da estrutura do meio material, a partir dos fenômenos não lineares observados. Estudos pilotos de aplicação desta nova técnica e da vibroacustografia foram realizados e comparados para a avaliação de potenciais aplicações, por exemplo, na avaliação do sinal acústico diante de mudanças nas propriedades viscoelásticas do meio induzidas por mudança de temperatura; formação de imagens em meios com inclusões isoecogênicas e com rigidez ligeiramente diferentes; geração de imagens de estrutura óssea in vitro.

Palavras-chave: ultrassom, propriedades mecânicas, vibroacustografia, elastografia, efeitos não-lineares. 


\section{Abstract}

Baggio, A.L. Acoustic images generated by the interaction of ultrasonic radiation with the medium. 2011. Thesis (- Physics Applied to Medicine and Biology Graduate Program) - Faculdade de Filosofia, Ciências e Letras de Ribeirão Preto da Universidade de São Paulo. 2011.

In this work is presented a new modality of elastography images based on the acoustic emission when a material medium was subjected to a ultrasound radiation. This technique nonlinearity behavior of the acoustic wave propagation and the vibrational mechanical response were used to produce images from kilohertz frequencies when the sample was excited by ultrasound waves in megahertz. To produce images with this modality, tissue mimicking phantoms were made with stiffness inhomogeneities, and subjected a focused ultrasound radiation pulses. The sound emitted due the interaction of the ultrasound wave with the region of interest was recorded and processed in order to associate each small portion of the tissue to a value for image formation. The results showed that this method can produce images associated to the viscoelastic changes of the samples. The spatial resolution have showed strongly linked to the morphology of the excitation acoustic field, this way was possible to detect isolated structures in order of $0.25 \mathrm{~mm}$. The acquisition technique developed and presented in this work is similar to the vibroacoustography technique, however with reduced instrumentation setup and with the possibility to acquire further information about the structure of the material from the nonlinear phenomenal. 
$x v i$

Preliminary studies of this new technique and the vibroacoustography were made and compared to evaluate the potential applications, for example, in the evaluation of the acoustic signal behavior due changes in the viscoelastic properties changes induced by temperature variations; image formation in the medium with lightly stiffness inclusions; generation of the images of bone structure in vitro.

Keywords: ultrasound, mechanical properties, elastography, vibroacoustography, nonlinear effects. 


\section{Lista de Abreviaturas}

APE Acustografia por Pulso/Emissão.

CW Modo Onda Contínua (Continuous Wave).

FFT Transformada rápida de Fourier (Fast Fourier Transform).

FWHM Largura à meia altura (Full-width at half-maximum).

$\mathrm{kHz} \quad$ Unidade kilohertz.

KZK Equação de Khokhlov-Zabolotskaya-Kuznetsov.

$\mathrm{MHz} \quad$ Unidade Megahertz.

PSF Função espalhadora de pontos (Point spread function).

PZT Titanato zirconato de chumbo, abrev.de $\mathrm{Pb}\left[\mathrm{Zr}_{x} T i_{1-x}\right] \mathrm{O}_{3}$.

RCA Transdutor matricial reconfigurável (Reconfigurable array).

RMS Valor Eficaz, (Root mean square).

TB Modo Toneburst

US Ultrassom (Ultrasound).

VA Vibroacustografia (Vibroacoustography).

HIFU Ultrassom de alta intensidade (High Intensity Focused Ultrasound).

RSR Relação sinal ruído.

SNR (Singla to noise ratio). 
xviii 


\section{Lista de Símbolos}

$a_{1}$ raio do elemento central do transdutor de excitação.

$a_{21}, a_{22}$ Raios menor e maior do elemento externo do transdutor confocal.

A Área.

co Velocidade do som.

$c_{n} \quad$ Relaciona a função modo vibracional com sua frequência.

$c_{a} \quad$ Relaciona a pressão com a frequência do modo vibracional.

$\vec{d}_{r} \quad$ Vetor coeficiente de arrasto.

$d B \quad$ Decibel.

dS Elemento de área.

f Frequência.

$f(t) \quad$ Função envelope.

F $\quad$ Amplitude da Força de radiação.

$F_{d} \quad$ Componente dinâmica da força de radiação.

$f_{r}(P, t) \quad$ Força de radiação acústica.

$f_{R} \quad$ Fator de correção das resoluções das imagens.

$F_{Z} \quad$ força na zona focal.

$H_{\omega_{e}} \quad$ Função transferência. 
$H_{n} \quad$ Fator de Magnificação.

$n_{P} \quad$ Número de polos do filtro digital.

jinc Função de Bessel cilíndrica de primeira ordem.

$k \quad$ Número de onda.

$p \quad$ Pressão.

$P_{1}, P_{2}, P_{i} \quad$ Amplitude de pressão.

$P_{\omega_{e}} \quad$ Pressão acústica emitida pela fonte.

$Q_{\omega_{e}} \quad$ Admitância acústica.

$q \quad$ Densidade de fontes.

$\vec{r} \quad$ Vetor posição.

$\overrightarrow{r_{h}} \quad$ Vetor posição do hidrofone.

$\vec{r}_{S} \quad$ Vetor posição da fonte emissora.

$S$ Área da secção de choque.

$s(t) \quad$ Área da secção de choque.

$t \quad$ Tempo.

U $\quad$ Amplitude de Vibração.

$V \quad$ Elemento de volume.

$x, y, z \quad$ Coordenadas cartesianas.

$W(P, t) \quad$ Função que combina os modos vibracionais.

$W_{n}(P) \quad$ Função correspondente ao n-ésimo modo vibracional.

$\vec{W} \quad$ Vetor Peso.

Z Impedância acústica característica. 
$Z_{0} \quad$ Posição no eixo $z$ paralela a direção do feixe de excitação.

$\alpha \quad$ Coeficiente de atenuação total.

$\beta \quad$ Componente real da compressibilidade adiabática.

$\gamma \quad$ Calor Específico.

$\delta \quad$ Delta de Dirac.

$\Delta \omega \quad$ Diferença de frequência angular.

$\Delta f \quad$ Diferença de frequência.

$\Delta \omega_{f d} \quad$ Largura de banda do filtro digital.

$\Delta t_{a q} \quad$ Tamanho da janela de processamento.

$\epsilon \quad$ Densidade de energia.

K Compressibilidade adiabática para ondas acústicas.

$\lambda_{1}, \lambda_{2} \quad$ Comprimento de onda.

$\eta_{n} \quad$ Coordenada generalizada.

$\Pi_{a}, \Pi_{e} \quad$ Potência absorvida e espalhada.

$\rho \quad$ Densidade do meio.

$\rho_{0} \quad$ Densidade no equilíbrio.

$\omega \quad$ Frequência angular $(\omega=2 \pi f)$.

$\omega_{c} \quad$ Frequência central.

$\omega_{f d} \quad$ Frequência de filtragem.

$\omega_{n} \quad$ Frequência de ressonância correspondente ao n-ésimo modo vibracional.

$\sigma_{f d} \quad$ Deslocamento na frequência de ressonância de um modo vibracional.

$\theta \quad$ Ângulo genérico. 
xxii 


\section{Lista de Figuras}

1.1 Esquema ilustrando o princípio da Vibroacustografia . . . . 5

1.2 Imagem ilustrando o funcionamento da vibroacustografia (modificada de $[1]$ ) . . . . . . . . . . . . . 6

1.3 Ilustração da técnica APE: Um pulso ultrassônico excita uma porção da amostra fazendo-a vibrar e o som emitido é detectado por um hidrofone. . . . . . . . . . . . 8

2.1 Função envelope $f(t)$ (linha de contorno do pacote) para um pulso $s(t) \ldots \ldots \ldots \ldots \ldots \ldots \ldots$

2.2 Densidade de fontes distribuídas em uma amostra . . . . . 16

2.3 Resposta do filtro do tipo Butterworth centrado em $50 \mathrm{kHz}$ com largura de banda em 1\% para 4 diferentes números de polos . . . . . . . . . . . . . . . 23

2.4 Transdutor ultrassônico focalizado . . . . . . . . . . . . 25

2.5 Posições relativas entre fonte emissora e hidrofone. $\mathrm{R}$ é a distância fonte detector . . . . . . . . . . . . . . . . 29

2.6 Modelo mecânico de um sistema massa mola amortecido . 30

3.1 Transdutor Ultrassônico de excitação confocal . . . . . . . 34

3.2 Arranjo experimental para formação de imagens por APE . . 35

3.3 Sistema de posicionamento da amostra e processo de desgaseificação da água. . . . . . . . . . . . . . 36

3.4 Sequência temporal utilizada no processo de excitação e aquisição na técnica APE . . . . . . . . . . . . . . 38

3.5 Plano da amostra escolhido para a geração da imagem. . . 40 
xxiv

3.6 Diagrama representando a sequência de processamentos para geração da imagem . . . . . . . . . . . . . . . . . . 42

3.7 Circuito Mixer, emulador da frequência de batimento $\Delta \omega$ a partir das frequências $\omega_{1}$ e $\omega_{2} \ldots \ldots$. . . . . . . 45

3.8 Diagrama experimental paras as duas modalidades de VA e para a técnica APE. . . . . . . . . . . . . . 46

3.9 Fotografia do sistema de aquecimento do gel e exemplo de fantoma . . . . . . . . . . . . . . . . . . . . . 49

3.10 Fantoma contendo pequenas inclusões com diferentes valores de rigidez. . . . . . . . . . . . . . . . . . . 50

3.11Fotografia do equipamento utilizado para os ensaios quase-estáticos . . . . . . . . . . . . . . . . . . 52

3.12 Experimento ilustrando a ativação de dos modos vibracionais . . . . . . . . . . . . . . . . . . . . . 53

3.13Arranjo experimental para o experimento demonstrando a detecção do modo vibracional . . . . . . . . . . . . . . 54

4.1 Arranjo Experimental para a mensuração da Potência do feixe ultrassônico . . . . . . . . . . . . . . 58

4.2 Potência acústica do transdutor focal em função da frequência de excitação do transdutor ultrassônico para uma voltagem no gerador de $40 \mathrm{Vpp} \ldots . . \ldots$

4.3 Potência acústica em função da voltagem aplicada no transdutor ultrassônico. . . . . . . . . . . . . . . . . . . 61

4.4 Resposta em voltagem do hidrofone ITC6050C em função da frequência para uma amplitude de 1,0 Pa . . . . . . . 62

4.5 Campo acústico simulado para um transdutor ultrassônico confocal . . . . . . . . . . . . . . . . . . . 64

4.6 a) Fotografia da grade de fios de diferentes espessuras utilizada na determinação da PSF. b) Transdutor ultrassônico movia-se ao longo da direção X para a PSF transversal e axial na direção y para a PSF Iongitudinal. . . . . . . . . . . 66 
4.7 Perfil de detecção da APE:a)Imagem demonstrando a disposição dos fios metálicos; b) perfil do sinal ao longo do eixo $\mathrm{X}$ mostrando a resolução do sinal par diferentes estruturas. . . . . . . . . . . . . . . . . . . . . . 67

4.8 Discretização da APE: a) Fotografia dos pares de fios metálicos para determinação da resolução; b) sinal detectado pela APE ao longo do corte transversal dos fios . . . . . . 68

4.9 Ajuste para decaimento $1 / R \ldots$. . . . . . . . . . . 70

4.10Amplitude RMS do sinal de baixa frequência captado com o hidrofone em distâncias diferentes da esfera sob o foco . 71

5.1 Comparação entre a APE e a VA em modo toneburst para duas frequências de excitação . . . . . . . . . . . 76

5.2 Pulso acústico emitido pelo transdutor e o respectivo envelope. . . . . . . . . . . . . . . . . . . . . . . . 77

5.3 Espectro de frequência correspondente a segunda derivada temporal do envelope do pulso de excitação . . . . . 78

5.4 Resposta em frequência da amplitude de potência do sinal acústico adquirido em duas situações: com o foco centrado na esfera e diretamente na água . . . . . . . . . . . 79

5.5 Imagem ilustrando os sinais adquiridos, através de um vibrometro laser, de um diapasão vibrando . . . . . . . . . . 81

5.6 Contraste em amplitude de pressão acústica em função da voltagem de excitação e número de ciclos do pulso $\ldots . .82$

5.7 Contraste em amplitude de pressão acústica entre a esfera e o meio para diferentes valores de voltagem e distância amostra-hidrofone . . . . . . . . . . . . . . . . . 882

5.8 Imagens de uma esfera obtidas pelas diferentes técnicas acustográficas . . . . . . . . . . . . . . . . 84

5.9 Resposta em frequência para o corpo do fantoma devido a um impulso ultrassônico . . . . . . . . . . . . . . . . . . . 85 
5.10 Imagem de um fantoma contendo inclusões mais rígidas.

a) diagrama representado a disposição morfológica das inclusões com diferenças de rigidez; b) Imagem produzida a partir da técnica APE; c) Imagem produzida por ultrassonografia no modo brilho . . . . . . . . . . . . . . . 86

5.11Espectro do sinal adquirido em baixas frequências para diferentes frequências de excitação de uma esfera de 0,664 mm de diâmetro . . . . . . . . . . . . . . . . . . 8 87

6.1 Fotografia do fantoma constituido por um úmero de galinha inserido em gelatina. . . . . . . . . . . . . . 90

6.2 Imagem de um osso (úmero de galinha) produzida pela técnica APE. . . . . . . . . . . . . . . . . . . . . . 91

6.3 Módulo de Young de um fantoma de gelatina a 8\% para diferentes valores de temperatura utilizando o método de ensaio quase-estático . . . . . . . . . . . . . . . . . 95

6.4 Relação entre o módulo de young em função da temperatura para um fantoma com $8 \%$ de gelatina. . . . . . . . . . 96

6.5 Configuração para avaliação da técnica em um tubo ressonante . . . . . . . . . . . . . . . . . . . 98

6.6 Resposta em frequência para diferentes pontos de excitação em um tubo metálico . . . . . . . . . . . . . . . . . . 99

6.7 Espectros de frequência para diferentes condições de corrosão de uma pequena região do tubo $\left(6 \mathrm{~cm}^{2}\right) \ldots \ldots \ldots$. . 100 


\section{Lista de Tabelas}

1.1 Valores típicos de velocidade do som, impedância acústica característica e atenuação em diferentes tecidos biológicos, para temperatura entre $27^{\circ} \mathrm{C}$ e $34^{\circ} \mathrm{C}$ [2] . . . . . 8

3.1 Tabela contendo os ingredientes para a fabricação de simuladores de tecidos biológicos . . . . . . . . . 47

3.2 Porcentagem em massa, em relação a água, dos componentes utilizados para a confecção da base do fantoma e para as cinco inclusões. . . . . . . . . . . . . . . . . . 50

4.1 Resultados simulados da largura a meia altura dos campos acústicos gerados pelos elementos do transdutor ultrassônico . . . . . . . . . . . . . . . . . . . . . . . 65

4.2 Resultados da largura a meia altura para as diferentes espessuras de fios. O símbolo (*) indica que o valor não foi determinado ................... 66

5.1 Módulos de Young obtidos pelos ensaios quase-estáticos para as inclusões e para o corpo do fantoma. . . . . . . 85

5.2 Relação sinal ruído e contraste para o fantoma com inclusões mais rígidas. . . . . . . . . . . . . . 86 
xxviii 


\section{Sumário}

Resumo xiii

$\begin{array}{ll}\text { Abstract } & \text { XV }\end{array}$

Lista de Abreviaturas $\quad$ xvii

Lista de Símbolos $\quad$ xix

Lista de Figuras $\quad$ xxiii

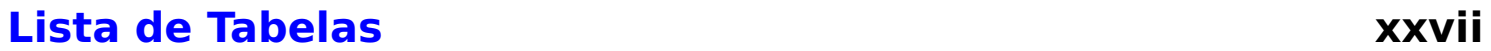

1 Introdução 1

1.1 Elastografia . . . . . . . . . . . . . . . . . 2

1.2 Imagens por Vibroacustografia . . . . . . . . . . . . . . 4

1.3 Motivação . . . . . . . . . . . . . . . . . . 9

1.4 Objetivos ......................... 10

1.4 .1 Objetivo Geral . . . . . . . . . . . . . . . . . . 10

1.4 .2 Objetivos específicos . . . . . . . . . . . . 10

1.5 Organização do trabalho . . . . . . . . . . . . . . . . . . . 11

2 Fundamentação teórica 13

2.1 Efeitos não lineares associados a propagação acústica . . . 13

2.1.1 Efeitos não-lineares para a propagação de um trem de pulso ultrassônico . . . . . . . . . . . . . . . . 15

2.2 Teorema da expansão modal . . . . . . . . . . . . . . . . . . . . 19

2.2.1 Resposta do filtro digital . . . . . . . . . . . . . 22 
2.3 Campo Acústico para um transdutor ultrassônico focalizado 24 2.3.1 Campo acústico Modulado pela VA . . . . . . . . 24

2.4 Densidade de energia acústica . . . . . . . . . . 25

2.4.1 Densidade de energia acústica no campo modulado pela VA . . . . . . . . . . . . . . 26

2.5 Força de radiação acústica . . . . . . . . . . . . 26

2.6 Pressão acústica emitida . . . . . . . . . . . . . . . . . . 28

2.7 Modelo mecânico de $2^{a}$ ordem: frequência de ressonância . 29

3 Materiais e métodos 33

3.1 Transdutor ultrassônico para excitação . . . . . . . . . . 33

3.2 Arranjo experimental da técnica APE. . . . . . . . . . 34

3.2 .1 Excitação . . . . . . . . . . . . . . . . . 37

3.2.2 Processamento dos sinais . . . . . . . . . 37

3.2.2.1 Janelamento do sinal adquirido . . . . . . . 38

3.2.2.2 Transformada rápida de Fourier . . . . . . . . 39

3.3 Estimativa da função envelope . . . . . . . . . . . . . . . 39

3.4 Formação de Imagens a partir da técnica APE. . . . . . . . . 40

3.5 Arranjo experimental da VA . . . . . . . . . . 43

3.6 Preparação dos simuladores de tecidos biológicos . . . . . 47

3.6.1 Experimento com inclusões mais rígidas . . . . . . . . 49

3.7 Ensaios quase estáticos para determinação da rigidez das amostras ..................... 51

3.8 Experimento para detecção do modo vibracional . . . . . . 51

3.9 Análise Estatística- Relação Sinal/Ruído . . . . . . . . . . . . 55

4 Caracterização do Sistema 57

4.1 Potência acústica do transdutor de excitação . . . . . . . . . 57

4.1 .1 Introdução . . . . . . . . . . . . . . . . 57

4.1 .2 Materiais e Métodos . . . . . . . . . . . . . . . 58

4.1 .3 Resultados . . . . . . . . . . . . . . . . . . . 59

4.1.3.1 Resposta em frequência do transdutor de excitação . . . . . . . . . . . . . . 59 
4.1.3.2 Resposta em função da voltagem de excitação . . . . . . . . . . . . . 60

4.2 Sensibilidade do hidrofone em função da frequência . . . . 61

4.3 Resolução espacial . . . . . . . . . . . . . . . . 662

4.3.1 Função de Espalhamento Pontual . . . . . . . . . . 63

4.3.1.1 PSF de um feixe acústico focalizado . . . . . . 63

4.3.1.2 PSF de um feixe acústico focalizado VA. . . . . 63

4.3.1.3 Campo acústico simulado . . . . . . . . . . . 63

4.3.2 Materiais e Métodos para determinação da PSF . . . 65

4.3.2.1 Resultados PSF . . . . . . . . . . . . . . . 65

4.4 Atenuação da onda Acústica de Baixa frequência em função da distância fonte-detector . . . . . . . . . . . . . . . 67

4.4.1 Materiais e Métodos . . . . . . . . . . . . . 68

4.4 .2 Resultados . . . . . . . . . . . . . . . . . . 69

5 Resultados e discussão $\quad 73$

5.1 Justificativa da técnica de APE . . . . . . . . . . 73

5.1.1 Formação de ondas de baixa frequência por autodemodulação . . . . . . . . . . . . 76

5.1.2 Contribuição da reverberação da onda acústica no sinal detectado . . . . . . . . . . . . . 78

5.2 Livre emissão acústica . . . . . . . . . . . . . . . 80

5.3 Formação de imagens pela técnica APE e pela VA . . . . . 8 83

5.4 Mudança de rigidez . . . . . . . . . . . . . 83

5.5 Variações na frequência de excitação do pulso ultrassônico 85

5.6 Discussão geral sobre a técnica APE . . . . . . . . . . . 86

6 Estudos de aplicação da técnica APE $\quad 89$

6.1 Aplicação da técnica APE na geração de imagens de tecido ósseo "in vitro" . . . . . . . . . . . . . . . . . . . . . . . . 89

6.1 .1 Materiais e métodos . . . . . . . . . . . . . . . 90

6.1 .2 Resultados . . . . . . . . . . . . . . . . . . . . 90

6.2 Utilização da técnica APE na avaliação da temperatura local 92 
xxxii

6.2.1 Materiais e Métodos . . . . . . . . . . . . . . 93

6.2.1.1 Preparação dos fantomas . . . . . . . . . . 93

6.2.1.2 Aplicação da técnica APE . . . . . . . . . . 93

6.2.1.3 Ensaios quase-estáticos . . . . . . . . . . 93

6.2.1.4 Simulação da amplitude do sinal esperada devido a mudanças na rigidez . . . . . . . . . 94

6.2 .2 Resultados . . . . . . . . . . . . . . . . . . . . . . 95

6.3 Experimento tubo ressonante . . . . . . . . . . . . . 996

6.3.1 Materiais e métodos . . . . . . . . . . . . . . . . . 97

6.3.2 Resultados com o tubo ressonante . . . . . . . . . . 97

7 Considerações finais $\quad 101$

7.1 Vantagens da Técnica APE . . . . . . . . . . . . . . . 101

7.2 Trabalhos Futuros . . . . . . . . . . . . . . . . 102

$\begin{array}{ll}\text { Referências Bibliográficas } & 103\end{array}$ 


\section{Capítulo}

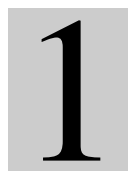

\section{Introdução}

$D$ oenças relacionadas às propriedades mecânicas e acústicas, bem como os diagnósticos baseados nestas propriedades físicas, são relatados desde a Grécia antiga [3][4]. A palpação é dos exemplos de procedimentos de diagnóstico relacionados às propriedades mecânicas dos tecidos. Estes procedimentos são utilizados amplamente até os dias atuais, como forma de auxilio ao diagnóstico de enfermidades, relacionadas à elasticidade e textura de tecidos biológicos[5]. Palpações mais profundas, na região abdominal, podem ser utilizadas para detectar a presença de massas anormais no fígado, rins é muito utilizada nos procedimentos de detecção de tumores de mama sendo que, a própria retração da pele da mama ou assimetria podem indicar uma lesão subjacente potencialmente grave. Alguns cânceres podem ser associados a mudanças de textura e rigidez, alguns nódulos geralmente não são moles, e lesões benignas são mais propensas a serem elásticas ou firmes, móveis, e bem definidas. Da mesma forma, lesões suspeitas de próstata tem a forma de nódulos duros e irregulares dentro da próstata, enquanto que a hiperplasia prostática benigna (HPB) apresenta-se como um leve alargamento simétrico da glândula.

A acústica também é um fenômeno amplamente utilizado no auxílio ao diagnóstico, como se pode destacar nos procedimentos de percussão e auscultação. A percussão é um procedimento diagnóstico usado para determinar a densidade de uma região do tecido, tocando 
a superfície com suaves golpes para avaliar os sons resultantes. No abdômen, por exemplo, pode ser usada para detectar líquidos (ascite ${ }^{\dagger}$ ), o procedimento é também usado frequentemente para avaliar o tórax e vias aéreas. Pequenas batidas no tórax produzem uma nota ressonante quando uma área saudável do pulmão é atingida, no entanto, um som mais abafado pode ser emitido se o pulmão contém fluidos, como nos casos de pneumonia. Um pulmão acometido por enfisema contém mais ar do que um pulmão saudável e produz hiper-ressonância. Outro método baseado no som emitido pelo corpo é a auscultação, que é realizada utilizando um estetoscópio para avaliar os sons produzidos pelo coração, pulmões, veias e intestino, por exemplo, a ausência de ruídos intestinais indica o não funcionamento do trânsito intestinal, já um som agudo, indicaria uma possível obstrução [4].

Como foi observado no parágrafo anterior, as propriedades viscoelásticas e acústicas estão intimamente ligadas a um conjunto grande de enfermidades e seus respectivos diagnósticos. No entanto, a maioria das técnicas estão sujeitas a sensibilidade humana e, por consequência, às limitações do tato, audição e treinamento dos profissionais da saúde. A consequência destas limitações são a baixa sensibilidade à detecção de nódulos pequenos ou posicionados em porções mais profundas do corpo. Existem trabalhos reportando a indetectabilidade em torno de $10 \%$ a $15 \%$ dos cânceres de mama [6].

\subsection{Elastografia}

Tendo em vista a importância das propriedades viscoelásticas no auxilio ao diagnóstico, nas duas últimas décadas o estudo de propriedades mecânicas em tecidos biológicos emergiu significantemente com a finalidade de introduzir novas técnicas que possibilitassem a geração de imagens relacionadas a rigidez dos tecidos, em especial destaca-

\footnotetext{
†ascite é uma acumulação de fluidos na cavidade do peritônio. É comum devido a cirrose e doenças graves do fígado
} 
se o relevante trabalho de Ophir et al. [7], que propunha a geração de imagens associadas a rigidez a partir da estimativa da deformação da porção do tecido diante de uma tensão aplicada, esta técnica de imagens foi denominada "Elastography'. Este trabalho foi de tamanha relevância que o termo elastografia é empregado como uma generalização de sistemas de imagens relacionados a rigidez tecidual. É importante destacar, aqui, que, a pesar do nome, a técnica originalmente não produzia imagens associadas a valores absolutos de rigidez, isto foi justificado pela complexidade de estimar a distribuição do tensor de tensões sobre o tecido biológico, devido a isto, a produção destas imagens é ponderada pelas deformações internas dos tecidos [7].

O principal objetivo das imagens elastográficas é mapear as propriedades mecânicas tais como: módulo de Young (ou rigidez), relação de Poisson e a viscosidade, destacando a rigidez como sendo frequentemente o parâmetro de maior importância, devido a sua dependência com a composição do tecido. Nos últimos 20 anos várias técnicas elastográficas foram desenvolvidas, baseadas em diferentes modalidades: ultrassom[7], imagens por ressonância magnética nuclear(MRI) [8] e métodos ópticos [9], empregando diferentes métodos de excitação e aquisição de parâmetros de movimento do tecido. L. Gao et al. [9] propuseram uma nomenclatura que definia elastografia como sendo a generalização das imagens elásticas, quando o ultrassom é utilizado para geração de imagens dos parâmetros elásticos.

Dentro do escopo de interesse dos estudos elastográficos, em 1990 Sugimoto et al. [10] apresentaram uma técnica que agia como uma palpação remota, de forma que uma pequena porção interna do tecido poderia ser pressionada utilizando força de radiação acústica. Nesta técnica, um feixe focalizado de ultrassom era aplicado a uma porção do tecido, de modo a provocar um impulso mecânico que deslocava o tecido e um outro transdutor ultrassônico, apontado para o mesmo ponto de excitação rastreava a posição do tecido após o impulso, de modo a acompanhar a relaxação do tecido, obtendo assim, os parâme- 
tros viscoelásticos.

O trabalho apresentado por Sugimoto é referência em outros trabalhos envolvendo força de radiação ultrassônica, entre elas destacamse a Vibroacustografia[11] que utiliza força de radiação ultrassônica modulada para excitar a amostra e um microfone para detectar a vibração, e a técnica de ARFI (Acoustic radiation force impulse imaging) [12] que herdou grande similaridade com a proposta de Sugimoto, porém utilizando um mesmo transdutor par excitação e rastreio. Estas vertentes de técnicas elastograficas baseadas em força de radiação acústica estão na vanguarda das modalidades elastográficas, pelo constante interesse de estimar mudanças de rigidez em pontos internos localizados.

\subsection{Imagens por Vibroacustografia}

A vibroacustografia (VA) [1] [11] é uma modalidade de imagem elastográfica que utiliza força de radiação ultrassônica de alta frequência (na faixa de megahertz) modulada em quilohertz, para vibrar uma pequena porção de tecido na frequência de modulação. O som associado a estas vibrações pode ser detectado por um hidrofone, processado e associado a cada ponto da imagem. Dependendo das propriedades mecânicas da porção do tecido excitado, a amplitude do som emitido em uma determinada frequência, pode ser mais ou menos intensa, gerando assim o contraste na imagem. A modulação desta força é obtida a partir de uma interação não-linear entre dois feixes ultrassônicos, focalizados no mesmo ponto, porém com frequências ligeiramente diferentes na ordem de $\mathrm{MHz}$. A diferença entre essas frequências é da ordem de quilohertz que é a frequência de modulação desejada, que na acústica tradicional é conhecido como efeito de batimento como é ilustrado na figura 1.1.

A frequência de batimento é escolhida de modo que, cada porção do tecido vibre com maior ou menor intensidade, dependendo da resposta 


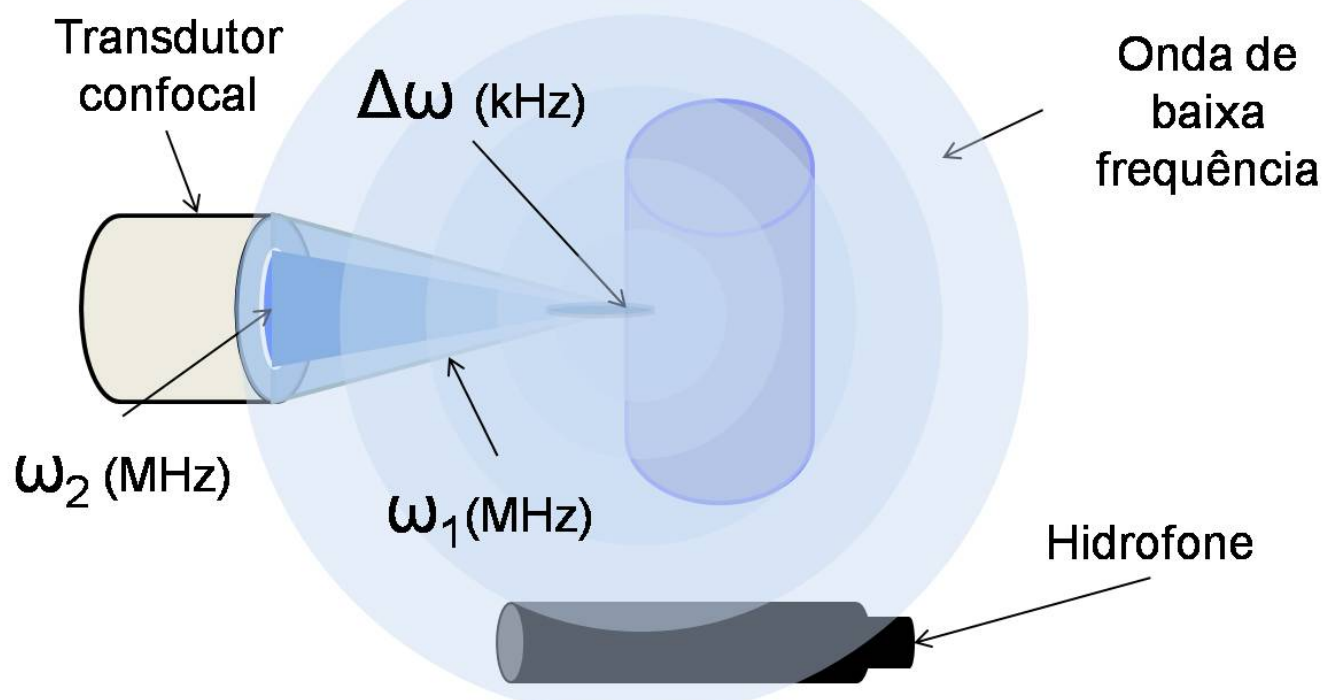

Figura 1.1: Esquema ilustrando o princípio da Vibroacustografia. Dois feixes ultrassônicos focalizados no mesmo ponto com frequências $\omega 1$ e $\omega 2$ ligeiramente diferentes, produzem na amostra uma baixa frequência $\Delta w$

mecânica do tecido à esta frequência de batimento escolhida. Posteriormente, surgiram variantes da técnica de VA. Inicialmente, existia a modalidade conhecida por CW (Continuous Wave), que mantinha os dois feixes excitando a amostra continuamente enquanto um robô deslocava os feixes por todo o plano de imagem na amostra. As desvantagens deste modo eram os grandes artefatos de reverberação, e formação de ondas estacionárias, tanto nas paredes do tanque d'água quanto dentro da própria amostra. Com o intuito de reduzir estes artefatos, modificações no modo de excitação criaram uma modalidade conhecida como toneburst, no qual cada ponto da amostra era excitado por um intervalo curto de tempo, burst, reduzindo assim os artefatos[13]. Outros trabalhos de relevância foram apresentados aplicando combinações de feixes demodulados em multi-frequências [14] [15] de modo a obter imagens com informações adicionais sobre as propriedades de não linearidades de propagação das ondas na amostra.

O som emitido por uma amostra excitada por um impulso de força de 
radiação acústica, como no caso de 'VA na modalidade toneburst(TB), é o resultado de alguns fenômenos acústicos que podem ter suas influências destacadas na formação das imagens. Quando Fatemi e Greenleaf [11] apresentaram seu trabalho sobre VA, eles ilustraram o processo de formação da imagem como sendo a resposta ressonante de porções do tecido à uma frequência de excitação, como em um sistema amortecido forçado agindo sobre um diapasão, como ilustrado na figura 1.2 retirada do artigo[1]. Mas, como apresentado neste trabalho, este não é o único fenômeno envolvido. O espalhamento das ondas devido a diferença de impedância acústica, cujos valores podem ser vistos na tabela 1.1, contribui significantemente para o sinal acústico emitido de meios, (tais como ossos, microcalcificações, estenoses, etc), nestes casos, o espalhamento tem maior peso no contraste da imagem do que a resposta ressoante, de modo que a imagem pode ser adquirida em outras frequências que não as de ressonâncias do sistema. Um outro fenômeno importante foi apresentado por Calle et al.[16] relata os aspectos da não linearidade da propagação de ondas no processo de formação de imagens de VA.

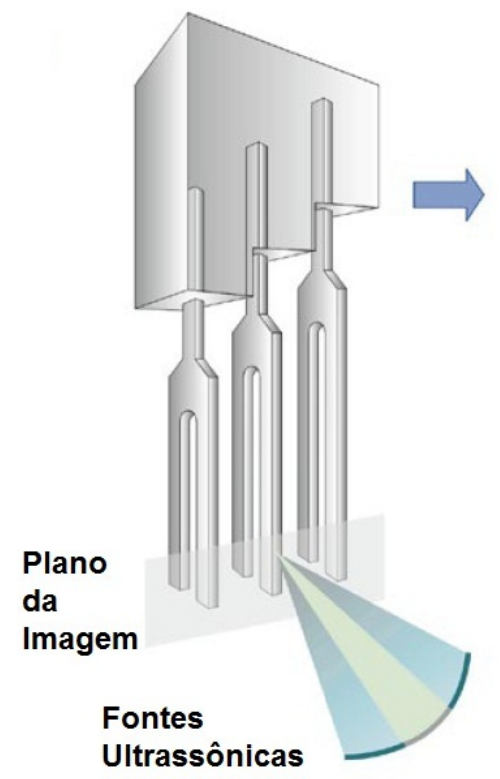

Figura 1.2: Imagem ilustrando o funcionamento da vibroacustografia (modificada de [1] ) 
Como dito anteriormente, o som emitido por um objeto devido a uma excitação por força de radiação ultrassônica está sujeito à uma série de fenômenos. O processo de aquisição de imagens por VA, tem como condição inerente, a escolha prévia (ou seja antes da aquisição) da frequência de batimento que será utilizada, e todo o processo de aquisição é feito nesta frequência. Porém, devido a complexidade da estrutura tecidual, fica praticamente inviável a pré determinação de uma frequência ressonante que traria melhor contraste na imagem. Na prática, torna-se necessária a aquisição em várias frequências até que se obtenha a otimização da imagem. Deve-se no entanto ressaltar que, para os casos onde o objetivo é destacar estruturas com diferença abrupta de impedância acústica, uma frequência padrão adotada ${ }^{\dagger}$ produz imagens de boa qualidade. Vários trabalhos utilizam a VA para a formação de imagens baseadas na emissão acústica, dentre eles, podese destacar, a aplicação da técnica na detecção de microcalcificações em tecidos mamários [17], posicionamento de sementes de braquiterapia [18], além dos estudos sobre potenciais aplicações em lesões de próstata [19] e estimativa de rigidez de veias [20][21].

Quando o objetivo é fazer imagens de objetos cuja a diferença de impedância acústica é sutil, como no estudo de distribuição de dose de radiação ionizante sobre géis dosimétricos [22], por exemplo, a escolha da frequência de batimento pode ser exaustiva. Pensando nestes casos, e com base nos fenômenos não lineares de interação do ultrassom com o meio, propusemos uma modificação no processo de excitação e processamento que daria origem a uma nova modalidade de imagem acústica, a qual denominamos Acustografia por Pulso/Emissão ou simplesmente pelo acrônimo (APE). Nesta nova técnica proposta, um único feixe de ultrassom em modo burst em frequência de $\mathrm{MHz}$ é utilizado para excitação da amostra, e o som emitido pelo alvo $(\mathrm{kHz})$ é adquirido por um hidrofone dedicado, como ilustrado na figura 1.3.

\footnotetext{
${ }^{\dagger}$ Geralmente nestes casos, a frequência é escolhida em função da frequência de ressonância do detector (hidrofone)
} 
Tabela 1.1: Valores típicos de velocidade do som, impedância acústica característica e atenuação em diferentes tecidos biológicos, para temperatura entre $27^{\circ} \mathrm{C}$ e $34^{\circ} \mathrm{C}$ [2]

\begin{tabular}{lccc}
\hline \hline Tecidos & $\begin{array}{c}\text { Velocidade de } \\
\text { propagação } c\end{array}$ & $\begin{array}{c}\text { Impedância Acústica } \\
\text { Característica } Z\end{array}$ & $\begin{array}{c}\text { Coeficiente de } \\
\text { Atenuação } \alpha\end{array}$ \\
\hline água $\left(20^{\circ} \mathrm{C}\right)$ & 1480 & $\left(\mathrm{~kg} \cdot \mathrm{s}^{-1} \cdot \mathrm{m}^{-2}\right)$ & $\left(\mathrm{dB} \cdot \mathrm{cm}^{-1} \cdot \mathrm{MHz}^{-1}\right)$ \\
osso cortical & $3000-4000$ & $4,0.10^{6}-8,0.10^{6} 1$ & $a^{*}$ \\
gordura & 1450 & $1,38 \cdot 10^{6}$ & $1-10$ \\
músculo & $1550-1630$ & $1,65.10^{6}-1,74.10^{6}$ & $0,8-1,5$ \\
pele & 1600 & $1,7.10^{6}$ & $2-4$ \\
\hline A atenuação apresenta uma relação quadrática com a frequência f. e seu valor é \\
descrito por $\alpha(f)=0,002 \cdot f^{2} \mathrm{~dB} \cdot \mathrm{cm}^{-1}$
\end{tabular}

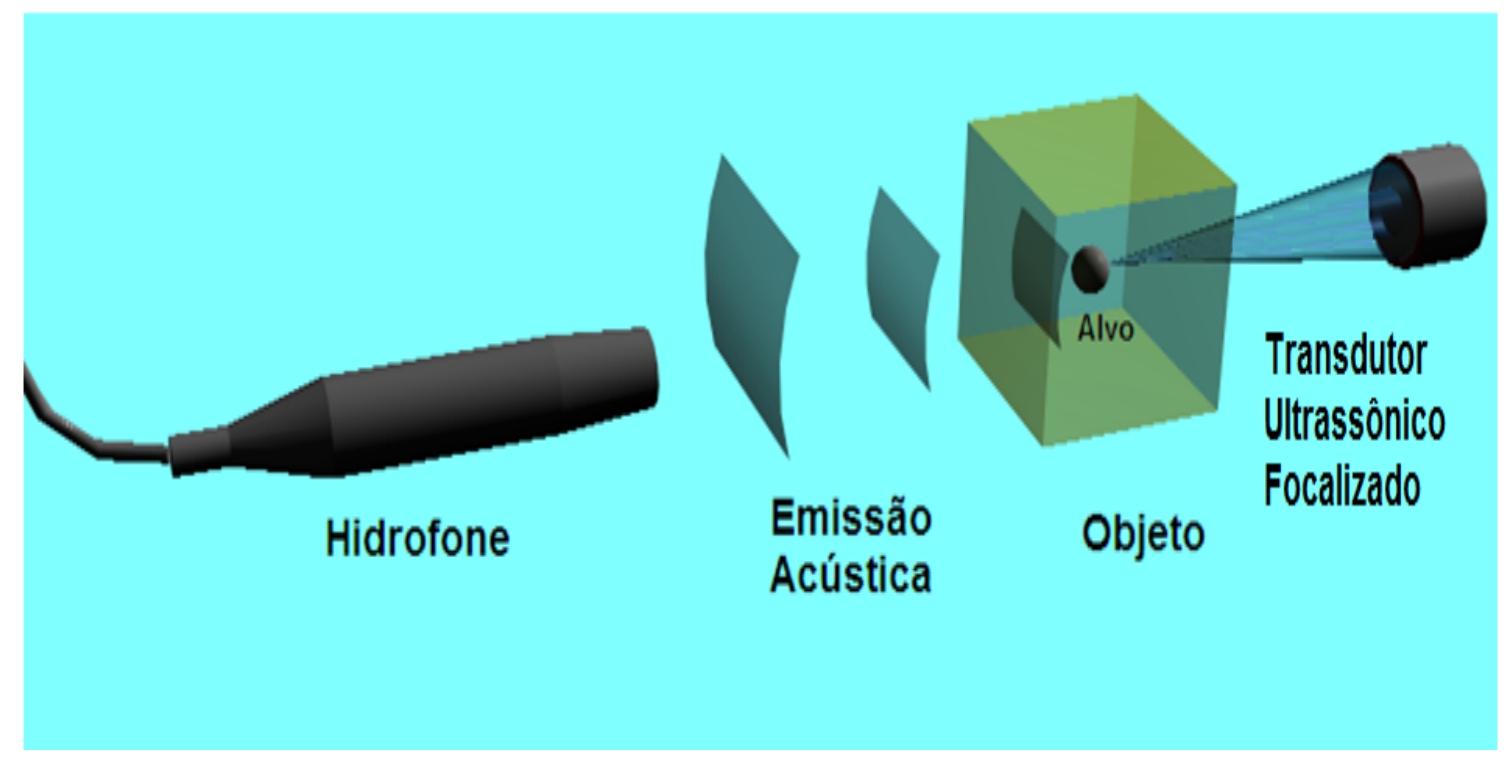

Figura 1.3: Ilustração da técnica APE: Um pulso ultrassônico excita uma porção da amostra fazendo-a vibrar e o som emitido é detectado por um hidrofone. 
Conforme será discutido no capítulo 2 de fundamentos teóricos, pulsos de ultrassom em alta frequências $(\mathrm{MHz})$ propagando em um meio absorvedor, produzem ondas secundárias de baixas frequências $(\mathrm{kHz})$ por um processo de auto-demodulação a partir de propriedades não lineares de propagação de onda acústica do meio. Deste modo, as frequências geradas pelo processo de auto-demodulação também poderiam ser utilizadas na formação da imagem, seja pelas diferenças de frequências provocadas por diferenças no meio, ou pelo espalhamento das ondas de baixa frequência em interfaces de diferenças de impedância acústica. Na última década, apareceram um conjunto muito grande de trabalhos científicos utilizando o processo de auto-demodulação de ondas acústicas em materiais de alta absorção, entre eles destacam se as aplicações de caracterização de materiais granulares [23][24][25] e em análises de água saturada de areia [26]. Este fenômeno destaca-se nestes materiais porque a alta atenuação da onda incidente intensifica os efeitos não lineares, dando origem a frequências mais baixas com atenuação menor que permite o estudo destes materiais. Mesmo que em menor intensidade, a presença deste fenômeno em tecido biológico é suficientemente importante e deve ser explorado nos estudos viscoelásticos e no processo de formação de imagens anatômicas.

\subsection{Motivação}

A motivação para o desenvolvimento deste trabalho se deu inicialmente pela oportunidade de explorar e inovar uma técnica moderna envolvendo radiação acústica para excitar um meio material com ondas ultrassônicas em $\mathrm{MHz}$, e avaliar a resposta utilizando um transdutor acústico na faixa de $\mathrm{kHz}$.

Identificamos ainda, que a técnica possui um conjunto de atributos a serem explorados, que nos motivaram a torná-la uma ferramenta com potencial aplicação na caracterização de tecidos biológicos, dentre eles destacam-se: 
- O fenômeno de auto-demodulação presente na propagação do meio traz informação adicional sobre o meio na forma de variações no espectro das baixas frequências demoduladas.

- Alguns modos vibracionais naturais do objeto são estimulados e revelados a partir do impulso mecânico provocado pela força de radiação ultrassônica.

- Independência da escolha prévia da frequência de modulação do feixe de excitação.

- Simplificação da instrumentação utilizada com relação a técnica de VA.

Com um entendimento mais amplo dos fenômenos envolvidos na formação do som emitido pela amostra, poder-se-ia, com uma única aquisição obter imagens ponderadas nas propriedades de demodulação do meio, ou pelo padrão de espalhamento devido às estruturas com diferenças de impedância ou ainda pelas diferenças nos modos vibracionais de cada secção da amostra.

\subsection{Objetivos}

\subsubsection{Objetivo Geral}

Este trabalho tem como objetivo principal apresentar uma nova modalidade de imagem elastográfica baseada nos fenômenos de demodulação de ondas ultrassônicas e da livre emissão acústica.

\subsubsection{Objetivos específicos}

- Desenvolver um protocolo de imageamento usando radiação ultrassônica com frequência em $\mathrm{MHZ}$ e detecção em baixa frequência kHz. 
- Determinar a resolução espacial e o contraste desta nova modalidade de imagem acústica.

- Explorar e identificar os principais fenômenos físicos envolvidos na forma de excitação por ultrassom, na interação da onda ultrassônica com o meio material e na emissão sonora em baixa frequência.

- Comparar a técnica desenvolvida com a técnica de vibroacustografia.

- Avaliação do potencial da técnica desenvolvida na caracterização de tecidos biológicos através de algumas aplicações piloto in vitro, tais como: identificação de inclusões com diferenças de rigidez em meios com propriedades mecânicas e acústicas equivalentes aos tecidos biológicos; avaliação da técnica com mudanças induzidas por variação térmica e viabilidade da técnica APE em ensaio não destrutivos de materiais

\subsection{Organização do trabalho}

O Capítulo 2 trata dos fundamentos teóricos que dão suporte à interpretação dos fenômenos envolvidos na técnica APE. Neste capítulo, são abordadas as teorias de auto-demodulação acústica, o teorema da expansão modal, as equações de emissão acústica de um alvo vibrante irradiado por um feixe de radiação ultrassônica e a teoria que compreende a técnica de vibroacustografia.

O Capítulo 3 descreve os materiais e métodos utilizados na obtenção do sinal baseado na técnica APE, o processo de formação de imagens baseadas na nova técnica, a metodologia das imagens de vibroacustografia nas modalidades CW e TB e o processo geral adotado para a confecção dos simuladores de tecidos biológicos.

O Capítulo 4 apresenta os resultados de caracterização do sistema, tais como potência acústica de excitação, Função de espalhamento 
pontual, e contraste das imagens geradas pela APE.Neste capítulo são apresentados uma pequena introdução, materiais e métodos e resultados de cada uma das caracterizações.

O Capítulo 5 apresenta os resultados e respectivas discussões relativos aos sinais que dão origem a técnica APE e os diversos espectros de frequências acústicas baseados nos fenômenos discutidos no capítulo de fundamentos teóricos, também são apresentadas aplicações da técnica APE na geração de imagens e também são comparadas as técnicas APE e VA.

O Capítulo 6 apresenta alguns exemplos de aplicação da técnica APE: uma imagem "in vitro", uma metodologia para avaliação de temperatura local e ó potencial da técnica como ferramenta de ensaios não destrutivos.

O Capítulo 7 faz um apanhado geral das discussões e as principais conclusões provenientes da caracterização da técnica, dos experimentos piloto e da qualidade da imagem formada. Também são apresentadas as vantagem da técnica APE além das propostas futuras contendo os desafios para o aperfeiçoamento da nova modalidade de imagem. 


\title{
Capítulo
}

\section{Fundamentação teórica}

\begin{abstract}
$N$ este capítulo são abordadas as teorias que dão suporte à interpretação da geração de sinais sonoros de baixas frequências $(\mathrm{kHz})$ a partir de um impulso ultrassônico de alta frequência $(\mathrm{MHz})$ aplicado sobre um meio material. Primeiramente serão tratadas as duas teorias que justificam a formação de baixas frequências a partir de uma excitação em alta frequência. A primeira trata da auto-demodulação da onda primária de alta frequência dentro do meio de propagação, e a segunda teoria, parte do pré-suposto de que uma força de radiação ultrassônica atinge um alvo fazendo-o vibrar em seus modos vibracionais naturais emitindo um som. As duas teorias serão abordas pois acredita-se que o som detectado pelo hidrofone é devido tanto pela interação das frequências de demodulação no alvo espalhador quanto pela resposta vibracional do alvo diante de uma força mecânica impulsiva incidente. Em seguida são apresentados os conceitos relacionados ao campo acústico formado por um transdutor ultrassônico focalizado e a força de radiação consequente deste campo.
\end{abstract}

\subsection{Efeitos não lineares associados a pro- pagação acústica}

A ideia de utilizar as propriedades não lineares da propagação acústica floresceu por volta da década de 1960 quando Westervelt[27] 
concebeu o emissor paramétrico. Em 1965, Berktay [28] sugeriu uma metodologia para produzir sinais pulsados por meio de autodemodulação de uma onda primária de forma que o espectro temporal não permanece discreto, mas se estende continuamente através de uma estreita largura de banda. Usando o modelo de onda plana, Berktay [28] demonstrou que uma portadora primária com uma amplitude modulada por um envelope $f(t)$ (figura 2.1), produz um sinal secundário cujo padrão é definido por: $\partial^{2}\left(f^{2}\right) / \partial t^{2}$. O problema inverso, isto é, otimizar o sinal de excitação de modo a obter um sinal adquirido desejado tem sido estudado por processos numéricos e interativos [29]. Em 1993 Averkiou et al. [30] utilizaram a equação de onda não linear $\mathrm{KZK}^{\dagger}$ para descrever acuradamente o processo de auto-demodulação e Cervenka e Alais [31] mostraram um formalismo matemático baseado na teoria de Fourier para descrição deste fenômeno.

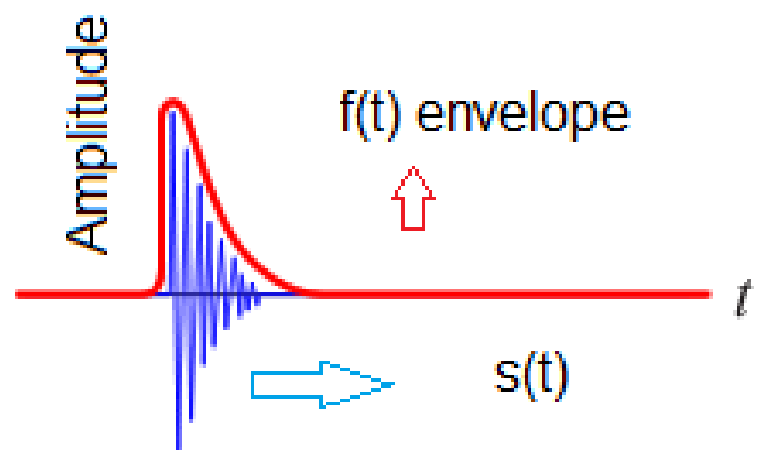

Figura 2.1: Função envelope $f(t)$ (linha de contorno do pacote) para um pulso $s(t)$

\footnotetext{
†equação Khokhlov-Zabolotskaya-Kuznetsov
} 


\subsubsection{Efeitos não-lineares para a propagação de um trem de pulso ultrassônico}

Quando uma onda acústica emitida por um determinado intervalo de tempo finito (um pacote da onda portadora, ou trem de pulso) propaga-se por um meio homogêneo, a pressão de radiação em um determinado ponto tem sua intensidade coerente com o envelope desta onda. De fato este artifício é utilizado para medir a intensidade destas ondas[32]. Contudo, devido a não linearidade da propagação acústica, a onda primária interage com ela mesma de modo a formar novas ondas de frequência menores que se propagam independentemente da onda primária[28]. Um possível modelo utilizando o princípio de Huygens[33] foi apresentado por Westervelt [27] para demonstrar a formação destas ondas secundárias de mais baixa frequência a partir de fenômenos de interferências não-lineares entre fontes pontuais distribuídas em um volume $V$ (figura 2.2 a). Westervelt mostrou que, um feixe ultrassônico modulado de alta potência, agiria como um vetor direcional de dipolos (como uma antena), cuja maior intensidade de propagação seria na direção do vetor de dipolos. Isto ocorre porque os termos não-lineares na equação de movimento fazem com que o feixe se comporte como uma distribuição de fontes para uma frequência modulada.

Considerando uma onda primária interagindo dentro de um pequeno volume $V$, e a partir do princípio de frentes de onda de Huygens, dentro deste volume, pode-se considerar um conjunto infinito de radiadores isotrópicos com densidade volumétrica $q$, o efeito coletivo de tal ação constitui uma nova frente de onda como ilustrado na figura 2.2. Se as ondas secundárias ou ondaletas de Huygens são assumidas como emitidas por cada um destes elementos infinitesimais, então o campo espalhado pode ser calculado pela integração do campo devido a cada fonte. Deste modo, a intensidade de cada fonte será $q d v$ sendo $d v$ o elemento de volume para uma densidade de fonte $q$, que é função da posição dentro de um particular elemento dentro do volume $V$. A 


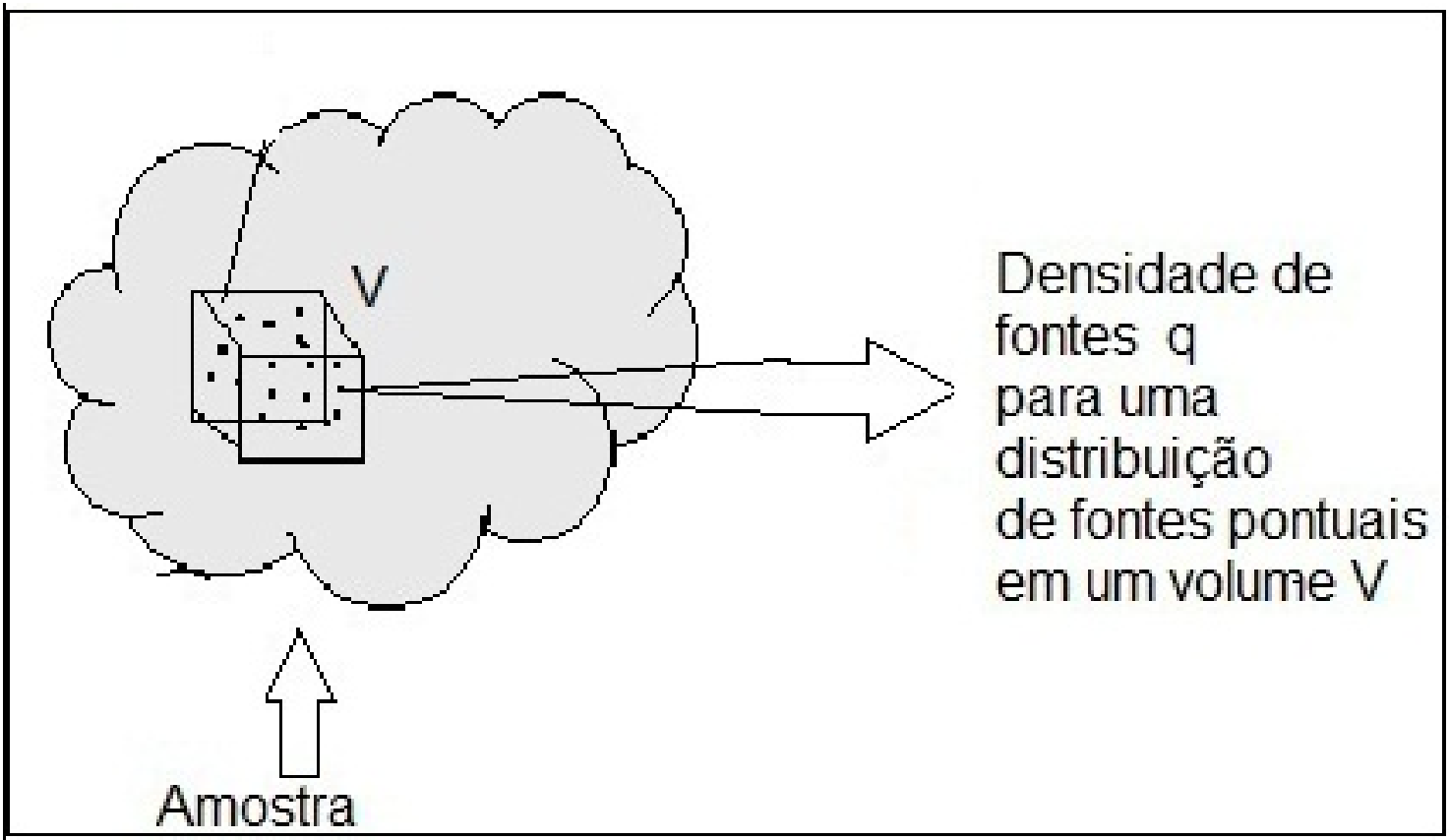

Figura 2.2: Princípio de Huygens. Amostra contendo pequenas fontes distribuídas em um pequeno volume $V$ com densidade de fontes por unidade de volume $q$.

expressão para esta densidade de fontes desenvolvida por Westervelt é dada pela equação 2.1 [34].

$$
q=\frac{1}{\rho_{0}^{2} c_{0}^{4}} \frac{\partial\left(p_{i}^{2}\right)}{\partial t}\left[1+\frac{\rho_{0}}{2 c_{0}^{2}}\left(\frac{d^{2} p}{d \rho^{2}}\right)_{\rho=\rho_{0}}\right]
$$

Sendo $p_{i}$ a pressão diferencial total devido às ondas primárias, $\rho_{0}$ a densidade do meio não perturbado e $c_{0}$ velocidade do som no meio não perturbado. O termo dentro dos colchetes $d^{2} p / d \rho^{2}$ da equação de densidade de fontes eq. 2.1 depende da relação entre pressão e densidade no meio acústico, assumindo este processo adiabático, este termo pode ser avaliado para um meio a partir da equação de estado adiabática (eq:2.2).

$$
P \rho^{-\gamma}=P_{0} \rho_{0}^{-\gamma}
$$

Sendo $\gamma$ o calor específico. Então, derivando duas vezes $P$ em função 
de $\rho$ e assumindo a condição $\rho=\rho_{0}$ :

$$
\left(\frac{d^{2} p}{d \rho^{2}}\right)_{\rho=\rho_{0}}=\frac{\gamma(\gamma-1) P_{0}}{\rho_{0}^{2}}
$$

Como $c_{0}^{2}=\gamma P_{0} / \rho_{0}$ [35], a expressão 2.3 será igual a $(\gamma-1) c_{0}^{2} / \rho_{0}$. Substituindo na equação 2.1 de densidade de fonte, temos:

$$
q=\frac{1}{\rho_{0}^{2} c_{0}^{4}} \frac{\partial\left(p_{i}^{2}\right)}{\partial t}\left[1+\frac{\gamma-1}{2}\right]
$$

Com a finalidade de compactar um pouco a formulação, será considerado aqui, que o calor específico é equivalente ao da água, ou seja, $\lambda=1 \mathrm{cal} / \mathrm{g}^{\circ} \mathrm{C}$, com isto, o termo em colchetes da equação 2.4 pode ser adotado como constante e de valor igual a 1 . Assim a equação de densidade pode ser resumida na forma:

$$
q=\frac{1}{\rho_{0}^{2} c_{0}^{4}} \frac{\partial\left(p_{i}^{2}\right)}{\partial t}
$$

Considerando agora, um pacote de onda acústica plana e colimada viajando através da direção $x$, a pressão diferencial primária para o ponto $x$ no tempo $t$ pode ser representada na forma da equação $2.6[28]$.

$$
p_{i}(t, x)=P_{1} e^{\left(-\alpha_{1} x\right)} f\left(t-\frac{x}{c_{0}}\right) \cos \left(\omega_{1} t-k_{1} x\right)
$$

sendo $f(t)$ a função que representa o envelope.

Assumindo que a maior componente em frequência da função $f$ é muito menor do que a frequência da portadora nos permite adotar um único coeficiente de absorção $\alpha_{1}$ que representa o pacote de sinal. A equação 2.1 de densidade de fonte, tem dependência com a pressão diferencial primária $P_{i}^{2}$, de modo que, elevando ao quadrado a equação 2.6 temos:

$$
p_{i}^{2}(t, x)=\frac{1}{2} P_{1}^{2} e^{\left(-2 \alpha_{1} x\right)} f^{2}\left(t-\frac{x}{c_{0}}\right)\left[1+\cos \left(2 \omega_{1} t-2 k_{1} x\right)\right]
$$


Assim, duas componentes são obtidas a partir da expressão para $P_{i}^{2}(t, x)$ como resultado da auto-interação do trem de onda pulsado. Uma destas componentes é a banda de sinal limitado com duas vezes a frequência da portadora $\left(2 \omega_{1}\right)$, e as ondas espalhadas devido a esta componente serão atenuadas com relativa rapidez. A outra componente é aquela que não contém a portadora. Como esta outra componente constitui somente uma compressão, poderia-se supor que não se propagaria, contudo qualquer espalhamento devido esta componente será dependente de uma função de fonte efetiva que é proporcional a derivada parcial temporal desta componente na expressão de $p_{i}^{2}$, deste modo o valor médio do termo é removido e as alternâncias negativas e positivas são estabelecidas para a função fontes efetiva.

Substituindo agora, a expressão 2.7 na expressão 2.5 de densidade de fonte e considerando a atenuação em alta frequência, tem-se:

$$
q=\frac{P_{1}^{2}}{2 \rho_{0}^{2} c_{0}^{4}} e^{-2 \alpha_{1} x} \frac{\partial}{\partial t}\left\{f^{2}\left(t-\frac{x}{c_{0}}\right)\right\}
$$

Para este caso, a densidade de fontes não é composta por uma única frequência, mas sim por uma banda de frequências, por isso, uma abordagem no espaço $K$ de frequências é mais conveniente. Fazendo a transformada de Fourier da função densidade de fontes e fazendo a aproximação de Westervelt para o modelo de emissor paramétrico [34], Berktay [28] chegou a seguinte expressão:

$$
p(t)=\frac{P_{1}^{2} S}{8 \pi \rho_{0} c_{0}^{4} R \alpha_{1}} \frac{\partial^{2}}{\partial t^{2}}\left\{f^{2}\left(t-\frac{R}{c_{0}}\right)\right\}
$$

A equação 2.9 mostra a dependência da pressão acústica com a segunda derivada temporal da função envelope $f(t)$. Deste modo, conhecendo a modulação do pulso de excitação é possível justificar o espectro de frequências resultante do fenômeno de auto-demodulação.

\footnotetext{
${ }^{\dagger}$ Lembrando a relação em que $\cos ^{2} x=1 / 2(1+\cos 2 x)$
} 


\subsection{Teorema da expansão modal}

A resposta de um sistema viscoelástico a uma excitação mecânica, seja ela uma força impulsiva como na APE ou harmônica como na VA, pode ser interpretada como uma superposição dos modos vibracionais naturais do sistema diante desta força [36]. Estes modos correspondem às frequências de ressonância mecânica do sistema. Quando uma parte deste sistema (meio material) apresenta uma mudança nas propriedades viscoelásticas, alguns destes modos vibracionais locais são alterados e, consequentemente, uma região da amostra que tenha uma pertubação na rigidez, apresentará um espectro de frequência diferente do restante da amostra. Como por exemplo, se escolhermos um destes modos $w_{n}(P)$, representado pela frequência $\omega_{n}$, a região com perturbação na rigidez apresentará uma frequência $\omega_{n}^{\prime}$, ligeiramente diferente da frequência $\omega_{n}$. O processo para geração das imagens, baseadas tanto na APE como na VA, tem como característica a utilização de filtros digitais centrados em uma determinada frequência, como por exemplo a $\omega_{n}$. os sinais filtrados, correspondentes à região com rigidez diferente, terão amplitudes menores, dando origem ao contraste da imagem.

O teorema da expansão modal [36] oferece uma formulação geral para a resposta mecânica de sistemas contínuos. Se desconsiderarmos o amortecimento, um sistema contínuo qualquer pode ser descrito pela equação diferencial parcial 2.10:

$$
L[W(P, t)]+M(P) \frac{\partial^{2} W(P, t)}{\partial t^{2}}=f_{r}(P, t)
$$

sendo $f_{r}(P, t)$ a força de excitação do sistema agindo no ponto $P, L$ é um operador relacionado à distribuição de rigidez do sistema, $M(P)$ está relacionado à distribuição de massa em um domínio $D$.

Usando o teorema da expansão modal e o método de separação de variáveis, a solução para a equação 2.10 pode ser escrita como uma superposição dos modos normais $W_{n}(P)$, correspondentes às frequên- 
cias naturais $\omega_{n}$, multiplicado pelas coordenadas generalizadas $\eta_{n}(t)$, então:

$$
W(P, t)=\sum_{n=1}^{\infty} W_{n}(P) \eta_{n}(t)
$$

As coordenadas generalizadas representam os graus de liberdade do sistema e, para este caso, satisfazem a relação dada pela equação 2.12 .

$$
\frac{\partial^{2} \eta_{n}(t)}{\partial t}+\omega_{n}^{2} \eta_{n}(t)=N_{n}(t)
$$

$N_{n}(t)$ denota a força generalizada associada com a coordenada generalizada $\eta_{n}(t)$ de modo que:

$$
N_{n}(t)=\int_{D} W_{n}(P) f_{r}(P, t) d D(P)
$$

Nos casos onde a força de radiação é modulada, como é no caso da técnica VA, considera-se o sistema sobre uma força harmônica concentrada $f_{r}(P, t)=F \delta\left(P-P_{0}\right) e^{i \omega t}$ agindo na posição $P=P_{0}$ e medindo o deslocamento em qualquer outra posição, $F$ é a amplitude da força de excitação, a equação 2.13 resulta em $N_{n}(t)=F W_{n}\left(P_{0}\right) e^{i \omega t}$, e a equação 2.12 pode ser reescrita na forma da equação 2.14 :

$$
\frac{\partial^{2} \eta_{n}(t)}{\partial t}+\omega_{n}^{2} \eta_{n}(t)=F W_{n}\left(P_{0}\right) e^{i \omega t}
$$

A solução da equação 2.14 é [37]:

$$
\eta_{n}(t)=H_{n} \eta_{d m e} e^{i \omega_{m} t}
$$

$\eta_{d m e}=F W_{n}\left(R_{0}\right) / \omega_{n}^{2}$ a deflexão modal estática e $H_{n}$ é o fator de magnificação, definido por:

$$
H_{n}=\frac{e^{-i \phi_{n}}}{\left\{\left[1-\left(\omega / \omega_{n}\right)^{2}\right]^{2}+\left(2 \zeta \omega / \omega_{n}\right)^{2}\right\}^{1 / 2}}
$$


sendo $\zeta$ o fator de amortecimento e tang $\phi_{n}=\left(2 \zeta \omega / \omega_{n}\right) /\left(1-\left(\omega / \omega_{n}\right)^{2}\right)$ Este fator $H_{n}$ descreve a magnitude de um determinado modo vibracional quando a frequência excitação se aproxima da frequência deste modo, ou em outras palavras, quanto mais próximo for o valor de $\omega$ em relação a $\omega_{n}$ maior será a amplitude de vibração. A equação 2.11 pode então ser reescrita da seguinte forma:

$$
W(P, t)=\sum_{n=1}^{\infty}\left(F / \omega_{n}^{2}\right) W_{n}(P) H_{n} W_{n}\left(P_{0}\right) e^{i \omega t}
$$

No caso particular para a qual a frequência de excitação $\omega$, for igual a uma n-ésima frequência $\omega_{n}$ correspondente a um dos modos vibracionais $W_{n}$, a resposta do sistema pode ser aproximada pela expressão:

$$
W_{n}(P, t)=\left(F / \omega_{n}^{2}\right) W_{n}(P) H_{n} W_{n}\left(P_{0}\right) e^{i \omega_{n} t}
$$

Ou de forma simplificada:

$$
W(P, t)=c_{n} W_{n}\left(P_{0}\right)
$$

Para $c_{n}=\left(F / \omega_{n}^{2}\right) W_{n}(P) H_{n} e^{i \omega t}$

A vibração resultante do sistema produz um campo acústico que é proporcional a amplitude de vibração [38], que resulta em:

$$
P_{n}(P, t)=c_{a} c_{n} W_{n}\left(P_{0}, t\right)
$$

sendo $c_{a}$ uma constante de proporcionalidade entre a amplitude de vibração e a amplitude de pressão acústica.

$\mathrm{Na}$ Vibroacustografia, procura-se encontrar a frequência de excitação (batimento) a partir da análise do espectro de frequências obtido, fazendo uma varredura com diferentes valores de frequência de excitação $\omega$. Na técnica VA cada porção do sistema é forçada a vibrar na frequência de excitação (modulação) $\omega$, então, quanto mais próxima for $\omega$ de um determinado modo $\omega_{n}$ maior será o fator $H_{n}$ e consequentemente, maior será a pressão acústica com frequência $\omega$ detectada na saída do filtro. 
Para o caso da técnica APE, proposta neste trabalho, a forma de excitação é impulsiva de modo que a força sobre o sistema é definida como:

$$
f_{r}(P, t)= \begin{cases}F_{0} & \text { se } 0 \leq t \leq t_{0} \\ 0 & \text { se } t>t_{0}\end{cases}
$$

sendo o intervalo 0 até $t_{0}$ o tempo pelo qual a força age sobre a amostra.

Neste caso o sistema responde em seus modos vibracionais livres, sujeitos a atenuação proporcional a $\zeta$ e novamente a equação 2.17 representa o sistema. Como cada região do sistema está livre pra vibrar em seus próprios modos, as regiões com diferenças mecânicas irão apresentar espectros vibracionais distintos. Na técnica APE, a frequência escolhida como parâmetro do filtro $\omega_{f d}$ é obtida pela análise do espectro gerado pela FFT de um único sinal. Uma vez escolhida a $\omega_{f d} 0$ contraste da imagem será proporcional aos parâmetros do filtro digital e novamente de quão próximos estarão a frequência do filtro $\omega_{f d}$ com um dos modos vibracionais da amostra.

\subsubsection{Resposta do filtro digital}

Como as imagens acustográficas são geradas a partir da filtragem do sinal adquirido em cada ponto da imagem, os parâmetros do filtro utilizado são intimamente relacionados com o contraste da imagem gerada.

Considerando um filtro digital passa-banda do tipo Butterworth [39], um número $n_{P}$ de polos, largura de banda $\Delta \omega_{f d}$ em uma determinada frequência $\omega_{f d}$, é possível estimar a amplitude $\mathrm{RMS}^{\dagger}$ do sinal filtrado para um sinal de entrada com frequência $\omega_{n}$ próxima da frequência $\omega_{f d}$. Como por exemplo, se a frequência $\omega_{f d}$ for escolhida como parâmetro

\footnotetext{
${ }^{\dagger}$ sigla do inglês Root mean square (em português, valor quadrático médio ou valor eficaz)
} 
do filtro digital e, para uma dada porção da amostra, que tenha suas propriedades viscoelásticas ligeiramente diferentes, um de seus modos vibracionais tenha uma frequência de ressonância $\omega_{n}=\omega_{f} d \pm \sigma_{f d}$, ligeiramente diferente de $\omega_{f d}$, a atenuação do filtro digital reduziria a amplitude RMS do sinal filtrado gerando assim, o contraste naquele ponto da imagem. A resposta deste tipo de filtro foi simulada através de um algoritmo escrito em Matlab para uma frequência $\omega_{f d}=50 \mathrm{kHz}$ e largura de banda em $1 \%$ desta frequência para quatro diferentes número de polos. O resultado desta simulação pode ser visto no gráfico da figura 2.3. Neste exemplo, uma variação $\sigma_{f d}$ na frequência central do filtro $\omega_{f} d$ provocaria uma diminuição de aproximadamente $3 \mathrm{db}$ na amplitude de sinal filtrado para um filtro de 4 polos. A escolha da banda e do número de polos é fator determinante no contraste da imagem e tem sua escolha feita a partir da escolha de picos proeminentes no espectro de frequências.

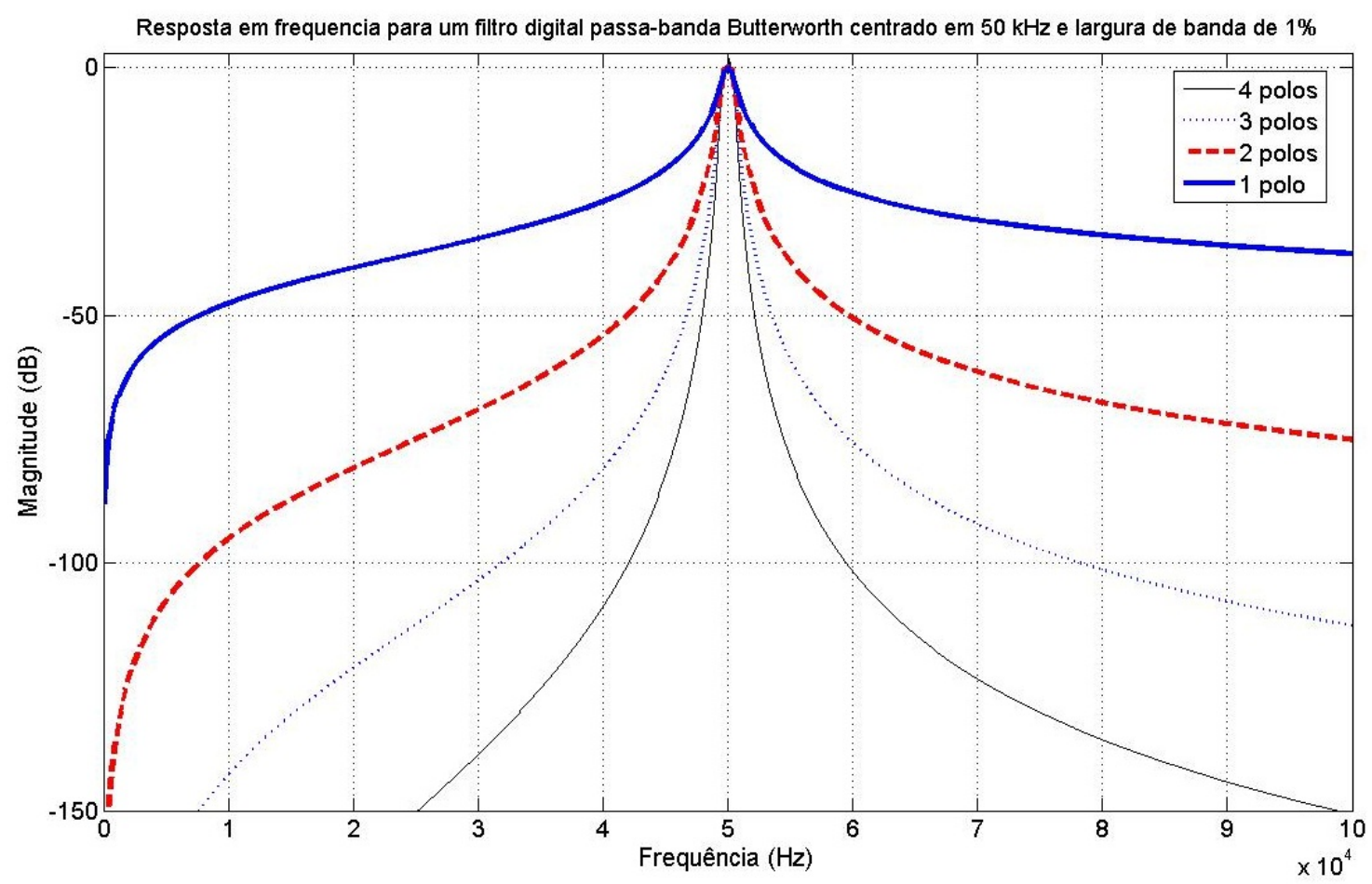

Figura 2.3: Resposta do filtro do tipo Butterworth centrado em $50 \mathrm{kHz}$ com largura de banda em $1 \%$ para 4 diferentes números de polos 


\subsection{Campo Acústico para um transdutor ul- trassônico focalizado}

Considerando um transdutor confocal esférico composto de um disco de raio $a$, a pressão acústica na região focal para uma frequência angular $\omega$ e número de onda $k$, é definida pela equação 2.22 [40]:

$$
P(r, t)=e^{-i(\omega t-k r)} P_{i}(r)
$$

A amplitude de pressão acústica $P_{i}(r)$ para um ponto $Z_{0}$, pertencente ao eixo axial, é definida pela equação 2.23 :

$$
P_{i}\left(Z_{0}\right)=\pi \rho c U\left(\frac{1}{\lambda Z_{0}}\right) j i n c\left(\frac{\text { asen } \alpha}{\lambda}\right) a^{2},
$$

sendo que, sen $\alpha=\xi Z_{0}, \xi^{2}=x^{2}+y^{2}$, jinc é a função de Bessel de primeira ordem, $\lambda$ é o comprimento de onda da frequência $\omega$. $U$ é a amplitude da velocidade de vibração do elemento e $a$ é o raio do elemento.

\subsubsection{Campo acústico Modulado pela VA}

Na Técnica VA, o campo acústico é modulado pela interação entre dois feixes acústicos de frequências ligeiramente diferentes $\omega_{1}$ e $\omega_{2}$. Considerando que os dois feixes sejam gerados por dois elementos piezoelétricos confocais, conforme ilustrado pela figura 2.4 , a pressão acústica modulada é obtida pela combinação entre elas, matematicamente dada por [1]:

$$
P(r, t)=e^{i\left(\omega_{1} t+k_{1} r\right)} P_{1}(r)+e^{i\left(\omega_{2} t+k_{2} r\right)} P_{2}(r),
$$

sendo $P_{1}(r)$ e $P_{2}(r)$ as amplitudes de pressão no ponto $r$, geradas pelas ondas ultrassônicas nas frequências $\omega_{1}$ e $\omega_{2}$ e números de onda $k_{1}$ e $k_{2}$ respectivamente. Para a disposição geométrica dos elementos 
dos transdutor com o elemento central com raio $a_{1}$ e o elemento externo com o diâmetro da coroa limitado pelos raios $a_{21}$ e $a_{22}$, temos que as amplitudes $P_{1}(r)$ e $P_{2}(r)$ são:

$$
\begin{gathered}
P_{1}\left(Z_{0}\right)=\pi \rho c U_{1}\left(\frac{1}{\lambda_{1} Z_{0}}\right) j i n c\left(\frac{a_{1} \operatorname{sen} \alpha}{\lambda_{1}}\right) a_{1}^{2} . \\
P_{2}\left(Z_{0}\right)=\pi \rho c U_{2}\left(\frac{1}{\lambda_{2} Z_{0}}\right)\left[j i n c\left(\frac{a_{21} \operatorname{sen} \alpha}{\lambda_{2}}\right) a_{21}^{2}-j i n c\left(\frac{a_{22} \operatorname{sen} \alpha}{\lambda_{2}}\right) a_{22}^{2}\right] .
\end{gathered}
$$

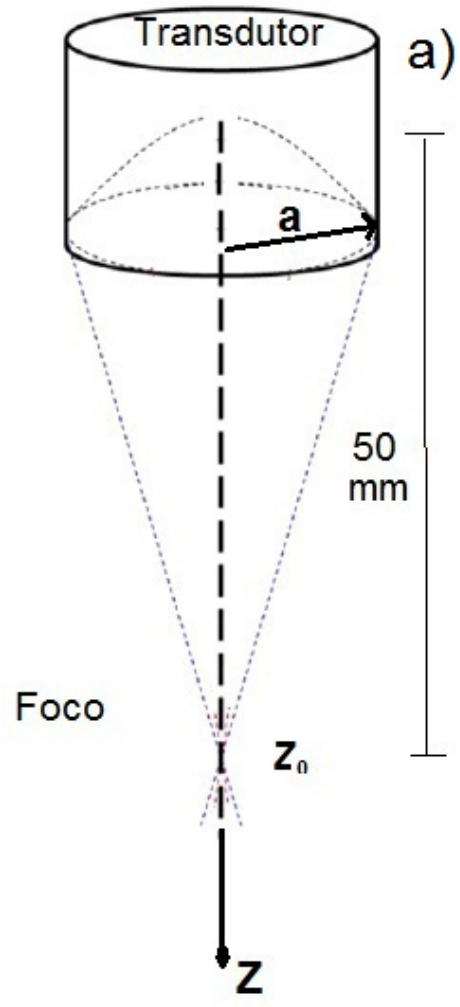

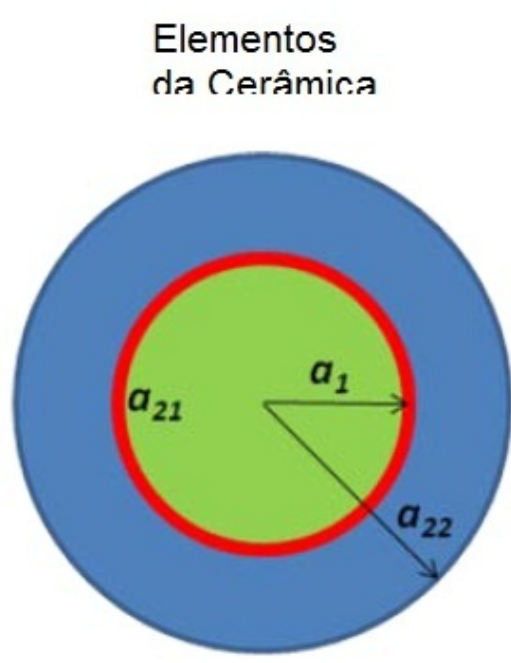

b)

Figura 2.4: Transdutor ultrassônico focalizado

\subsection{Densidade de energia acústica}

A energia transportada por uma onda acústica através de um meio fluido pode ser representada por duas formas: energia cinética dos elementos e potencial do fluído comprimido. A densidade instantânea 
de energia $(\epsilon)$ é dada pela razão entre a energia acústica total e o volume ocupado pelo fluido. Para uma onda esférica onde o raio de curvatura da superfície da onda é muito maior que o comprimento de onda $\lambda$, a frente de onda pode ser considerada plana e a densidade de energia pode ser expressa pela equação 2.27 :

$$
\epsilon=\frac{P\left(z_{0}, t\right)^{2}}{2 \rho c^{2}}
$$

sendo $\rho$ a densidade do meio material e $c$ a velocidade acústica da onda neste meio. Substituindo a equação 2.23 na equação 2.27 e tomando a parte real tem-se a densidade de energia na região do foco descrita pela equação 2.28

$$
\epsilon=\frac{P\left(z_{0}, t\right)^{2}}{2 \rho c^{2}}\left\{\operatorname{real}\left(P_{1}\left(z_{0}\right) e^{i\left(\omega t+k z_{0}\right)}\right)\right\}^{2} .
$$

\subsubsection{Densidade de energia acústica no campo mo- dulado pela VA}

A densidade de energia do campo modulado pela técnica de VA é dada pela equação:

$$
\epsilon=\frac{1}{2 \rho c^{2}}\left\{\operatorname{real}\left(e^{i\left(\omega_{1} t+k_{1} Z_{0}\right)} P_{1}\left(Z_{0}\right)+e^{-i\left(\omega_{2} t-k_{2} Z_{0}\right)} P_{2}\left(Z_{0}\right)\right)\right\}^{2} .
$$

\subsection{Força de radiação acústica}

Os estudos de força e pressão de radiação ultrassônica datam de mais de um século quando Lord Rayleigh publicou um de seus trabalhos sobre pressão de vibrações [41]. Análises mais recentes da teoria e da interpretação física e matemática podem ser encontradas no trabalho de Torr et al. [42]. Revisões críticas e históricas sobre força de radiação são apresentadas nos trabalhos de Boa-Teh Chu et al. [43] e R. E. Beyer,[44]. Alguns trabalhos relevantes aplicados à materiais atenuantes (tecidos biológicos por exemplo) são apresentados por: O. V. 
Rudenko, A. P. Sarvazyan, S. Y. Emelianov [45] e Z.-Y.jiang e J. F. Greenleaf [46].

Considere um feixe ultrassônico colimado incindindo sobre um objeto de impedância acústica diferente do meio como ilustrado na figura 2.4, interações não lineares de espalhamento e absorção transferem momento ao objeto e, consequentemente alteram a densidade de energia do sistema. Por consequência destas interações, uma força de radiação age sobre o objeto de modo que, a intensidade desta força é proporcional a radiação absorvida e retro-espalhada. De maneira resumida pode-se descrever esta força conforme a equação 2.30 [11]:

$$
F=d_{r} S\langle\epsilon\rangle
$$

sendo $S$ a área de secção de choque, $\langle\epsilon\rangle$ é a média temporal da densidade de energia da onda incidente, e $d_{r}$ é chamado coeficiente de arraste complexo. O coeficiente $d_{r}$ é uma grandeza adimensional e é função das propriedades de espalhamento e absorção do objeto e está relacionado a quantidade de momento que é transferido ao objeto.

O coeficiente de arraste complexo devido a pressão de radiação pode ser definido por unidade de densidade de energia da onda incidente conforme a equação 2.31 :

$$
d_{r}=\frac{1}{s}\left(\Pi_{a}+\Pi_{e}-\int \gamma \cos \beta d S\right)-\frac{j}{s} \int \gamma \cos \beta d S,
$$

sendo $\Pi_{a}$ e $\Pi_{e}$ as potências totais absorvidas e espalhadas respectivamente, $\gamma$ é a intensidade espalhada, $\beta$ é o ângulo formado entre o feixe incidente e o espalhado, $s$ é a secção de choque e dS é o elemento de área[47]. Em termos práticos, em algumas aplicações de vibroacustografia[11], os objetos são considerados como uma superfície plana normal ao feixe incidente de modo que $d_{r}$ é puramente real resultando em uma única componente normal da força $F$. Para o caso da VA, foi mostrado que a força de radiação no plano focal é dada pela 
equação [1]:

$$
F_{\Delta \omega}=F_{0} \cos (\Delta \omega t)
$$

\subsection{Pressão acústica emitida}

Nesta secção será apresentada uma abordagem teórica da pressão acústica emitida por um alvo, baseada na teoria apresentada por Fatemi e Greenleaf [11]. Nesta abordagem não são consideradas as interações não lineares do feixe ultrssônico com o meio material.

Considerando um alvo vibrando modelado por uma fonte do tipo pistão cilíndrico [41] com raio $b$ infinitesimal, a pressão acústica emitida é dada pela equação 2.33 [1]:

$$
P_{\omega_{e}}(\vec{r}, t)=4 \rho c^{2} H_{\omega_{e}}(l) Q_{\omega_{e}} F_{\omega e}
$$

sendo l a distância entre o ponto de observação e o detector, $\omega_{e}$ a frequência angular da onda sonora emitida, $Q_{\omega_{e}}$ é um termo que representa a admitância acústica do meio e é representada pela equação 2.34 e $H_{\omega_{e}}(l)$ é a função transferência e é representada pela equação 2.35 .

$$
\begin{gathered}
Q_{\omega_{e}}=\frac{2 \pi b^{2}}{Z_{\omega_{e}}}, e \\
H_{\omega_{e}}(l)=i \frac{\omega_{e}}{4 \pi l} e^{i \frac{\omega_{e} l}{c}}\left(\frac{2 . j i n c\left(\left(b \omega_{e} / c\right) \operatorname{sen} \phi\right)}{\left(b \omega_{e} / c\right) \operatorname{sen} \phi}\right),
\end{gathered}
$$

sendo $Z_{\omega_{e}}$ a impedância mecânica do fluido. .

A pressão acústica $P_{w_{e}}\left(\vec{r}_{h}, \vec{r}_{s}\right)$ mensurada no hidrofone, na posição $\overrightarrow{r_{h}}=\left(x_{h}, y_{h}, z_{h}\right)$ proveniente de uma fonte vibrando localizada em $\vec{r}_{s}=\left(x_{s}, y_{s}, z_{s}\right)$ pode ser modelada por [38]:

$$
P_{\omega_{e}}\left(\vec{r}_{h}, \vec{r}_{s}\right) e^{-i \omega_{e} t}=-i k \rho c S_{\omega_{e}} g_{\omega_{e}}\left(\vec{r}_{h}, \vec{r}_{s}\right) e^{-i \omega_{e} t},
$$


sendo que $s_{\omega_{e}}$ representa a fonte espalhadora com amplitude unitária, $g_{\omega_{e}}\left(\vec{r}_{h}, \vec{r}_{s}\right)$ a função de Green definida pela equação 2.37

$$
g_{\omega_{e}}\left(\vec{r}_{h}, \vec{r}_{s}\right)=\frac{e^{i k R\left(\vec{r}_{s}\right)}}{4 \pi R\left(\vec{r}_{s}\right)}
$$

sendo $R=\left|\vec{r}_{h}-\vec{r}_{S}\right|$ que é a distância fonte hidrofone, conforme figura 2.5.

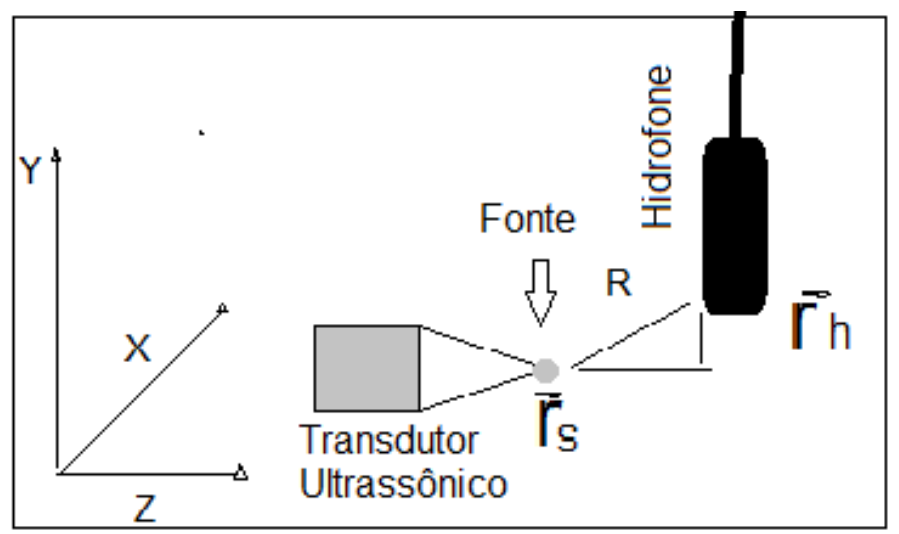

Figura 2.5: Posições relativas entre fonte emissora e hidrofone. R é a distância fonte detector

Para uma fonte simples, localizada na posição $\vec{r}_{S}$, tem-se:

$$
H_{\omega_{e}}(l) Q_{\omega_{e}}=-i \omega_{e} \rho \frac{i k R\left(\vec{r}_{s}\right)}{4 \pi R\left(\vec{r}_{s}\right)} .
$$

Substituindo a equação 2.38 em 2.33 , obtém-se a equação 2.39

$$
P_{\omega_{e}}(\vec{r}, t)=-i \omega_{e} \rho^{2} c^{2} \frac{e^{i k R\left(\vec{r}_{s}\right)}}{\pi R\left(\vec{r}_{s}\right)} F_{\omega_{e}}\left(\vec{r}_{s}, t\right)
$$

\subsection{Modelo mecânico de $2^{a}$ ordem: fre- quência de ressonância}

Tomando como base um sistema mecânico de segunda ordem, como sendo um exemplo geral da resposta característica de um sistema mecânico de segunda ordem, com um amortecimento definido por $B$, uma mola definida por $K_{s}$ agindo sobre uma massa $M$ de força peso $\vec{W}$, como 


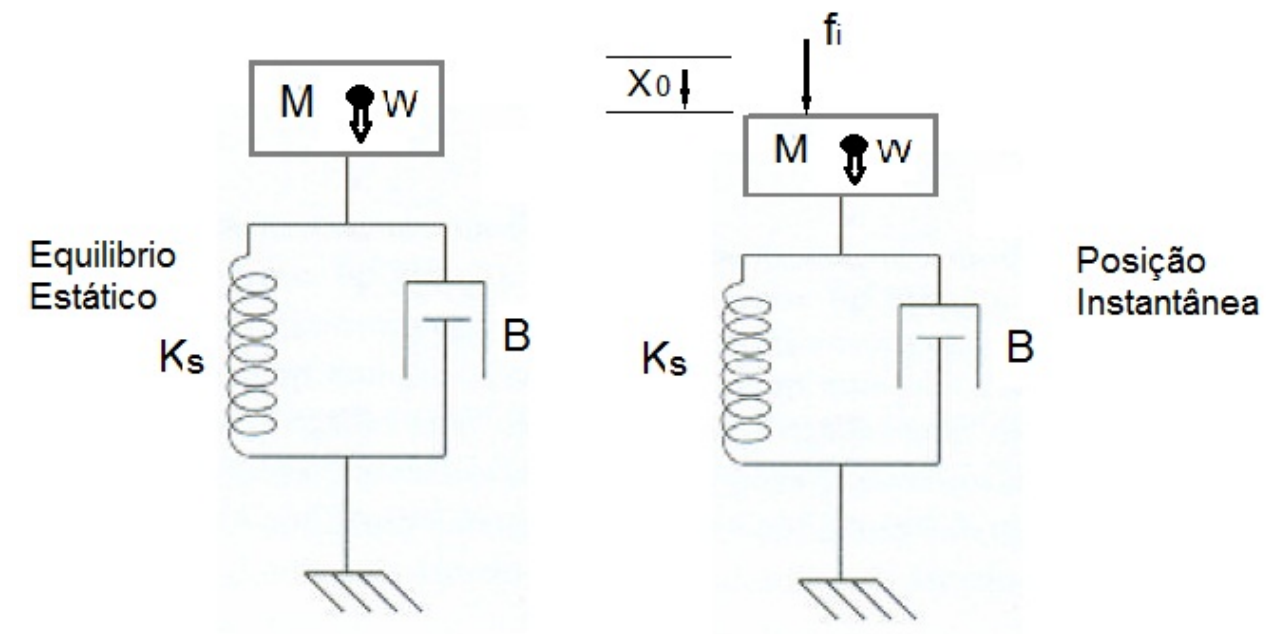

Figura 2.6: Modelo mecânico de um sistema massa mola amortecido

ilustrado pela figura 2.6. O sistema é orientado verticalmente de modo a considerar a força peso. Convenientemente, a posição de origem $x_{0}$ é colocada na posição de repouso da massa na condição em que somente o peso e a força da mola agem sobre $M$. Na condição de equilíbrio, a força da mola deve ser igual a $-\vec{W}$ para $X_{0}=0$, assim, pela segunda lei de Newton:

$$
f_{i}+W-\left(W+K_{s} X_{0}\right)-B \frac{\partial X_{0}}{\partial t}=M \frac{\partial X_{0}^{2}}{\partial t^{2}}
$$

Para o caso em que a origem está na posição de repouso pode-se eliminar a força gravitacional, então a equação 2.40 resulta [48]:

$$
M \frac{\partial X_{0}^{2}}{\partial t^{2}}+B \frac{\partial X_{0}}{\partial t}++K_{s} X_{0}=f_{i}
$$

A frequência de ressonância para a condição de impedância acústica puramente real é dada pela equação [48];

$$
\omega_{r}=\sqrt{K_{s} / M} .
$$

Derivando a equação 2.42 em função de $K_{s}$ é possível encontrar a variação da frequência de ressonância em função de uma variação da 
2.7 - Modelo mecânico de $2^{a}$ ordem: frequência de ressonância 31

constante elástica da mola, de modo que:

$$
\frac{\partial \omega_{r}}{\partial K_{s}}=\sqrt{\frac{1}{4 K_{s} M}} .
$$

A partir da equação 2.43 é possível estimar a variação da frequência de ressonância de um sistema viscoelástico a partir de uma variação na rigidez. 


\section{Capítulo}

\section{Materiais e métodos}

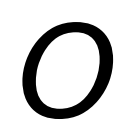
capítulo 3 apresenta os materiais e os métodos utilizados neste trabalho. São abordados os arranjos experimentais das técnicas de acustografia por pulso/emissão (APE) e a vibroacustografia (VA) em ambas as suas modalidades contínua (CW) e pulsada (TB). Também são descritos os procedimentos para confecção dos simuladores de tecidos biológicos.

\subsection{Transdutor ultrassônico para excitação}

Para os experimentos envolvendo as técnicas APE e VA, um mesmo transdutor ultrassônico foi utilizado para a excitação. O transdutor foi construído a partir de uma cerâmica do tipo PZT 4 * de formato semiesférico com diâmetro de $45 \mathrm{~mm}$ e raio de $50 \mathrm{~mm}$, que implica em um foco de mesmo comprimento.

Como observado no capítulo 2, a VA utiliza dois feixes ultrassônicos com foco comum, deste modo, a cerâmica foi dividida em dois elementos, um circulo central e uma coroa externa, cada um destes elementos tem áreas semelhantes, de modo a garantir potências acústicas equivalentes, como ilustrado na figura 3.1. Cada elemento tem alimentação elétrica independente, podendo assim, ser energizados com frequências diferentes mantendo o ponto focal comum. Para a técnica APE

\footnotetext{
*Tipo de cerâmica piezoelétrica de classificação Navy Type ("Hard")
} 
apenas um elemento deste transdutor é utilizado, tendo sido escolhido o elemento central.
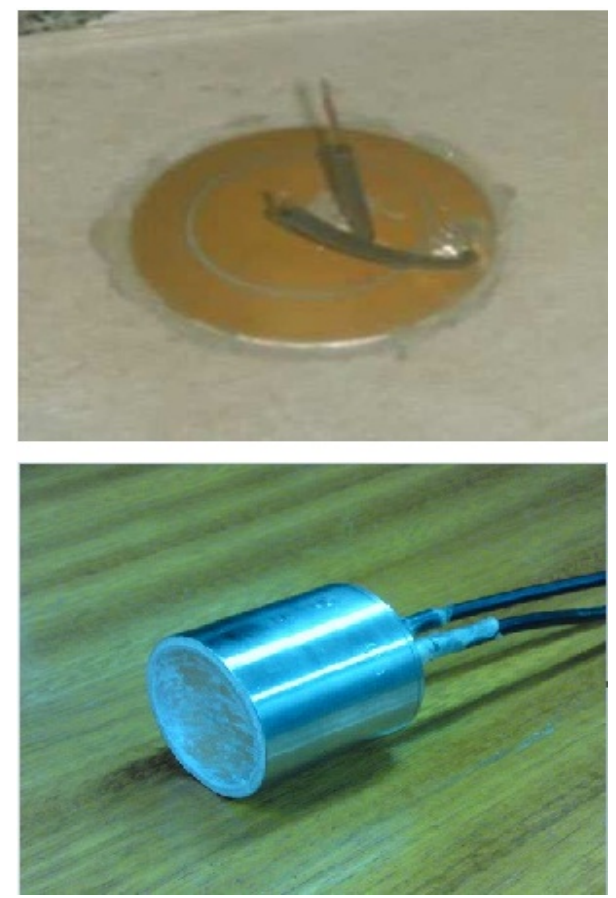

(a) Cerâmica PZT4 dividida em dois elementos para aplicação em VA e transdutor montado

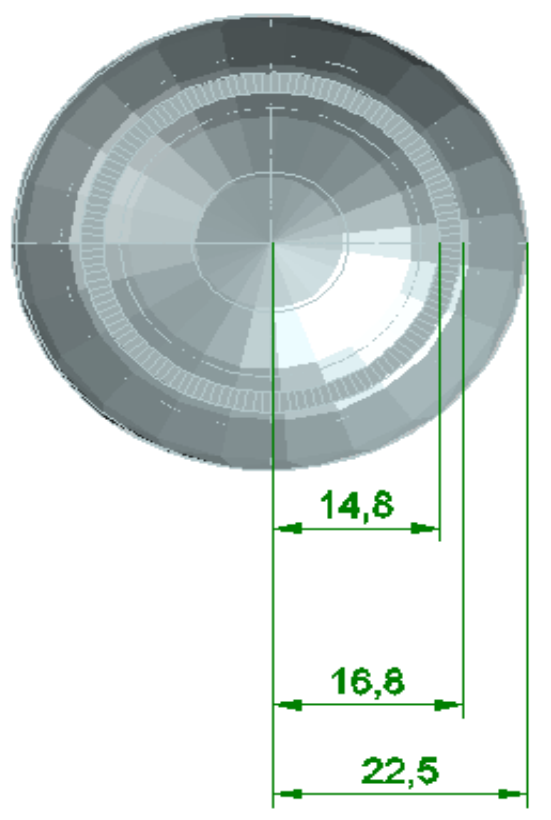

(b) disposição geometria dos elementos da cerâmica

Figura 3.1: Trandutor ultrassônico de excitação confocal. Cabos coaxiais foram colados, usando um tipo especial de cola condutora a base de prata, em cada eletrodo interno. Após a ligação dos cabos a conectores externos, a cerâmica foi acoplada a um cilindro de aço inox oco, que foi selado com borracha de silicone e envernizado.

\subsection{Arranjo experimental da técnica APE.}

Para a maioria dos experimentos baseados nos sinais produzidos pela $A P E$, foi montada uma configuração comum. Este arranjo contava, basicamente, com um sistema de excitação ultrassônica na faixa de megahertz e um sistema de aquisição na faixa de quilohertz como ilustrado na figura 3.2.

Os experimentos foram realizados em um tanque acústico de dimensões $100 \times 64 \times 37 \mathrm{~cm}$ contendo água desgaseificada à tempera- 


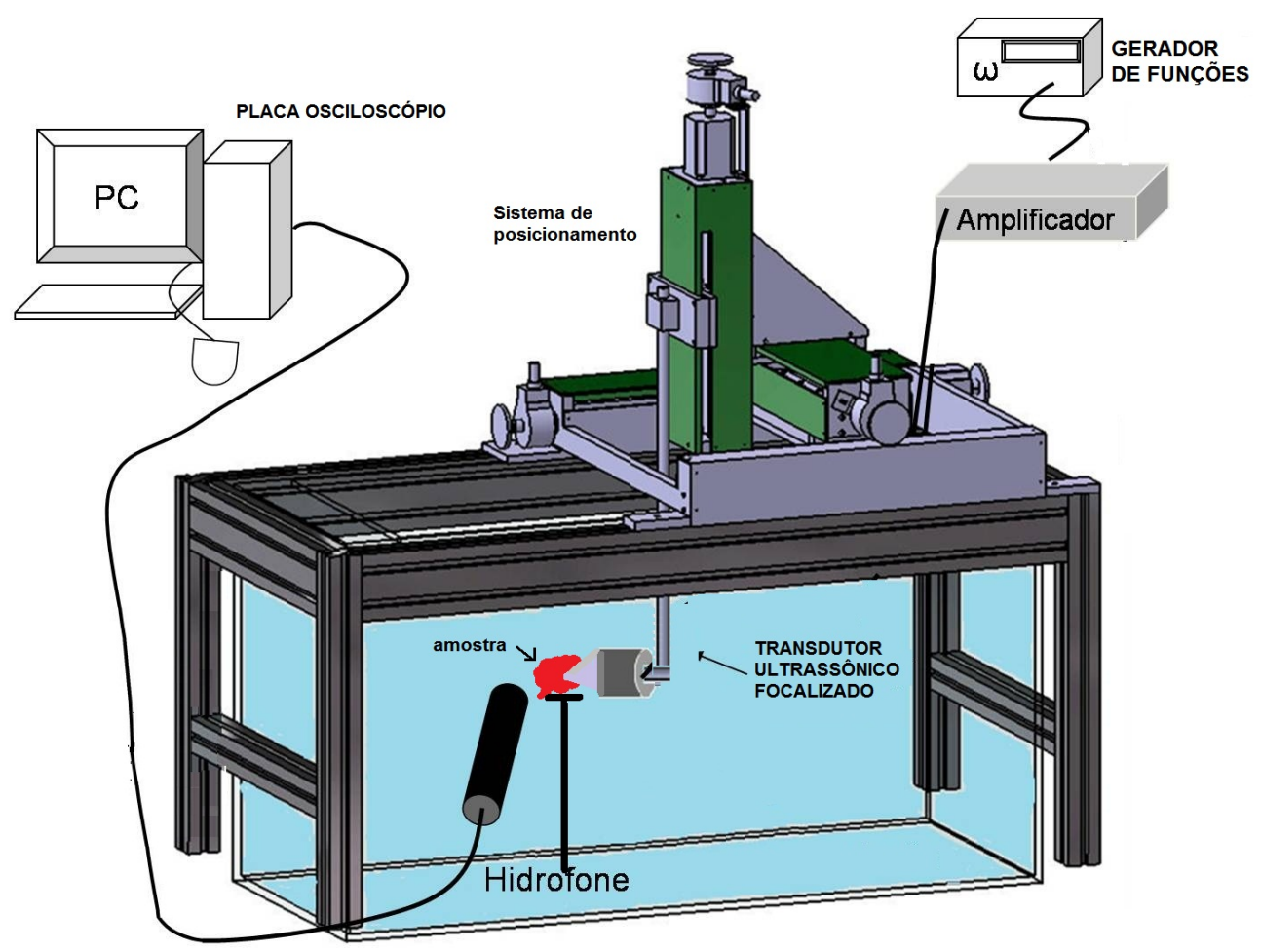

Figura 3.2: Arranjo experimental para formação de imagens por APE: Um gerador de funções cria um padrão de sinal no modo burst que é amplificado de modo a energizar o transdutor ultrassônico. Um robô posiciona o foco do transdutor em diferentes pontos da amostra. Para cada ponto o sinal acústico é detectado pelo hidrofone e procesado

tura ambiente $\left(25^{\circ} \mathrm{C}\right)$. O processo de desgaseificação da água conta com um circuito hidráulico desenvolvido em nosso laboratório GIIMUS, que, através de um sistema de filtragem, aquecimento, produção de vácuo e circulação de água, reduz significantemente os gases diluídos, como ilustrado na figura 3.3(a).

As amostras foram posicionadas dentro de um tanque acústico e dispostas entre o transdutor de excitação e o hidrofone. Para posicionar o ponto focal de excitação em um determinado ponto do objeto, foi utilizado um sistema de pulso/eco que contava com um equipamento de US pulso/eco ( Pulse/Receiver modelo 5601A, Panametrics, USA) e um osciloscópio (Agilent 6006 USA). Através da distância temporal ( $\Delta t$ ) entre o sinal de trigger e o eco foi possível determinar a distância espacial entre o alvo e o foco, através da relação $d=c \Delta t 2$, sendo $c$ a 
velocidade de propagação do som na água. Este sistema é ilustrado na figura 3.3(b).

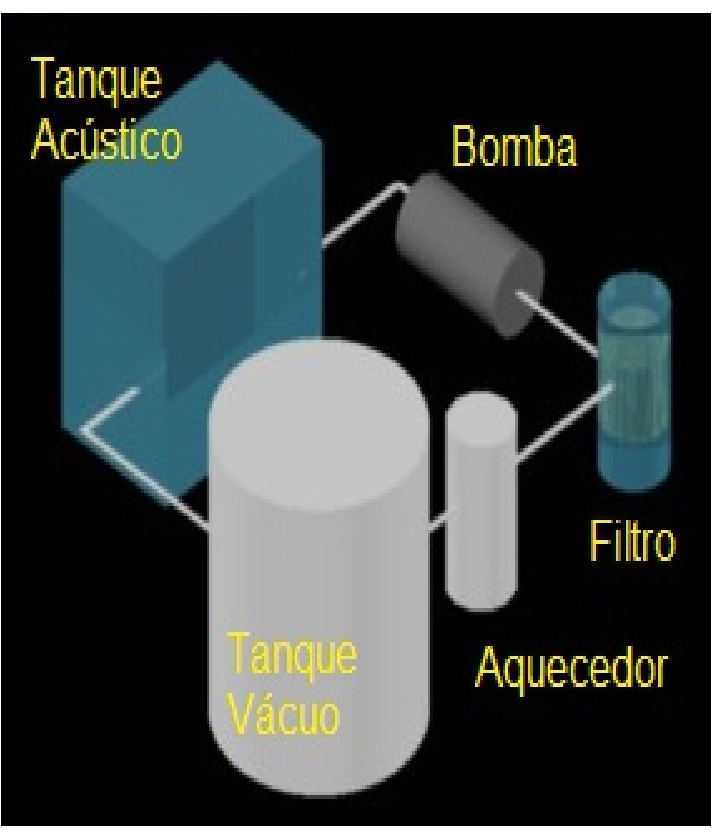

(a) Circuito hidráulico para desgaseificação da água: a água sai do tanque através de uma bomba hidráulica até um reservatório menor passando por um aquecedor que eleva a temperatura para aproximadamente $40^{\circ} \mathrm{C}$, no reservatório menor é produzido vacuo até cerca de $500 \mathrm{mmHg}$ continuamente, e então, por gravidade a água retorna ao tanque de experimentação

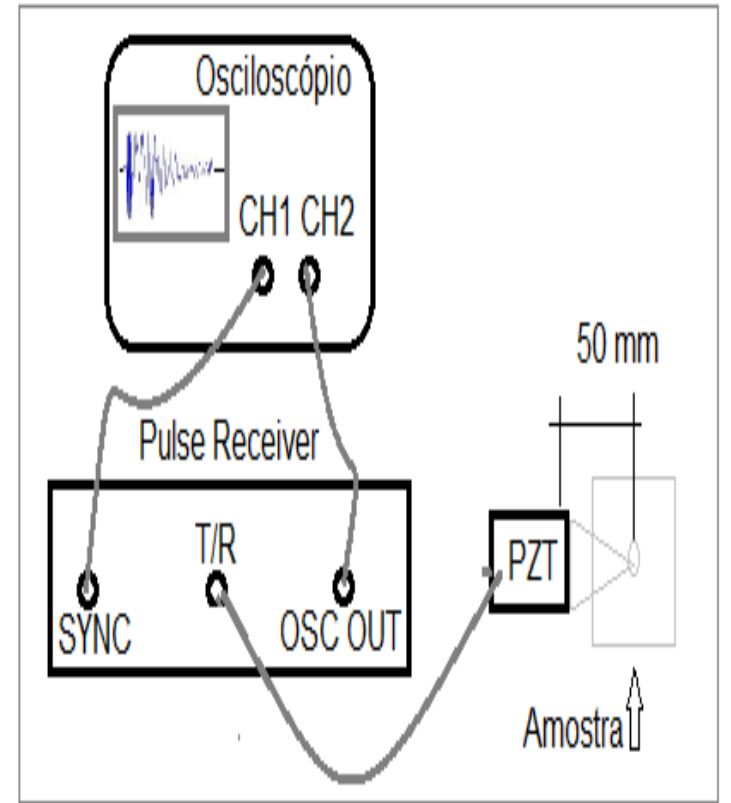

(b) Sistema pulso/eco para posicionamento do foco na amostra

Figura 3.3: Sistema de posicionamento da amostra e processo de desgaseificação da água.

A sequência para obtenção dos sinais gerados pela técnica APE pode ser divida em três etapas:

- Excitação (MHz)

- Aquisição (kHz)

- Processamento (Janelamento- FFT) 


\subsubsection{Excitação}

De modo a otimizar a potência da onda ultrassônica produzida pelo transdutor, a cerâmica foi excitada por uma diferença de potencial elétrico oscilatório de forma senoidal e com amplitude 40,0 Vpp (com frequência igual a frequência de ressonância do elemento piezoelétrico $\left(\omega_{c}=3,43 \mathrm{MHz}\right)$, durante período $\Delta T$ correspondente a um pacote contendo $N_{c}$ de ciclos completos da frequência $\omega_{c}$.

Para produzir este padrão de excitação, foi utilizado um gerador de funções (modelo Agilent 33220A Santa Clara California EUA) configurado na modalidade burst, cujo sinal foi amplificado por um amplificador de altas frequências produzido no próprio laboratório,(GIIMUS -001 Ribeirão Preto BR) com ganho nominal de amplitude de voltagem de $20 d B$. A figura 3.4 demonstra uma sequência temporal entre o processo de excitação e aquisição controlado por um software compilado em linguagem Labview ${ }^{\circledR}$ ( versão 8.0 National Instruments).

O sinal acústico de baixas frequências foi detectado por um hidrofone* modelo (ITC 6050C Santa Barbara EUA) alimentado por uma fonte $\mathrm{DC}$ de $24 \mathrm{~V}$, com banda de aquisição na faixa de $0,3 \mathrm{kHz}$ a $100 \mathrm{kHz}$ e sensibilidade média de $157 d B / V / \mu P a$. O sinal do hidrofone foi então ligado à uma placa osciloscópio modelo (NI $5122 \mathrm{PCl}$ da National Instruments Austin Texas EUA) acoplada a um computador. A aquisição foi sincronizada com o pulso de excitação para uma taxa de amostragem de 2,0 $\mathrm{MHz}$ e posteriormente, arquivada em formato *.dat.

\subsubsection{Processamento dos sinais}

Uma vez adquiridos os sinais, os dados são processados utilizando um algoritmo escrito em Matlab. A primeira parte do processamento é dedicada ao janelamento do sinal que será processado, após escolhido o intervalo do sinal que será utilizado, realiza-se uma FFT de um sinal para a escolha da frequência que será utilizada no processamento

\footnotetext{
*Tipo especial de microfone que pode ser utilizado dentro d'água
} 


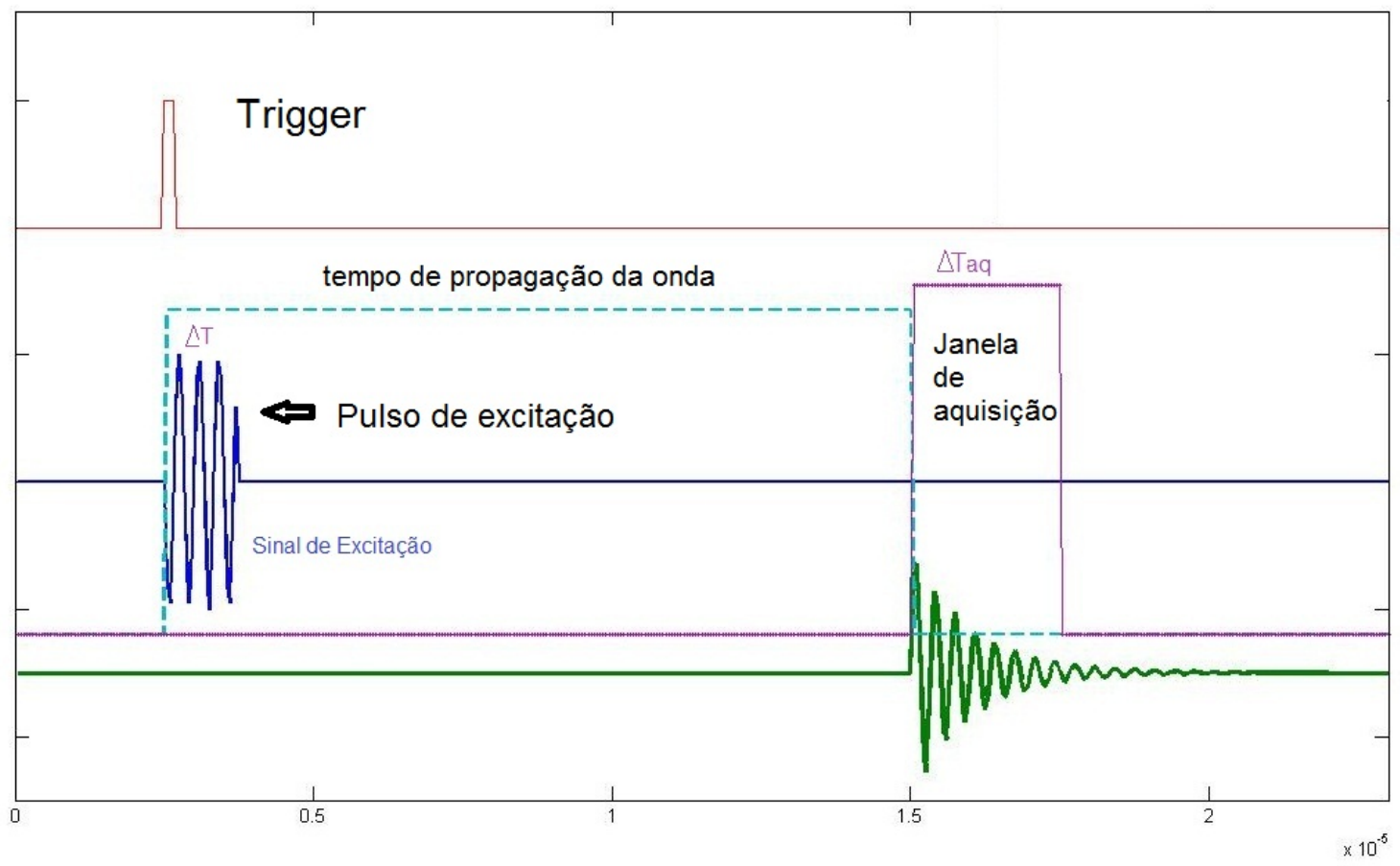

Figura 3.4: Sequência temporal utilizada no processo de excitação e aquisição na técnica APE. Após o sinal de sincronização enviado pelo computador (linha fina- vermelha) um pacote contendo um número $N_{c}$ de ciclos é emitido pelo gerador. Após o tempo de propagação da onda acústica (linha tracejada- azul) é realizada aquisição do sinal acústico emitido pela amostra por um intervalo de tempo $\Delta T_{a q}$.

do restante dos sinais. Por último, todos os sinais são filtrados na frequência escolhida de modo a obter um valor que possa ser associado a intensidade de brilho de um pixel da imagem formada.

\subsubsection{Janelamento do sinal adquirido}

A definição do trecho de sinal acústico utilizado para o processamento, é um dos fatores mais críticos para a relação sinal/ruído. Para seccionar a parte do sinal que seria utilizada, foi definida uma janela temporal do sinal adquirido. Para diminuir os artefatos de secção do sinal, foi utilizada uma janela do tipo Hamming [49] que reduz as componentes de frequências no espectro devido ao corte do sinal. O jane- 
lamento Hamming segue a equação 3.1

$$
W_{h}(t+1)=0.54-0.46 \cos \left(\frac{2 \pi t}{n-1}\right)
$$

Sendo $W_{h}$ a função janela e $n$ é o tamanho da janela.

O intervalo de tempo $\Delta T_{a q}$ é definido a partir de um tempo $t_{0}$ que corresponde ao inicio do sinal. O tempo $t_{0}$ é obtido calculando o tempo de propagação da onda desde o transdutor de excitação até a chegada ao hidrofone. O sinal acústico detectado sofre influências de reverberações presentes dentro da amostra e no tanque acústico, deste modo o intervalo de tempo $\Delta T_{a q}$, que define a janela de processamento, foi escolhido o mais curto possível porém respeitando um tamanho mínimo que contivesse ao menos dois períodos completos da menor frequência que se desejava observar. O tamanho do pacote de excitação e da janela de processamento escolhida para cada experimento são apresentadas junto aos resultados.

\subsubsection{Transformada rápida de Fourier}

A resposta em frequência do sinal era calculada a partir da Transformada rápida de Fourier (FFT) do sinal no intervalo da janela de processamento. Para a obtenção da FFT foi utilizado um algoritmo presente no pacote de funções do Matlab ${ }^{\circledR}$ (Mathworks). A discretização das frequências foi de $10 \mathrm{~Hz}$ e o espectro de potência foi obtido pelo módulo dos valores complexos calculados pela função FFT.

\subsection{Estimativa da função envelope}

Para a obtenção da função envelope $f(t)$ para um dado pulso $s(t)$ gerado pelo transdutor, foi utilizado a transformada de Hilbert aplicada ao sinal $s(t)$. A transformada de Hilbert [50] é definida pela equação 3.2:

$$
u(s(t))=-\frac{P}{\pi} \int_{-\infty}^{\infty} \frac{s(n)}{n-t} d n
$$


A função envelope para um sinal $s(t)$ pode ser obtida através da equação 3.3 [50];

$$
f(t)=\sqrt{u(s(t))^{2}+s(t)^{2}}
$$

\subsection{Formação de Imagens a partir da téc- nica APE.}

Para utilizar a técnica APE na formação de imagens, primeiramente é definido o plano $x, y^{\ddagger}$ que corresponde a uma fatia da amostra, como ilustrado na figura 3.5, em seguida, este plano é discretizado, levando em consideração os limites impostos pela PSF do sistema. Para cada ponto $P(x, y)$ o sinal é adquirido e, após processado, um valor é associado à intensidade de cada pixel da imagem gerada.

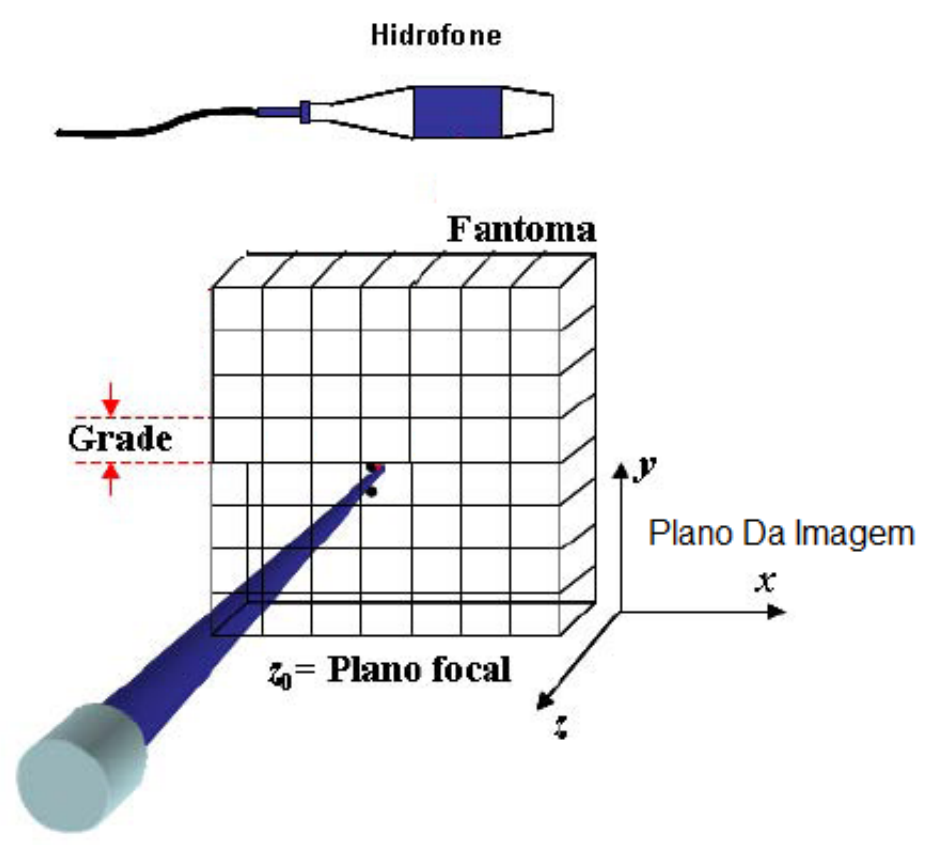

Transdutor

Figura 3.5: Plano da amostra escolhido para a geração da imagem.

\footnotetext{
${ }^{\ddagger}$ Nas imagens geradas a partir da APE o plano da imagem é ortogonal ao feixe ultrassônico. Em outras imagens como por exemplo, no ultrassom modo $B$, este plano é paralelo ao plano que contém o feixe de ultrassom
} 
Para o posicionamento do foco do transdutor de excitação em cada ponto $P(x, y)$ foi utilizado um robô do tipo prismático de três eixos (Sistema de rastreio 3D-Figlabs, Ribeirão Preto, BR) que movia o transdutor ou a amostra ao longo do plano $x, y$ paralelo ao feixe ultrassônico de excitação que estava alinhado à direção $z$.

A FFT é calculada para um único ponto da imagem como o objetivo de reconhecer as frequências que compõem o sinal. A partir da escolha de uma frequência de interesse $f_{e}$ (geralmente a que apresenta maior intensidade), todos os sinais, referentes aos demais pontos da imagem, são filtrados digitalmente em uma banda em torno de $f_{e}$. Foi utilizada uma função do Matlab para emular um filtro do tipo Butterworth passabanda de 4 polos com largura de banda em $5 \%$ em torno de $f_{e}$. A partir do sinal filtrado o valor RMS é calculado utilizando a equação 3.4, e associado a cada pixel da imagem. Após montada a matriz com os valores RMS, um filtro de mediana com janela $4 \times 4$ pixels é aplicado para reduzir valores muito discrepantes gerados muitas vezes por bolhas de ar. A escolha de uma determinada frequência $f_{e}$ faz com que a imagem gerada seja ponderada em cada um dos efeitos discutidos. O diagrama da figura 3.6 demonstra a sequência de processamento, cujos os detalhes são descritos na sequência abaixo.

1. Representa a amostra com o plano $x, y$ da imagem discretizada em ponto $P(x, y)$;

2. Sinal acústico adquirido de tensão versus tempo para cada posição $P(x, y)$. Em destaque a janela temporal contendo a porção do sinal utilizada para o processamento;

3. Espectro em frequência relativo ao sinal acústico, utilizado para determinação das frequências que serão utilizadas na amostra. Este procedimento é realizado para um único ponto de aquisição.

4. Uma vez definida a frequência do sinal acústico, todos os sinais são filtrados com um filtro passa-banda do tipo Butterworth de 4 


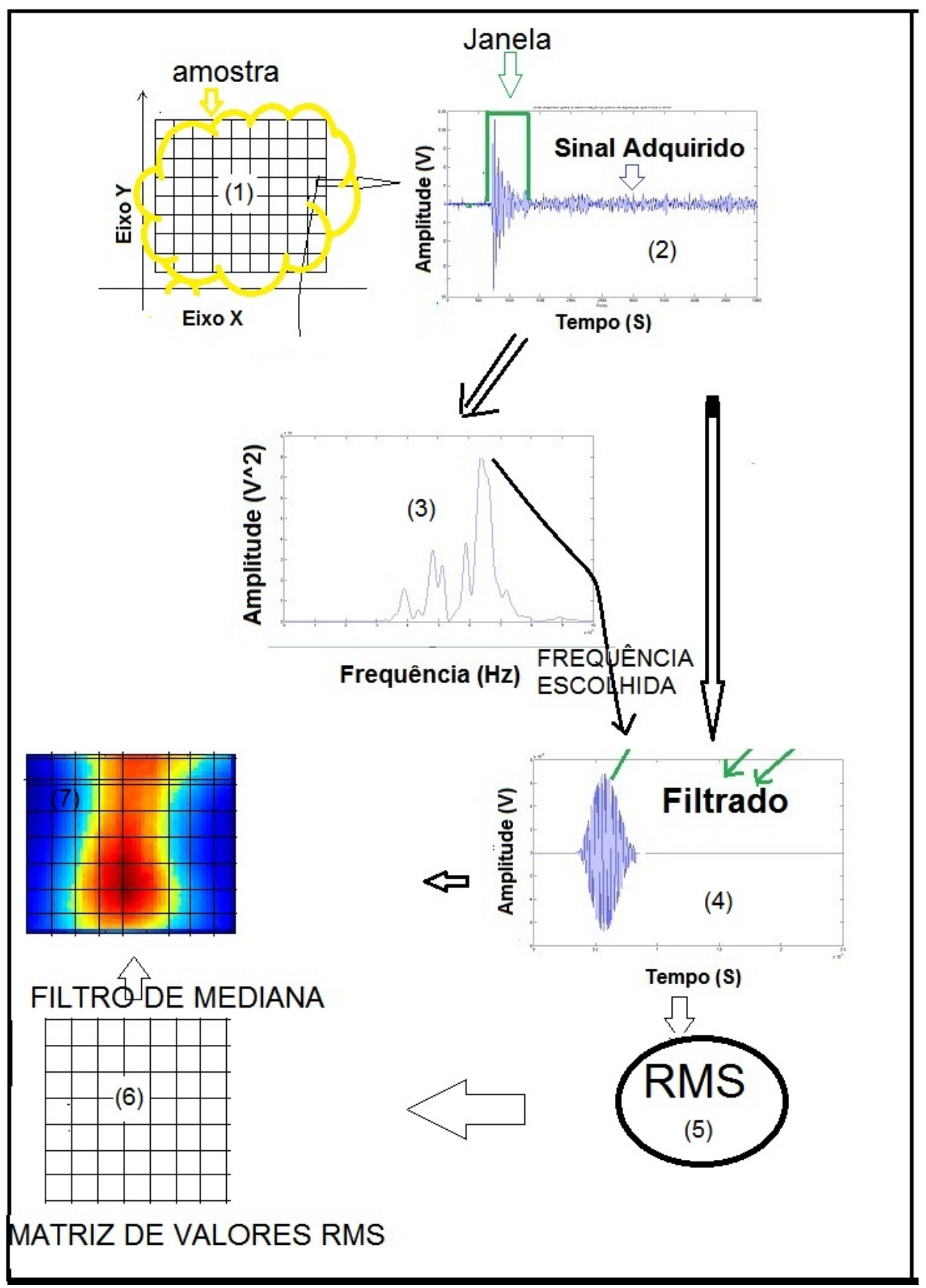

Figura 3.6: Diagrama representando a sequência de processamentos para geração da imagem

polos centrado nesta frequência.

5. Depois de filtrados são calculados os valores RMS para cada sinal e estes valores são atribuídos aos respectivos pontos $P(x, y)$. 
6. Um filtro de mediana é aplicada com janela quadrada de dimensão 4 pixels para eliminar alguns valores espúrios, provavelmente provocados por bolhas de ar residuais e por ruídos sonoros externos.

7. Imagem gerada a partir da matriz de valores de amplitude RMS do sinal processado.

O Valor RMS foi calculado para um intervalo de sinal definido de $T_{1}$ a $T_{2}$ utilizando a expressão 3.4:

$$
S_{R M S}=\sqrt{\frac{1}{T_{2}-T_{1}} \int_{T_{1}}^{T_{2}}[f(t)]^{2} d t}
$$

\subsection{Arranjo experimental da VA}

Os experimentos de VA foram realizados para as duas diferentes modalidades de excitação modulada: a CW e a TB. A montagem experimental é similar para ambas as modalidades, com exceção dos equipamentos utilizados na aquisição dos sinais. A figura 3.2, mostra detalhes desta montagem. Os fantomas foram posicionados dentro do tanque acústico, e próximo ao transdutor confocal e o hidrofone. neste arranjo, o transdutor de radiação acústica foi movido de forma matricial pelo plano $x, y$ paralelo ao feixe ultrassônico de excitação na direção $z$.

A radiação ultrassônica nas modalidades $\mathrm{CW}$ e TB foi gerada com o mesmo transdutor confocal de dois elementos. Ambos os elementos deste transdutor tem um foco comum em $50 \mathrm{~mm}$ e frequência central $\omega=3,43 \mathrm{MHz}$. O elemento interno é uma calota com raio projetado de $r_{1}=14,8 \mathrm{~mm}$, o elemento externo é uma coroa com raios de $r_{21}=16,8 \mathrm{~mm}$ e $r_{22}=22,5 \mathrm{~mm}$. O tanque acústico de dimensões $100 \times 64 \times 37 \mathrm{~cm}$ contendo água desgaseificada à temperatura ambiente $\left(25^{\circ} \mathrm{C}\right)$. O processo de desgaseificação da água conta com um circuito hidráulico, contendo um sistema de filtragem, aquecimento, 
produção de vácuo e circulação d'água, com o objetivo de reduzir significantemente os gases diluídos.

O som produzido pelo meio foi detectado por um hidrofone submerso (ITC modelo 6050C, Santa Barbara, CA, EUA), com sensibilidade de $-157 \mathrm{~dB} / 1 \mathrm{~V} / \mu \mathrm{Pa}$ e resposta em frequência entre $300 \mathrm{~Hz}$ à $100 \mathrm{kHz}$, colocado dentro do tanque d'água. As dimensões do hidrofone são de aproximadamente $30 \mathrm{~cm}$ de comprimento e diâmetro de $5 \mathrm{~cm}$ e que possui uma área sensível aproximadamente esférica de $28 \mathrm{~cm}^{2}$.

Uma vez escolhida a frequência de modulação $\Delta \omega$, este valor é dividido por dois. O valor $\Delta \omega / 2$ é somado a frequência central $\omega$ dando origem a $\omega_{1}=\omega+\Delta \omega / 2$, e subtraído de $\omega$ dando origem a $\omega_{2}=\omega-\Delta \omega / 2$. O valor de $\Delta \omega$ foi dividido ao meio de modo que $\omega_{1}$ e $\omega_{2}$ ficassem o mais próximo da frequência central, evitando assim sair da região de ressonância das cerâmicas. Os elementos central e externo, do transdutor foram energizados por duas fontes que forneciam voltagens oscilatórias senoidais nas frequências $\omega_{1}$ e $\omega_{2}$ e amplitude de $44 \mathrm{Vpp}$. Estas fontes eram compostas por dois geradores de função (Agilent modelo 33220A, Agilent Technologies, Palo Alto, CA EUA) e amplificados por dois amplificadores experimentais construídos no próprio laboratório, com ganho de $20 \mathrm{~dB}$.

Na VA operando no modo CW, a amostra foi excitada continuamente enquanto o transdutor percorria a amostra e o sinal detectado pelo hidrofone era acoplado a um amplificador do tipo lock-in* (Signal Recovery modelo 7265, AMETEK Inc. Comercializado formalmente pela EG\&G Instruments, Oak Bridge, USA). Este tipo de amplificador fornece informações de amplitude e fase de um sinal respectivo a uma determinada frequência de referência, que neste caso é a frequência de batimento $\Delta \omega$, e como esta frequência é resultado da interação dos dois feixes acústicos, foi preciso sintetizar o sinal de batimento para servir de referência para o lock-in.

\footnotetext{
* Lock-in são equipamentos compostos por filtros digitais e amplificadores que correlacionam um sinal de entrada com um sinal de referência de modo a fornecer a amplitude e fase do sinal de entrada em relação a frequência do sinal de referência
} 


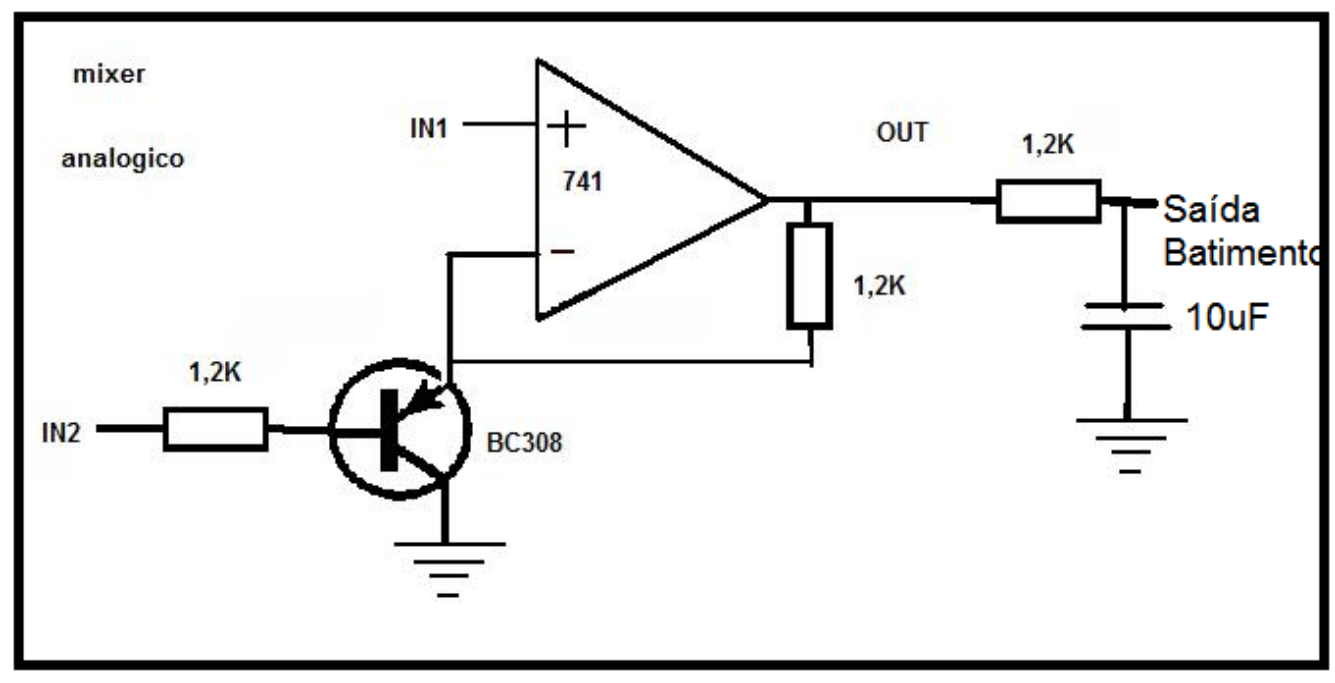

Figura 3.7: Circuito Mixer, emulador da frequência de batimento $\Delta \omega$ a partir das frequências $\omega_{1}$ e $\omega_{2}$

A figura 3.7 demonstra o circuito utilizado para simular a frequência de batimento para servir de referência para o lock-in. O circuito é composto basicamente por um amplificador operacional na configuração do tipo mixer acoplado a um filtro passa-baixas. Os sinais sintetizados pelos geradores foram enviados tanto para o amplificador como para o circuito mixer, o casamento de impedâncias foi realizado com um divisor de tensão de $50 \Omega$.

Os valores de amplitude do sinal fornecidos pelo lock-in foram transmitidos para um computador através de uma interface $\mathrm{GPiB}^{\dagger}$ e associados a cada ponto $x, y$ da amostra, de modo que, os valores de amplitudes correspondiam a uma intensidade de brilho da imagem formada.

Nas aquisições envolvendo VA no modo TB, os geradores eram configurados para operar no modo burst, ou seja, com a excitação definida por um intervalo de tempo $\Delta t$ (chamado pacote ou burst). Este pacote é definido, nestes geradores, pelo número de ciclos da frequência principal $\omega_{1}$ ou $\omega_{2}$, este número de ciclos foi definido a partir de $\Delta t$ que, para os nossos experimentos, foi padronizado como sendo cinco vezes o período da frequência de batimento $\Delta \omega$, valor este que é suficiente

\footnotetext{
${ }^{\dagger}$ GPiB é uma sigla inglesa para General Purpose Interface Bus que envolve o padrão de comunicação ANSI/IEEE Standard 488.1 1987.
} 
para realizar a FFT em torno de $50 \mathrm{kHz}$. A excitação foi sincronizada com a aquisição levando em consideração o tempo de propagação da onda da fonte até o detector.

Para o modo TB, o amplificador Lock-in foi substituído por um filtro digital (Stanford Research System modelo SR650, Sunnyvale, CA, USA), configurado no modo passa-bandas, centrado em $\Delta \omega$, com largura de banda em 10\% e amplificado em $20 \mathrm{~dB}$ na entrada e $20 \mathrm{~dB}$ na saída do sinal. Após passar pelo filtro digital, o sinal foi digitalizado por uma placa osciloscópio (National Instruments modelo NI $5122 \mathrm{PCl}$, National Instruments, Austin, Texas, EUA). O sinal de sincronização de saída de um dos geradores, disparava o segundo gerador e também a placa osciloscópio. Uma vez capturado, o valor RMS do sinal era calculado e associado ao brilho de cada pixel da imagem.

A figura 3.8 mostra as diferenças nos arranjos experimentais para as duas modalidades de VA e pra a APE. Observando o arranjo 3.8(c) notase uma redução considerável dos instrumentos utilizados em relação a técnica VA CW.

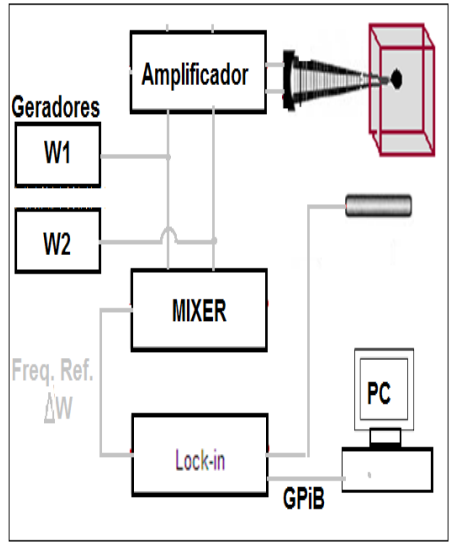

(a) Diagrama VA CW

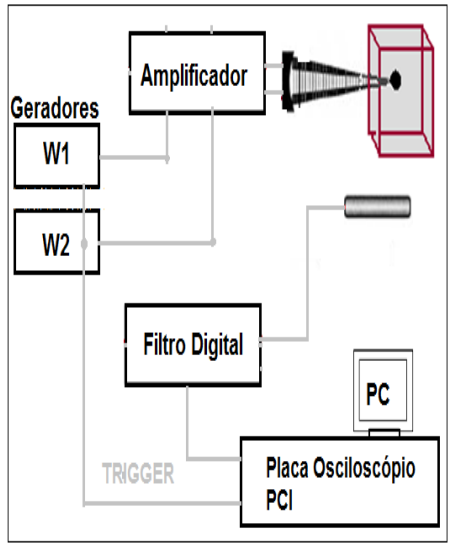

(b) Diagrama VA TB

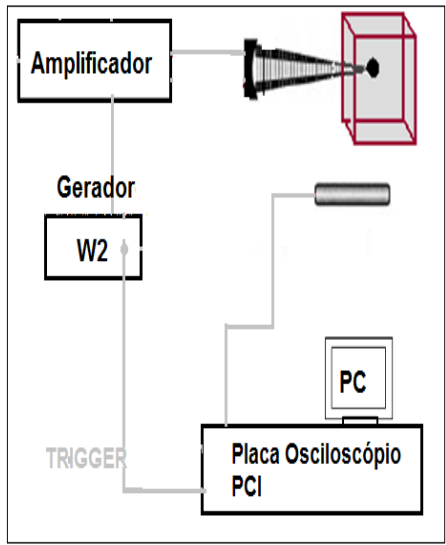

(c) Diagrama da técnica APE

Figura 3.8: Diagrama experimental paras as duas modalidades de VA e para a técnica APE. 


\subsection{Preparação dos simuladores de tecidos biológicos}

Tabela 3.1: Tabela contendo os ingredientes para a fabricação de simuladores de tecidos biológicos

\begin{tabular}{lcc}
\hline \hline Substâncias & Especificação & Porcentagem em massa \\
\hline Água & Desionizada & $94 \%$ \\
Gelatina Bovina & 300 bloom & $8 \%$ \\
Ágar & Powder & $0-6 \%{ }^{*}$ \\
Formaldeído & P.A.36,5\% & $0,37 \%$ \\
Pó de vidro & $38-74 \mu g$ & $1 \%$ \\
\hline
\end{tabular}

Os simuladores de tecidos biológicos, doravante denominados fantomas, tinham como base suspensões a base de gelatina e ágar seguindo as proporções conforme a tabela $3.1^{*}$. O ágar e a gelatina são materiais comumente usados no processo de confecção de fantomas aplicados em imagens elastográficas [51]. Neste trabalho, alguns fantomas foram fabricados contendo inclusões com rigidez diferenciadas e a mistura ágar/gelatina foi adotada para a confecção dos simuladores. Dentre as vantagens de se utilizar a mistura a base de ágar/gelatina, estão a estabilidade das propriedades elásticas ao longo do tempo e manutenção da forma geométrica das inclusões. A estabilidade geométrica das inclusões é mantida porque há baixa mudança de volume das inclusões devido a pressão osmótica, isto é possível porque, tanto as inclusões quanto o corpo do fantoma, tem a mesma concentração de gelatina [52]. Os fantomas a base de gel aquoso são considerados sólidos incompressíveis nas condições típicas de aplicações elastográficas [53].

O processo de confecção dos fantomas segue as seguintes etapas:

- Em um becker mistura-se água, gelatina e o ágar. A mistura é aquecida e agitada até que se atinja $70^{\circ} \mathrm{C}$, utilizando para isto um

\footnotetext{
${ }^{*}$ A quantidade de ágar foi variada conforme a rigidez desejada
} 
agitador magnético (modelo 753-A, Fisatom $\mathrm{Br}$ ), ao atingir esta temperatura o aquecedor é desligado e a mistura é posta a resfriar ao ambiente até que se atinja temperatura de $35^{\circ} \mathrm{C}$, como ilustrado na figura 3.9.

- Ao atingir $35^{\circ} \mathrm{C}$, o formaldeído é adicionado e a mistura é novamente colocada para agitar por cinco minutos.

- Após a homogenização com o formaldeído, a mistura é refrigerada em geladeira até que atinja um ponto de quase gelificação (em torno de $28^{\circ} \mathrm{C}$ ), neste momento o pó de vidro é adicionado mexendo suavemente para evitar a criação de bolhas durante aproximadamente um minuto. $\mathrm{O}$ aspecto cremoso da gelatina ajuda a evitar a decantação do pó de vidro.

- Após a mistura das partículas de vidro, o gel é acondicionado em formas de PVC com as aberturas seladas com filme plástico.

- Uma vez enformados, os fantomas são colocados em refrigerador em temperatura média em torno de $6^{\circ} \mathrm{C}$ por 24 horas para garantir a completa gelificação e a eliminação de possíveis bolhas de ar.

A adição de formaldeído é necessária pois eleva o ponto de fusão da gelatina gelificada de modo que seja possível trabalhar o fantoma em temperaturas ambiente entre $30^{\circ} \mathrm{C}$ a $40^{\circ} \mathrm{C}$, além disso, nas concentrações utilizadas, o formaldeído age como um agente anti-bactericida suficientemente eficaz quando as amostras são mantidas refrigeradas. O ágar foi utilizado como agente modificador da rigidez mantendo relativa ecogenicidade. O pó de vidro é obtido por um processo de moagem e peneiração e é incluído para aumentar a absorção da amostra e garantir um padrão de textura semelhante aos speckle encontrados em imagens modo-B de ultrassom ${ }^{\dagger}$.

\footnotetext{
${ }^{\dagger}$ Modo - B ou modo brilho são as imagens convencionais de ultrassom utilizadas na rotina clínica, speckles são artefatos nas imagens ultrassônicas semelhantes a granulações que são originadas pelo fenômeno de difração das ondas por estruturas da ordem do comprimento de onda de ultrassom
} 
a)

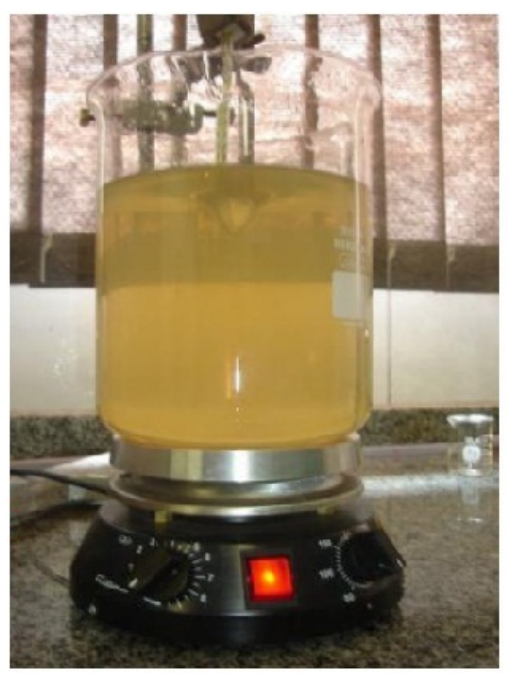

b)

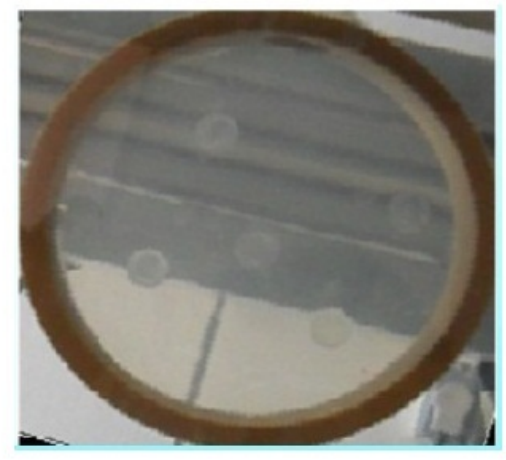

Figura 3.9: a) Fotografia do sistema de aquecimento do gel com um sistema de agitação magnética para garantir homogeneidade do fantoma e suporte contendo o gel. b) Exemplo de fantoma com inclusões.

\subsubsection{Experimento com inclusões mais rígidas}

Neste experimento a técnica desenvolvida foi aplicada com o objetivo de identificar pequenos nódulos com diferença de rigidez.

Para simular um tecido biológico com pequenos nódulos mais rígidos, um fantoma foi confeccionado contendo inclusões com diferenças de rigidez em relação a base do fantoma. O procedimento de confecção é baseado na formulação proposta por Mardsen et al. [54], No total cinco inclusões esféricas de $5 \mathrm{~mm}$ de diâmetro foram dispostas uniformemente no centro do fantoma como ilustrado na figura 3.10. A mudança de rigidez foi obtida a partir da mudança de concentração de Ágar. Os valores utilizados para cada inclusão são listados na tabela 3.2. Além das inclusões, foram confeccionadas amostras no formato cilíndrico de dimensões $25 \mathrm{~mm}$ de diâmetro e $10 \mathrm{~mm}$ de altura, nas diferentes formulações, para a estimativa do módulo elástico através de ensaios quase-estáticos.

É importante notar que as concentrações de gelatina são as mesmas para todas as amostras, minimizando assim a pressão osmótica entre as inclusões e o corpo do fantoma, além disso, mantendo as concen- 


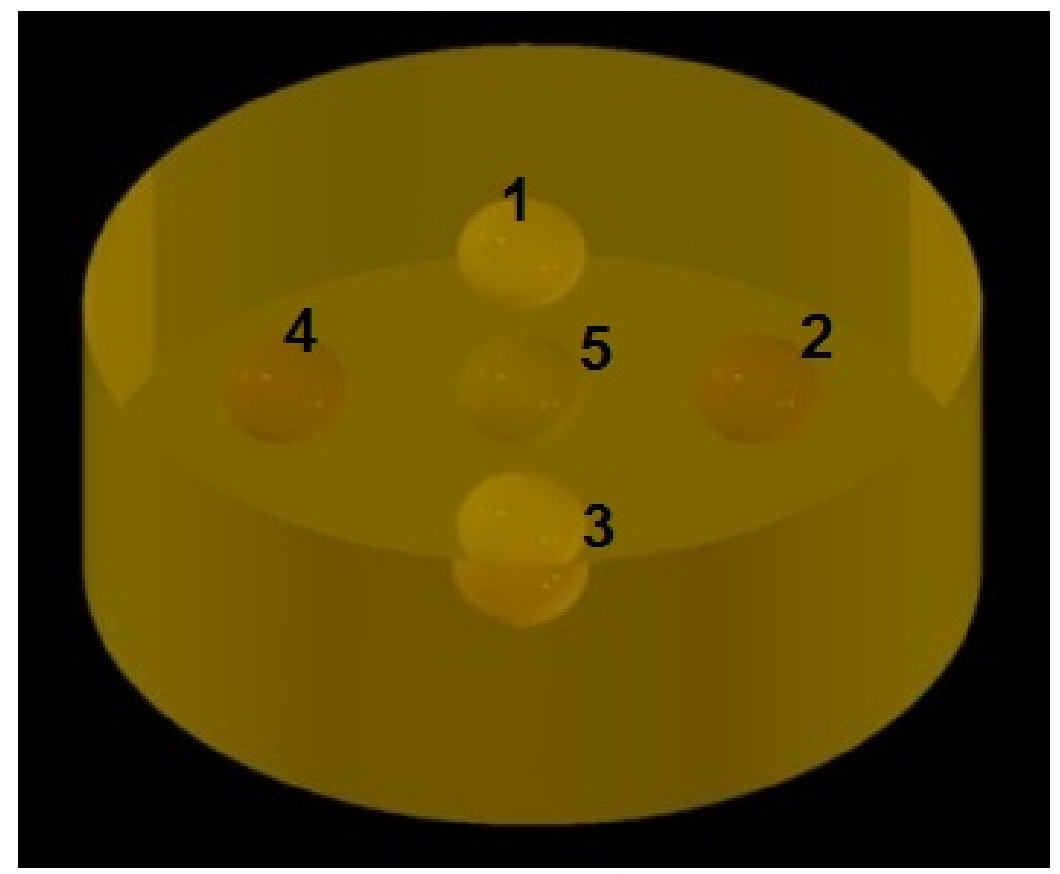

Figura 3.10: Fantoma contendo pequenas inclusões com diferentes valores de rigidez.

Tabela 3.2: Porcentagem em massa, em relação a água, dos componentes utilizados para a confecção da base do fantoma e para as cinco inclusões.

\begin{tabular}{lcccc}
\hline \hline Amostra & Ágar & Gelatina & Formaldeído & pó de vidro \\
\hline Corpo do fantoma & $2,0 \%$ & $8,0 \%$ & $0,37 \%$ & $0,5 \%$ \\
Esferas 1 e 4 & $4,0 \%$ & $8,0 \%$ & $0,37 \%$ & $0,5 \%$ \\
Esferas 2 e 3 & $3,0 \%$ & $8,0 \%$ & $0,37 \%$ & $0,5 \%$ \\
Esfera 5 & $2,0 \%$ & $8,0 \%$ & $0,37 \%$ & $0,5 \%$ \\
\hline
\end{tabular}

trações iguais de gelatina, a ligação entre as inclusões e o corpo do fantoma fica facilitada [52].

O testes mecânicos para determinação dos módulos de Young foram realizados através de ensaios quase-estáticos de tensão versus deformação. A figura 3.11 mostra uma fotografia do aparato experimental desenvolvido no laboratório GIIMUS para a realização de ensaios quase-estáticos para a obtenção dos módulos elásticos de amostras sólidas gelatinosas a partir do levantamento de curvas do tipo 
3.7 - Ensaios quase estáticos para determinação da rigidez das amostras51

tensão versus deformação. O sistema conta com um motor de passo, controlado via computador, acoplado a um micrômetro (Zaas Precision modelo $0-25 \times 0,01 \mathrm{~mm}$ e precisão de $10 \mu \mathrm{m}$ ) que produz pequenas deformações em amostras padronizadas, em formato cilíndrico e com dimensões de $25 \mathrm{~mm}$ de diâmetro por $10 \mathrm{~mm}$ de altura. A força resultante da resposta do material à deformação foi mensurada através de uma célula de carga (modelo CSA/ZL05 MK Controles- São Paulo BR) acoplada a base de sustentação da amostra. Um software controla o motor de passo de modo a oferecer pequenas rotações alternadas com frequência de giro da ordem de $0,5 \mathrm{~Hz}$ sincronizadas com a aquisição dos valores de tensão elétrica medidos na célula de carga. Os valores obtidos na célula de carga foram convertidos em valores de pressão através da curva de calibração e, calculando a tangente da curva tensão versus deformação obeteve-se os valores de módulo de Young.

\subsection{Ensaios quase estáticos para determi- nação da rigidez das amostras}

\subsection{Experimento para detecção do modo vibracional}

Este experimento foi realizado com o objetivo de ilustrar a ativação de um modo vibracional a partir da excitação mecânica por força de radiação ultrassônica pulsada. Para isto, foi utilizado um diapasão, cujo primeiro modo vibracional é conhecido e de valor igual a $582 \mathrm{~Hz}$ (dentro d'água). O experimento foi montado utilizando duas formas de excitação: a primeira utilizava como impulso mecânico a queda de uma esfera de 2,34 $\mathrm{mm}$ de diâmetro presa por um fio na forma de um pêndulo de modo a ser lançada em direção à extremidade do diapasão. No mesmo ponto onde a esfera atingia o diapasão, o foco do transdutor ultrassônico foi colocado de modo a oferecer também um impulso 


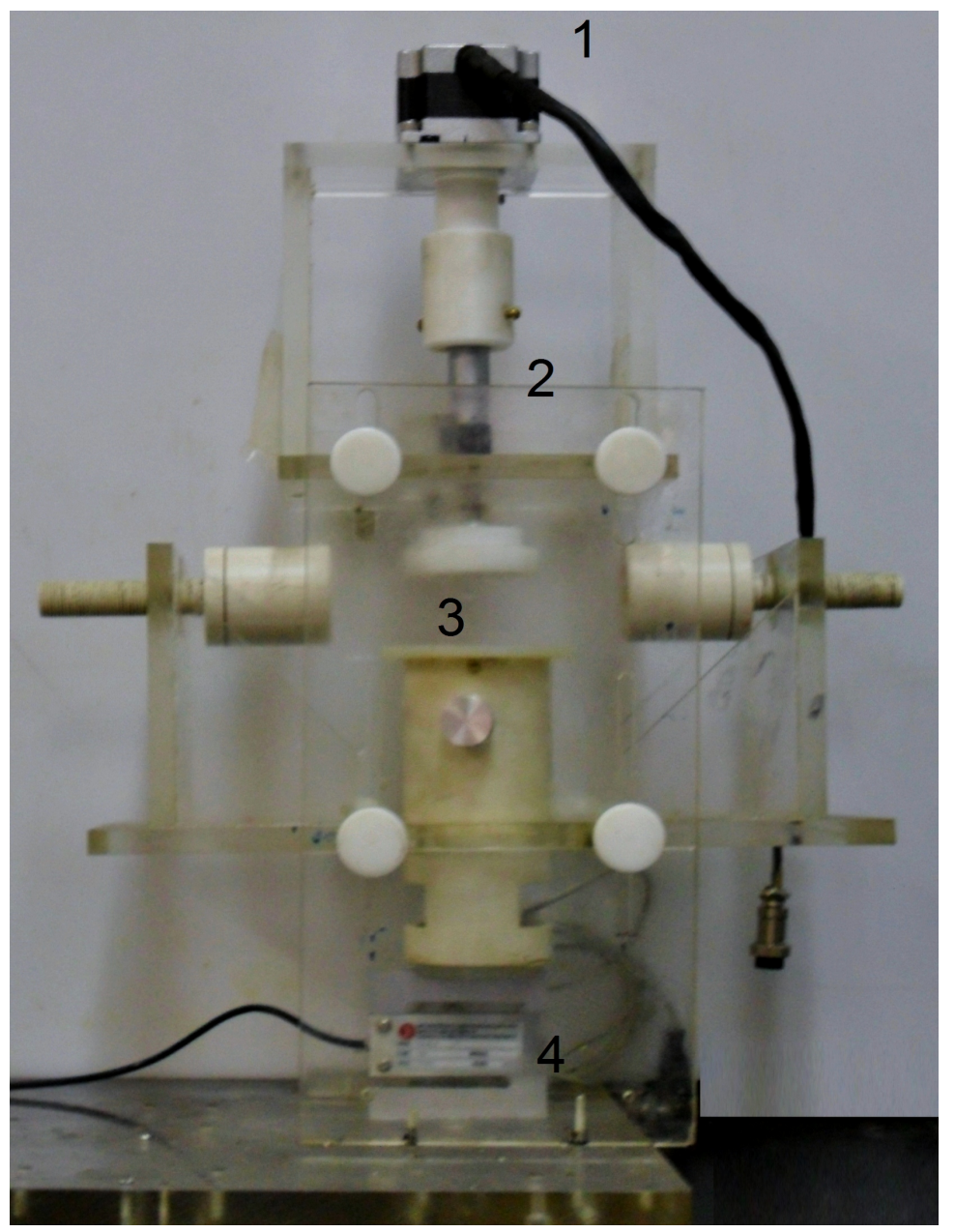

Figura 3.11: Fotografia do equipamento utilizado para os ensaios quase-estáticos para determinação do módulo de Young: 1) Motor de passo; 2) Micrômetro; 3) Porta Amostra; 4)Célula de carga.

mecânico como ilustrado na figura 3.12. Os pulsos ultrassônicos foram gerados utilizando o elemento central do transdutor ultrassônico excitado por um burst de 3000 ciclos na frequência de 3,43 $\mathrm{MHz}$ e amplitude de $44 \mathrm{Vpp}$.

As vibrações para ambos os casos foram detectadas utilizando um vibrômetro laser (Ometron vq-500-d, Hertfordshire, AL5 5BZ,United Kingdom) apontado para a extremidade do diapasão em uma região imediatamente acima do alvo de excitação, como mostra a figura 3.13. O sinal de velocidade de vibração detectado pelo vibrometro, foi amplificado e filtrado por um filtro digital (Stanford Research System modelo 

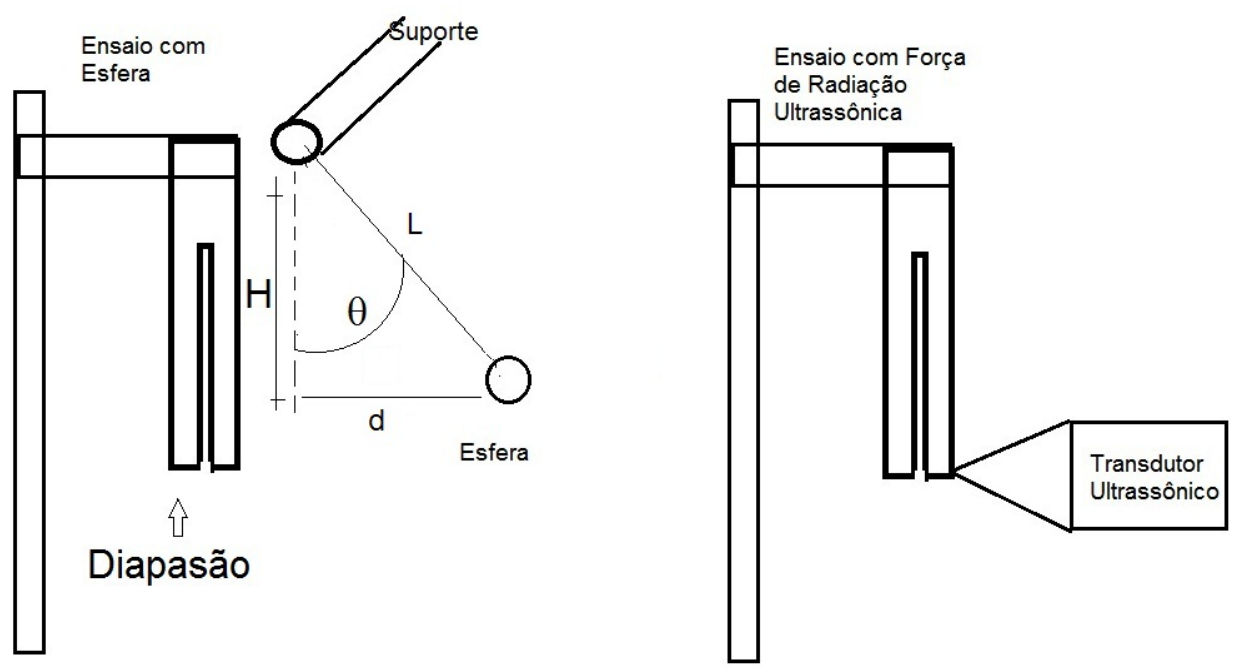

Figura 3.12: Experimento ilustrando a ativação de dos modos vibracionais para um diapasão a partir de impulsos mecânicos provocados por uma esfera e por força de radiação ultrassônica

SR650, Sunnyvale, CA, USA) na configuração passa banda com limites entre $200 \mathrm{~Hz}$ à $1000 \mathrm{~Hz}$. Para a esfera, o ganho no amplificador do filtro foi de $20 \mathrm{~dB}$, já para o impulso gerado por força de radiação, a amplificação foi de $40 \mathrm{~dB}$ na entrada mais $30 \mathrm{~dB}$ na saída do filtro, num total de $\Delta G=70 d b$, assim, os sinais apresentaram amplitudes equivalentes quando registrados por um osciloscópio digital (Agilent série 6000, USA).

Conhecendo a relação entre as amplitudes dos sinais gerados por ambas as formas de excitação e, conhecendo a força $\vec{F}_{e}$ que a esfera exerce sobre o mesmo alvo, é possível estimar a força de radiação ultrassônica $F_{r}$.

Em um sistema constituído de uma viga engastada em uma extremidade e livre como é o caso do diapasão, a força impulsiva gerada pelo impacto da esfera, gera vibrações transversais livres amortecidas. Isto faz o sistema oscilar com amplitudes decrescentes sucessivas, resultantes de vários mecanismos dissipativos de energia [55].

Quando a esfera atinge a haste do diapasão, esta sofre uma deformação proporcional a constante elástica da haste. A força impulsiva 


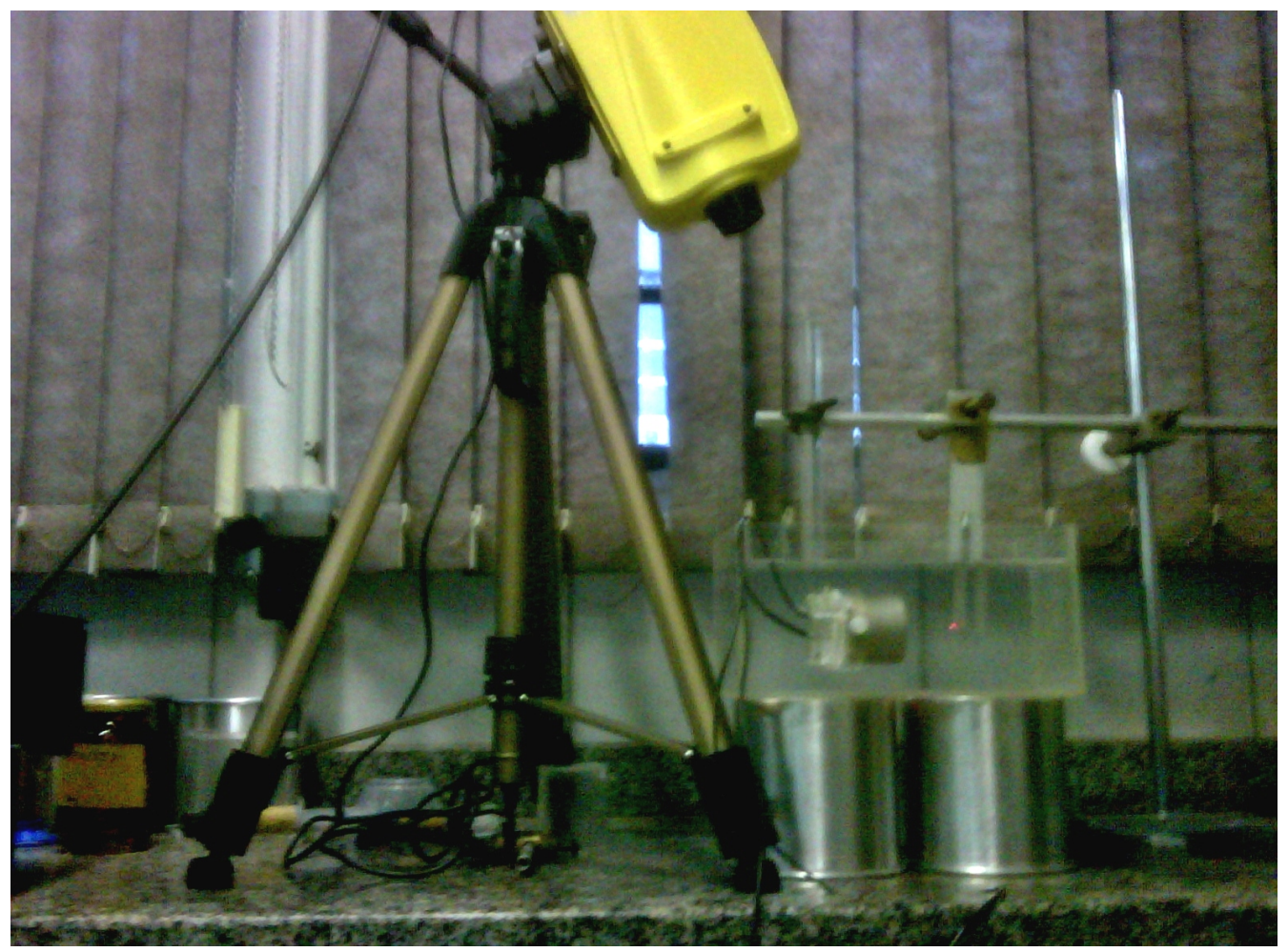

Figura 3.13: Arranjo experimental para o experimento demonstrando a detecção do modo vibracional a partir de impulsos mecânicos gerados pelo choque de uma esfera e por força de radiação ultrassônica contra um diapasão

pode ser definida por $F_{e}=-E x$, sendo $E$ o módulo de armazenamento e $x$ a deformação máxima da haste. $O$ vibrômetro laser oferece as velocidades instantâneas do objeto vibrante, de forma que, integrando a função de velocidade adquirida pelo vibrômetro, no tempo é possível obter o deslocamento em função do tempo $x(t)$, e encontrando o valor máximo de $\mathrm{x}(\mathrm{t})$ é possível estimar $F_{e}$. Sabendo que a amplitude de vibração é diretamente proporcional a força impulsiva aplicada, conhecendo a relação entre as amplitudes de vibração devido aos dois modos de excitação, é possível estimar a força de radiação acústica pela equação:

$$
F_{r}=\frac{n_{a} V_{\max }}{2 \sqrt{2} \pi f} 10^{\Delta G / 20}
$$


Sendo $n_{a}^{\ddagger}$ o índice de refração da água, $V_{\max }$ é a velocidade máxima, f é a frequência de ressonância e $\Delta G$ é a diferença de ganho no amplificador do filtro para a obtenção de sinais de mesma amplitude nos dois modos de excitação.

\subsection{Análise Estatística- Relação Sinal/Ruído}

Os parâmetros comuns para se avaliar um elastograma, são o contraste $\mathrm{C}$, relação contraste/ruído e a relação sinal/ruído (RSR). O contraste verdadeiro (C) é definido pela relação entre os módulos de Young da inclusão e do tecido circundante. RSR é definido como a relação entre o valor médio das regiões de interesse (RDI) dentro da inclusão e no corpo do fantoma para os dados que compõem a matriz base da imagem. A ROI é definida a partir dos limites da largura a meia altura do sinal sob a inclusão, e a partir da definição das dimensões da ROI, esta é aplicada para 4 diferentes regiões do meio circundante à inclusão. As equações 3.6 mostram as relações de contraste[?].

$$
C=\frac{E_{i} n c}{E_{b} k} \quad R S R=\frac{\overline{A_{S}}}{\overline{A_{b k}}}
$$

\footnotetext{
${ }^{\ddagger}$ Quando o vibrômetro é utilizado em medições dentro de líquidos, é preciso corrigir pelo índice de refração do meio
} 


\title{
Capítulo
}

\section{Caracterização do Sistema}

\begin{abstract}
Este capítulo apresenta alguns experimentos destinados à caracteriZ zação da técnica APE. Cada secção corresponde a um determinado experimento contendo subseções abordando uma pequena introdução teórica, os materiais e os métodos empregados e os resultados. Entre as caracterizações, destacam-se a potência acústica de excitação, a emissão acústica em função da direção axial, o contraste em função de parâmetros do feixe de excitação e a PSF do sistema para o caso das imagens baseadas na APE.
\end{abstract}

\subsection{Potência acústica do transdutor de ex- citação}

\subsubsection{Introdução}

Exitem na literatura, várias maneiras para quantificar a potência acústica de saída na faixa de ultrassom, e estão baseadas nos mais diversos princípios físicos, entre eles: a força de radiação, temperatura e ótica [56]. A norma IEC-61161 † é a referência internacional dos procedimentos de medição cujo princípio físico é baseado na força de radiação [57]. Um outro método inovador [58] de medir a pressão de força de radiação é baseado em um transdutor que mede a força a

\footnotetext{
${ }^{\dagger}$ Ultrasonic Power Measurement in Liquids in the Frequency Range 0,5 MHz to 25 MHz, publicada inicialmente em 1992 e revisada em 1998
} 
partir do deslocamento de um alvo magnético que modifica o campo magnético em torno de um sensor magneto-resistivo cuja voltagem de saída é associada a uma escala de pressão acústica. Este tipo de sensor foi idealmente projetado para transdutores ultrassônicos de feixe focalizados.

\subsubsection{Materiais e Métodos}

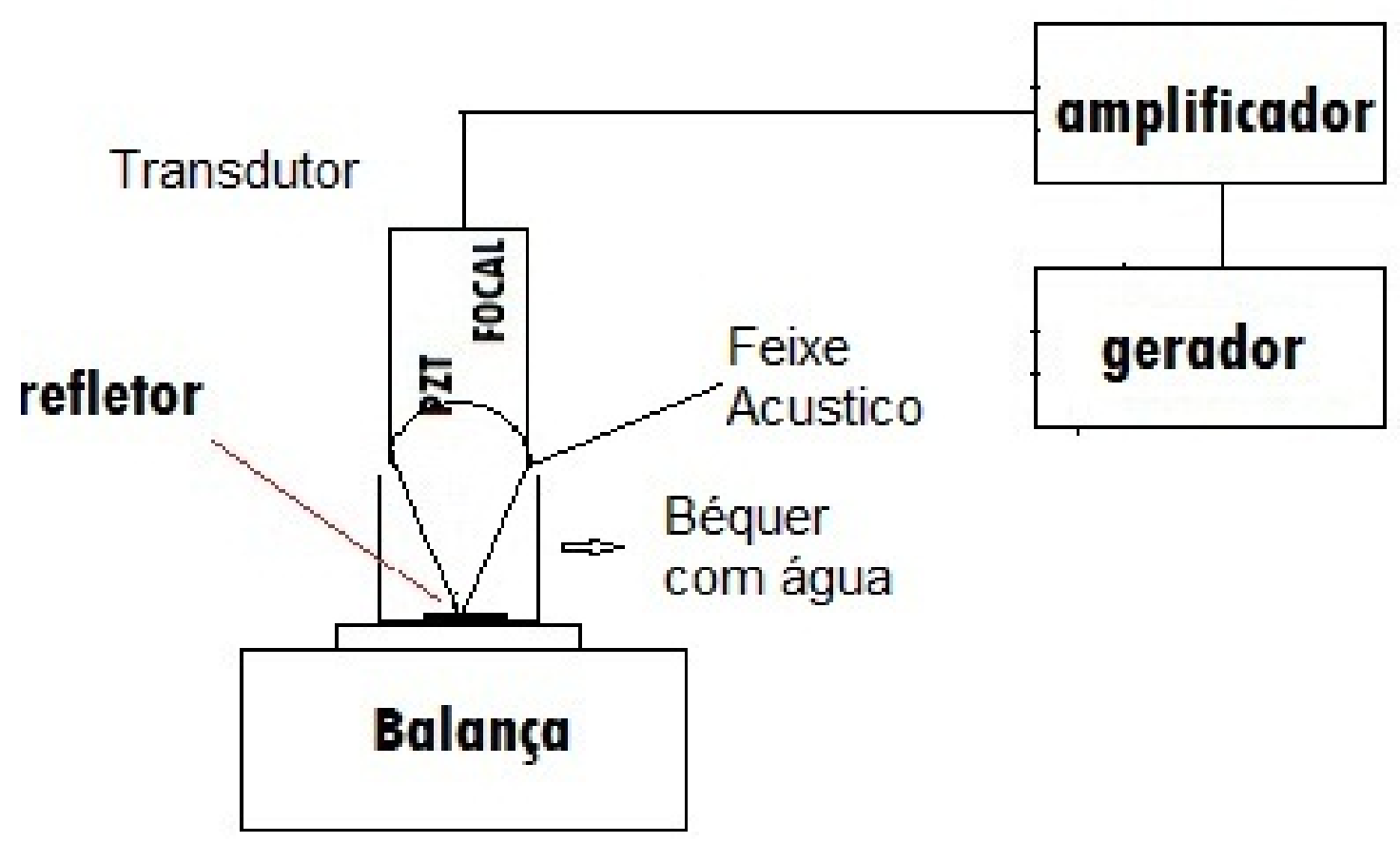

Figura 4.1: Arranjo Experimental para a mensuração da Potência do feixe ultrassônico

A figura 4.1 ilustra o arranjo experimental utilizado para medir a potência acústica do feixe de excitação ultrassônica. Neste experimento, um pequeno disco de borracha de silicone com dimensões $40 \mathrm{~mm}$ de diâmetro e $20 \mathrm{~mm}$ de espessura foi utilizado como alvo absorvedor da onda ultrassônica. Este alvo foi colado no fundo de um béquer preenchido com água desgaseificada. O conjunto béquer mais disco era então colocado sobre uma balança de precisão (BEL Engineering, modelo Umark 250A, Monza, Itália) de modo a mensurar o variação 
de massa com a introdução da força de radiação sobre o absorvedor. O transdutor de excitação foi fixado em um suporte e colocado dentro do béquer sem que este se apoiasse no béquer, mas garantindo o acoplamento com a água mantendo o foco posicionado no centro do absorvedor. Uma vez montado o sistema a balança é zerada e então, o transdutor é ligado e os valores de massa obtidos pela balança, são registrados para diferentes combinações de tensão e frequência de excitação.

A partir dos valores de massa, e utilizando a expressão 4.1 [57], foi possível encontrar a potência acústica em função da frequência de excitação e voltagem aplicada.

$$
P=\frac{2 c F}{1+\cos (\gamma)}
$$

sendo $F$ o módulo da força de radiação acústica, $c$ a velocidade do som na água, $\gamma=\operatorname{arcseno}(a / b)$, $a$ o raio do elemento ativo do transdutor e $b$ o comprimento focal geométrico [57].

\subsubsection{Resultados}

\subsubsection{Resposta em frequência do transdutor de excitação}

Observando o gráfico da figura 4.2 pode-se identificar que o pico de pressão ocorre na frequência aproximadamente de $3,43 \mathrm{MHz}$ o que difere acentuadamente do valor nominal apresentado pelo fabricante (Boston Piezo-Optics Inc., 38 B Maple Street Bellingham, MA, USA) que é de 3,0 MHz. Este experimento foi conduzido aplicando uma voltagem senoidal de 40,0 Vpp na cerâmica central e variando a frequência entre $0,1 \mathrm{MHz}$ em passos de 0,1 MHZ até $5 \mathrm{MHz}$. A diferença entre o valor nominal 3, $0 \mathrm{MHz}$ de frequência fornecido pelo fabricante e o valor medido 3,43 MHz \pm 0, $2 \mathrm{MHZ}$ pode ser atribuído ao processo de fabricação da cerâmica, mas também pela presença de uma camada de verniz sobre o elemento. Adotando o novo valor de frequência medido, obteve-se um ganho de aproximadamente de 9 vezes na potência acústica em 
relação ao valor nominal de 3, $0 \mathrm{MHz}$.

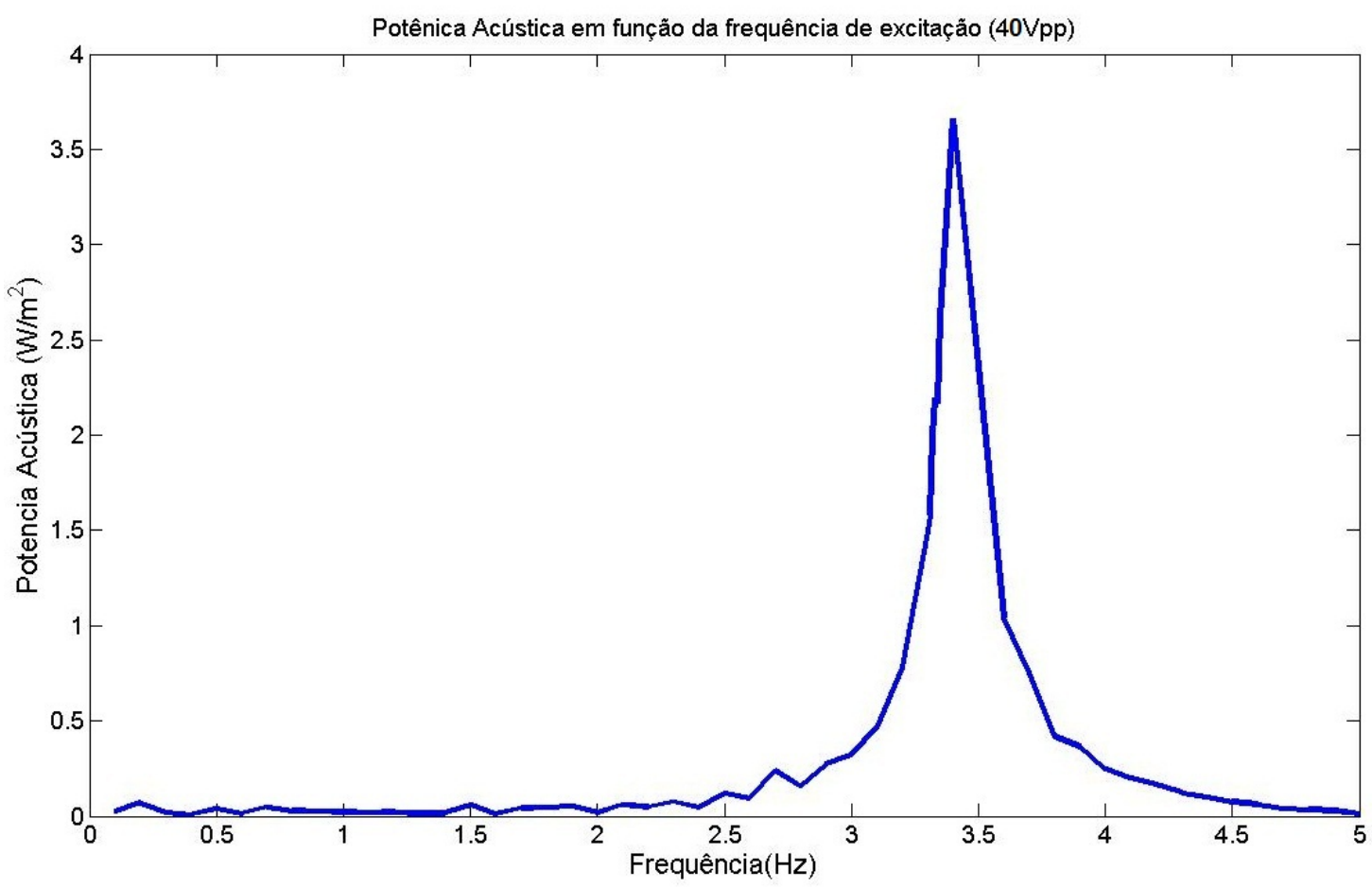

Figura 4.2: Potência acústica do transdutor focal em função da frequência de excitação do transdutor ultrassônico para uma voltagem no gerador de $40 \mathrm{Vpp}$

\subsubsection{Resposta em função da voltagem de excitação}

O gráfico da figura 4.3 demonstra a relação de potência do feixe acústico em função da amplitude da voltagem de excitação da cerâmica central. Fazendo uma regressão linear a partir dos pontos obtidos neste gráfico, encontramos um perfil quadrático da relação entre a potência e a voltagem aplicada, que é um resultado esperado, pois a potência acústica é proporcional ao quadrado da pressão acústica, que por sua vez é linearmente proporcional a voltagem aplicada ao elemento piezoelétrico. 


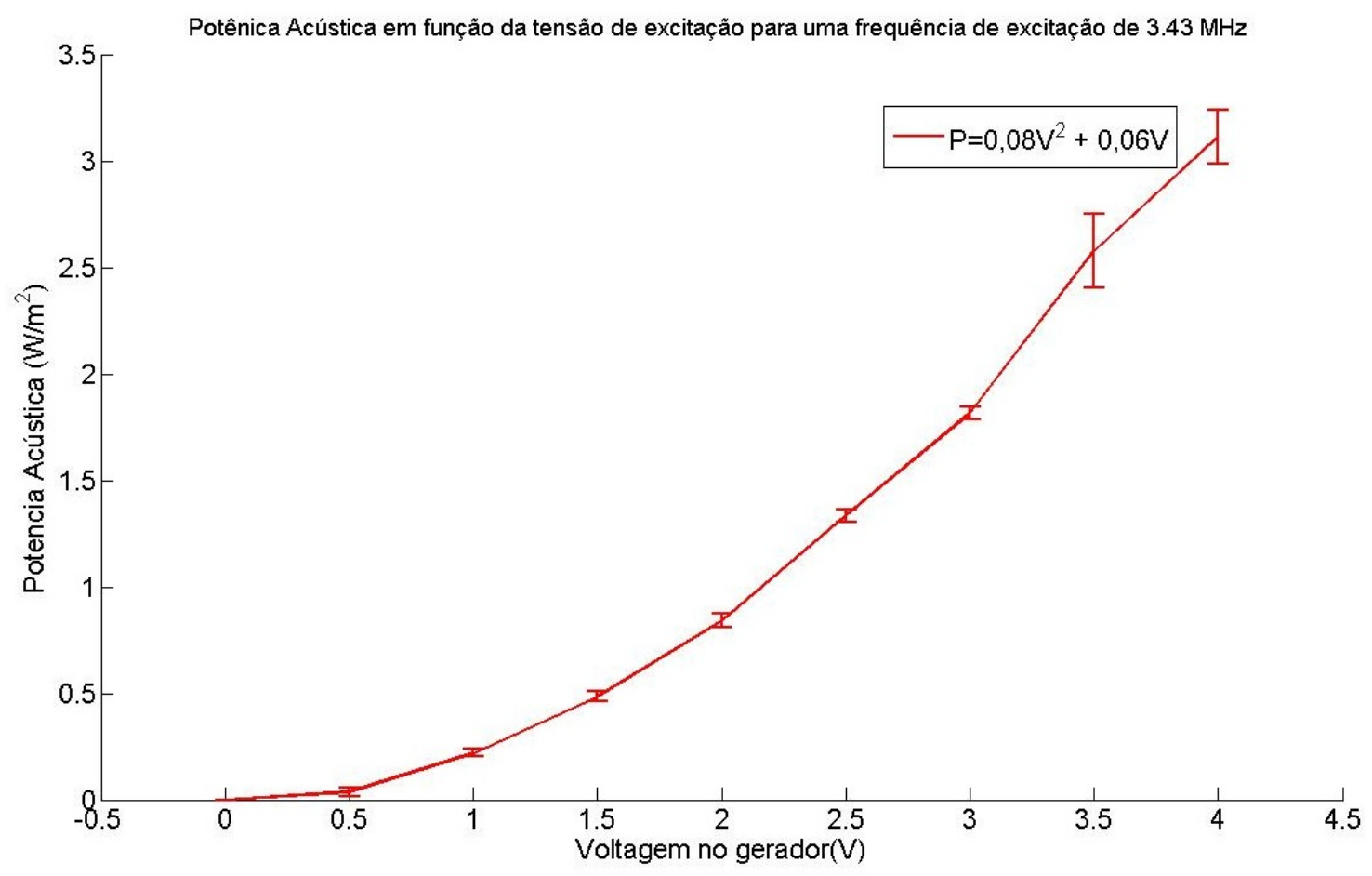

Figura 4.3: Potência acústica em função da voltagem aplicada no transdutor ultrassônico.

\subsection{Sensibilidade do hidrofone em função da frequência}

O gráfico da figura 4.4 demonstra a resposta de voltagem de saída do hidrofone utilizado em função da frequência. A curva foi obtida a partir dos dados de calibração de fábrica do hidrofone quando alimentado por uma fonte de alimentação de $24 \mathrm{~V}$. O que é importante notar é que a amplitude de voltagem, na frequência de ressonância do hidrofone $(50 \mathrm{kHz})$, é cerca de duas vezes maior que a média para toda a banda entre $300 \mathrm{~Hz}$ a $40 \mathrm{kHz}$ e é sete vezes maior para uma frequência em torno de $90 \mathrm{kHz}$. E desta variação na sensibilidade tem como consequência os baixos valores detectados nos espectros de frequência dos sinais adquiridos para frequências superiores a $70 \mathrm{kHz}$. 


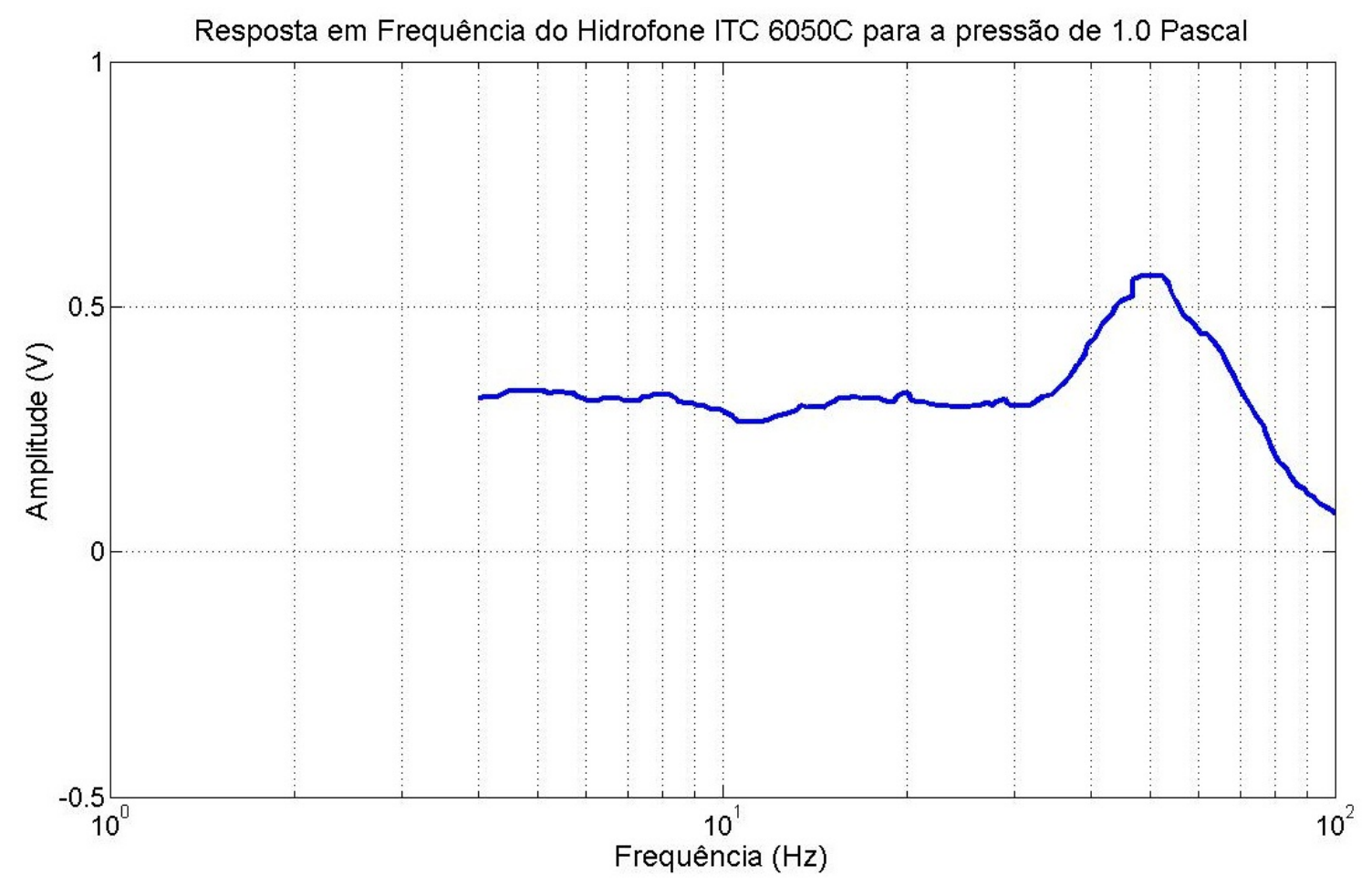

Figura 4.4: Resposta em voltagem do hidrofone ITC6050C em função da frequência para uma amplitude de 1,0 Pa

\subsection{Resolução espacial}

Nos experimentos realizados neste trabalho, a intensidade de cada pixel da imagem é proporcional a amplitude do sinal acústico emitido pelo alvo, quando perturbado por uma radiação ultrassônica focalizada.A função de espalhamento pontual ou como é conhecida usualmente PSF $^{*}$ descreve a resposta de um sistema de imagem para uma fonte pontual, que em outras palavras, corresponde ao borramento da imagem, a partir da determinação desta função é possível estimar a resolução espacial do sistema de imageamento para os sistemas de aquisição.

\footnotetext{
${ }^{*}$ do ingles Point Spread Function
} 


\subsubsection{Função de Espalhamento Pontual}

A PSF do sistema é assumida como sendo a função resultante da distribuição de radiação ultrassônica no plano focal. A imagem gerada por um sistema de aquisição é o resultado da convolução espacial entre a função objeto $f_{o b j}(x, y)$ com a PSF do sistema definida pela função $f_{P S f}(x, y)$ mais o ruído.

$$
f_{i m}(x, y)=f_{o b j}(x, y) \otimes f_{P S F}(x, y)+\text { ruido }
$$

\subsubsection{PSF de um feixe acústico focalizado}

A técnica APE utiliza apenas um feixe focalizado, e a partir da distribuição de pressão acústica pode-se definir a PSF pela expressão:

$$
f_{P S F}(x, y)=\frac{F_{d}(x, y)}{F_{d}\left(x_{0}, y_{0}\right)}=\frac{1}{a_{1}^{2}} j i i n c\left(\frac{r a 1}{\lambda_{1} R}\right)
$$

\subsubsection{PSF de um feixe acústico focalizado VA.}

Por analogia geométrica, e considerando apenas as interações lineares entre os campos, a PSF no ponto focal para o caso da VA é definida pela equação:

$f_{P S F}(x, y)=\frac{F_{d}(x, y)}{F_{d}\left(x_{0}, y_{0}\right)}=\left(a_{2 e}^{2}-a_{2 i}^{2}\right)^{-1} j i i n c\left(\frac{r a 1}{\lambda_{1} R}\right)\left[a_{2 e}^{2} j i i n c\left(\frac{r a_{2 e}}{\lambda 2 R}\right)-\left(\frac{r a_{2 e}}{\lambda 2 R}\right)\right]$

\subsubsection{Campo acústico simulado}

A figura 4.5 mostra os resultados de uma simulação dos campos acústicos gerados pelo transdutor ultrassônico para cada um dos elementos piezoelétricos e para a condição dos dois elementos excitados. Na tabela 4.1 é apresentada a largura a meia altura (FWHM) das PSFs axiais e transversais dos elementos simulados no Field II. 


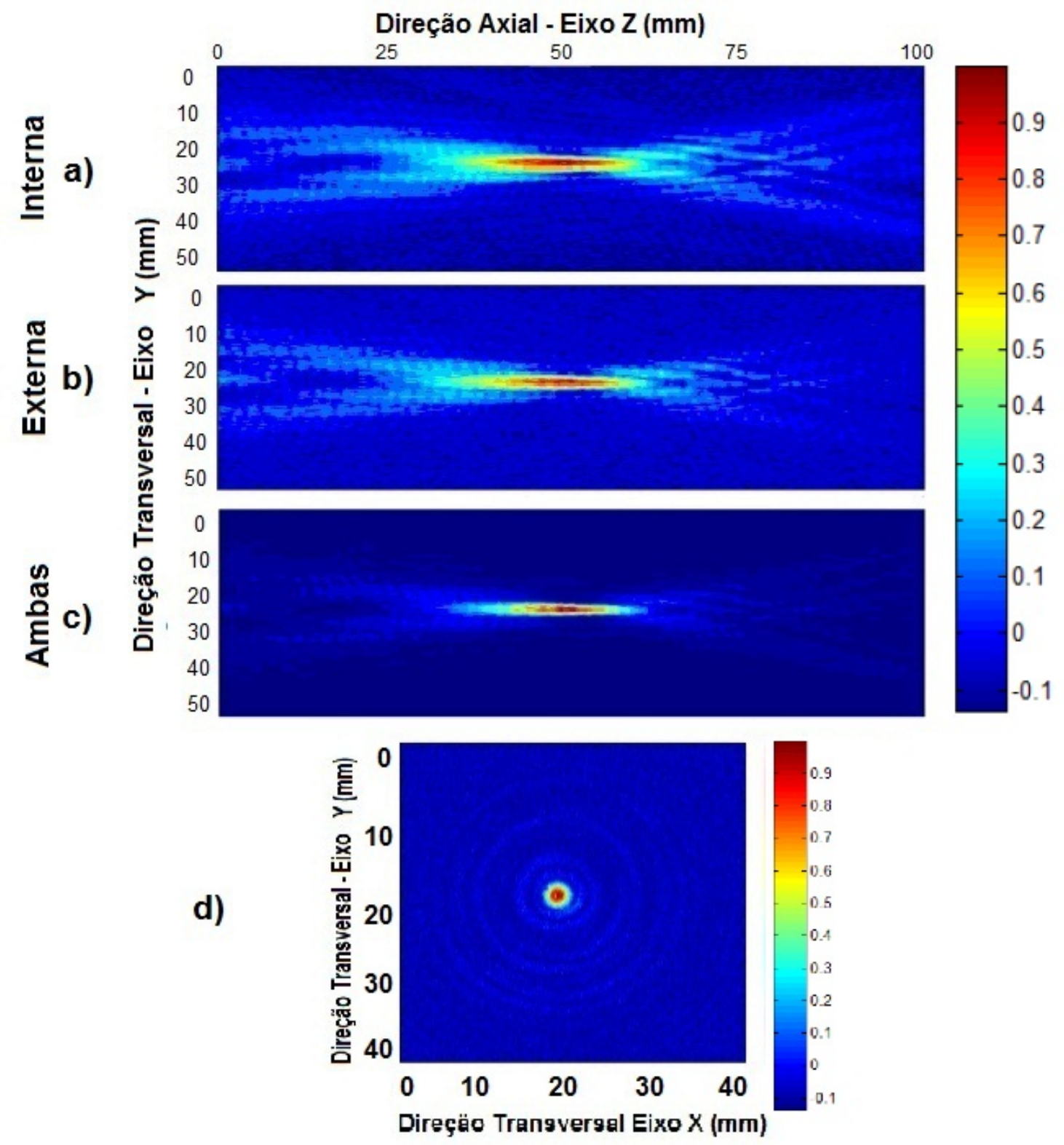

Figura 4.5: Campo acústico simulado em Filed II [59] de um transdutor focalizado a $5 \mathrm{~cm}$ : a) corresponde ao campo acústico longitudinal para o elemento interno (disco central) do transdutor; b) corresponde ao elemento externo (coroa); c) O campo longitudinal para os dois elementos e d) O campo na direção transversal ao feixe. 
Tabela 4.1: Resultados simulados da largura a meia altura dos campos acústicos gerados pelos elementos do transdutor ultrassônico

\begin{tabular}{cc}
\hline \hline Elemento & FWHM (mm) \\
\hline Interno longitudinal & 16,5 \\
Externo longitudinal & 15,6 \\
Ambos longitudinal & 14,5 \\
Interno Transversal & 2,0 \\
Externo Transversal & 1,9 \\
Ambos Transversal & 1,7 \\
\hline
\end{tabular}

\subsubsection{Materiais e Métodos para determinação da PSF}

Para determinar a PSF do sistema, um arranjo experimental foi preparado combinando estruturas com diferentes espessuras de modo a determinar a menor estrutura que pode ser resolvida. A figura 4.6 mostra uma fotografia do aparato montado, neste instrumento foram dispostos fios metálicos com diferentes espessuras equidistantes $5 \mathrm{~mm}$ e em outra parte uma grade com fios iguais mas com distâncias diferentes são montados para determinar a capacidade de distinguir dois pontos. O foco do transdutor ultrassônico percorria transversalmente pela direção $X$ os fios de modo a gerar o perfil do sinal através dos fios. Os sinais foram gerados em um período curto de 3 ciclos de $3.43 \mathrm{MHZ}$ e amplitude de $44 \mathrm{Vpp}$ e o sinal foi adquirido a cada $25 \mu \mathrm{s}$.

\subsubsection{Resultados PSF}

Observando os valores da tabela 4.2 e os gráficos das figuras 4.7 e 4.8, é possível notar que o menor valor detectado foi o fio com espessura de 0,21 mm porém com largura a meia altura de 0,9 $\mathrm{mm}$. A discretização das estruturas, que define a resolução espacial transversal, ficou em torno de $1,8 \mathrm{~mm}$ que é muito próximo (cerca de $5 \%$ para o interno) da PSF da distrubuição do campo acústico do transdutor de ex- 


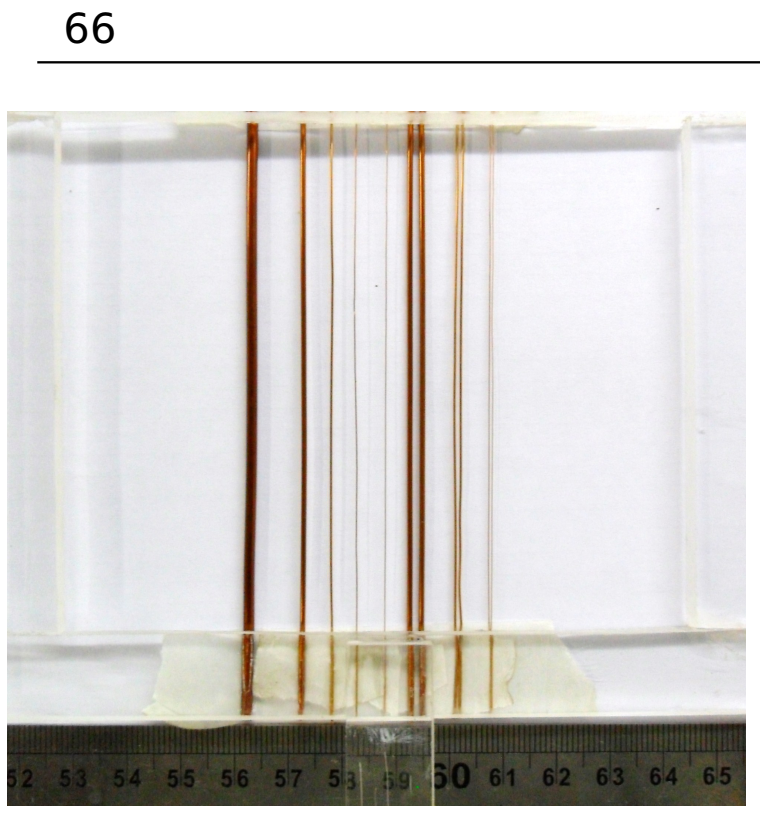

(a)

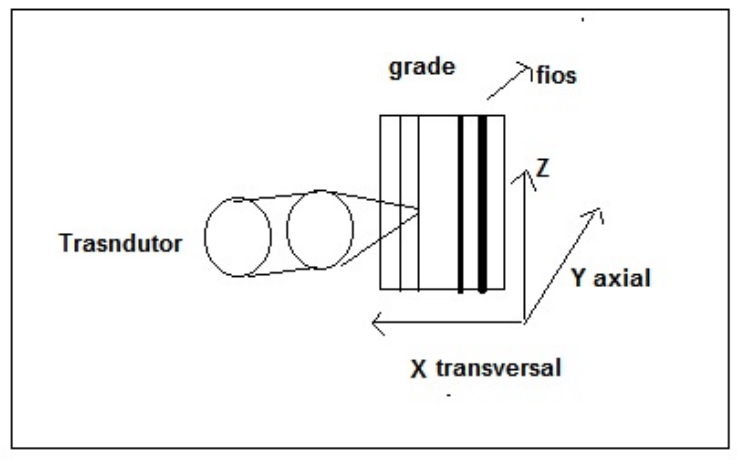

(b)

Figura 4.6: a) Fotografia da grade de fios de diferentes espessuras utilizada na determinação da PSF. b) Transdutor ultrassônico movia-se ao longo da direção X para a PSF transversal e axial na direção y para a PSF longitudinal.

Tabela 4.2: Resultados da largura a meia altura para as diferentes espessuras de fios. O símbolo (*) indica que o valor não foi determinado

\begin{tabular}{ccc}
\hline \hline Diâmetros dos Fios $(\mathbf{m m}) \epsilon=50 \mu m$ & FWHM (mm) & SNR \\
\hline 2,02 & 1,6 & 5,3 \\
1,06 & 1,1 & 4,1 \\
0,48 & 0,9 & 3,2 \\
0,21 & 0,9 & 1,5 \\
0,15 & $*$ & 1.1 \\
\hline
\end{tabular}

citação simulada pelo Field II (1,9 mm), confirmando a forte dependência da técnica com o campo acústico de excitação. Apesar da técnica estar limitada a PSF do campo acústico limitando a resolução espacial a valores em torno de 1 a $2 \mathrm{~mm}$, a capacidade de detectar estruturas individuais na ordem de $210 \mu m$ permite sua aplicação na detecção de estruturas como microcalcificações, similarmente ao que se obtém na técnica VA. 
a)

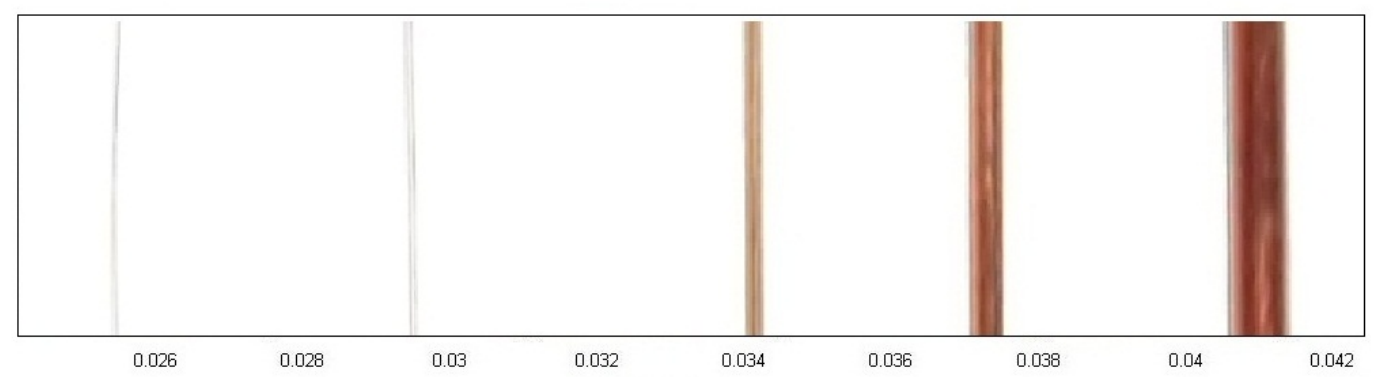

b)

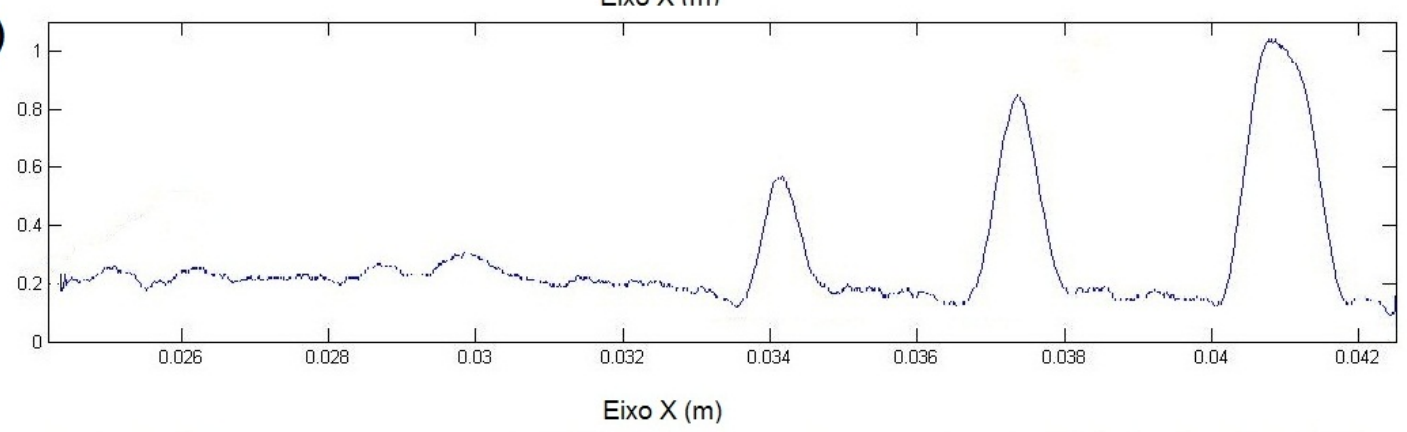

Figura 4.7: Perfil de detecção da APE:a)Imagem demonstrando a disposição dos fios metálicos; b) perfil do sinal ao longo do eixo $X$ mostrando a resolução do sinal par diferentes estruturas.

\subsection{Atenuação da onda Acústica de Baixa frequência em função da distância fonte-detector}

Considerando as interações não-lineares de dois feixes acústicos de excitação sobre uma pequena esfera rígida (poucas centenas de microns), a emissão acústica deste pequeno alvo vibrante é tratada, na maioria dos estudos apresentados na literatura como um modo de emissão característico de um monopolo[60] ou seja, com decaimento radial proporcional a $1 / r$. Assim como na VA um pacote de um único feixe pulsado APE também dá origem a efeitos não lineares como demonstrado por Averkiou et al. [30]. Não há até então grandes avanços nos estudos de não-linearidade considerando o espalhamento na emissão acústica.

Com o objetivo de observar as características de emissão acústica por um pequeno espalhador, um experimento foi realizado observando 
a)

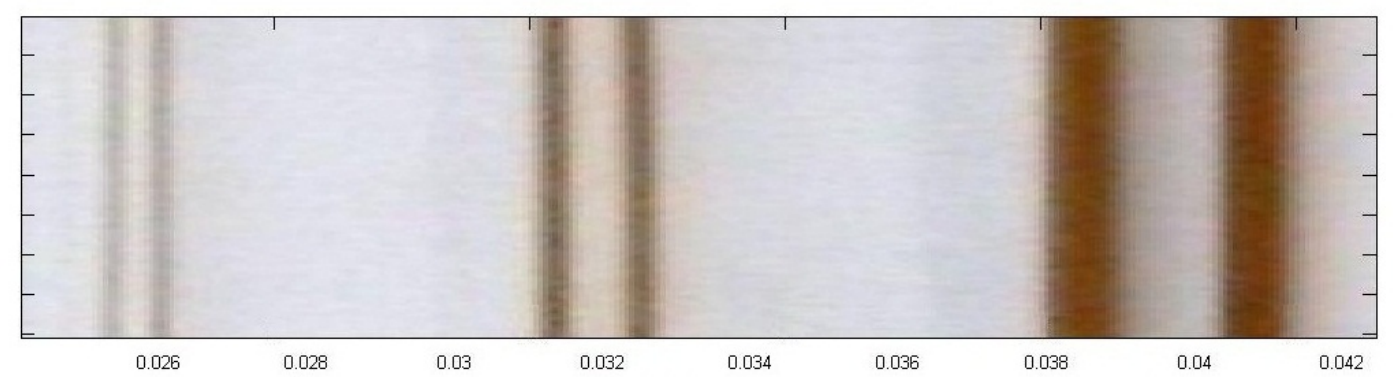

Eixo $X(\mathrm{~m})$

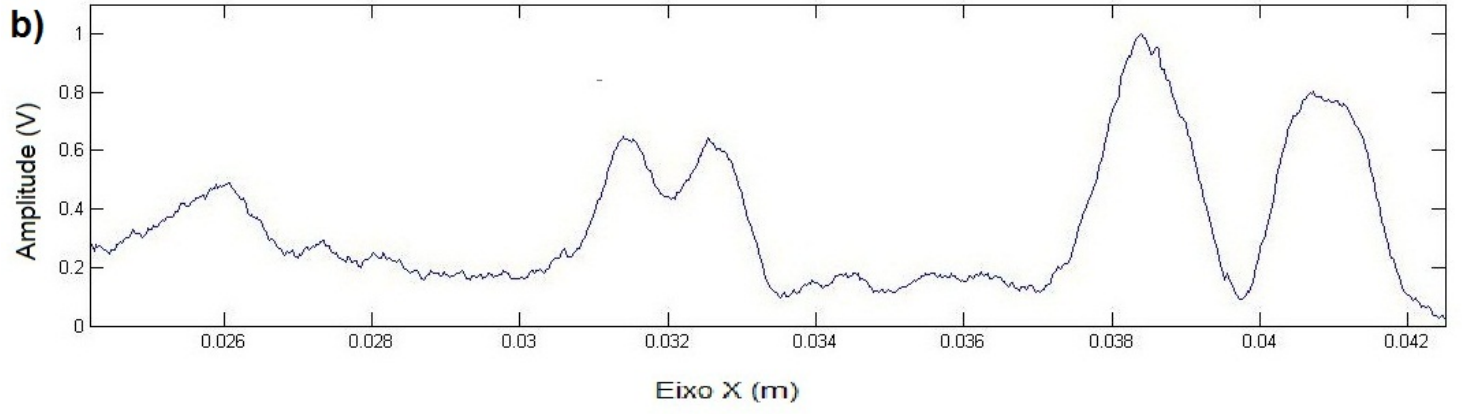

Figura 4.8: Discretização da APE: a) Fotografia dos pares de fios metálicos para determinação da resolução; b) sinal detectado pela APE ao longo do corte transversal dos fios

a amplitude média do sinal acústico, filtrado em baixas frequências, ao longo do eixo axial de emissão acústica. Os resultados são comparados com duas teorias de emissão, uma considerando o decaimento radial proporcional ao inverso da distância entre o transdutor e a fonte, e a segunda teoria considerando um decamento proporcinal a $\ln (r) / r$. Esta segunda teoria está relacionada a interação não-linear das ondas espalhadas [61][62].

\subsubsection{Materiais e Métodos}

Como objeto espalhador foi escolhida uma esfera de aço com densidade de 7, $28 \mathrm{~g} / \mathrm{cm}^{3}$ e diâmetro de 0,66 $\pm 0,05 \mathrm{~mm}$, fixada em um filme de PVC em um suporte cilíndrico de diâmetro de $70 \mathrm{~mm}$. A excitação foi em pacotes de 300 ciclos de 3,43 MHZ e voltagem de $40 \mathrm{~V}$. Para cada aquisição, o hidrofone foi afastado da amostra de modo a obter a amplitude RMS do sinal emitido da amostra a diferentes distâncias 
fonte detector. O percurso do hidrofone foi de 1 a $16 \mathrm{~cm}$ em passos de $0,5 \mathrm{~cm}$ na direção axial ao feixe ultrassônico. O valor de amplitude foi calculado a partir do cálculo do valor RMS do sinal filtrado por um filtro digital do tipo Butterworth de 4 polos, passa-banda no intervalo de $0,1 \mathrm{kHz}$ até $100 \mathrm{kHz}$.

\subsubsection{Resultados}

As figuras 4.9 e 4.10 mostram os dados adquiridos da amplitude do sinal para as diferentes distâncias fonte hidrofone para dois tipos de ajuste, o primeiro considerando uma emissão em onda esférica de forma que o sinal decai ao longo deo eixo axial na forma $1 / R$ e e outro na forma $\ln (R) / R$. Os parâmetros dos ajustes mostram uma melhor aproximação do decaimento da emissão acústica seguindo o modelo sugerido por G. T. Silva. 
Modelo 1/(r)

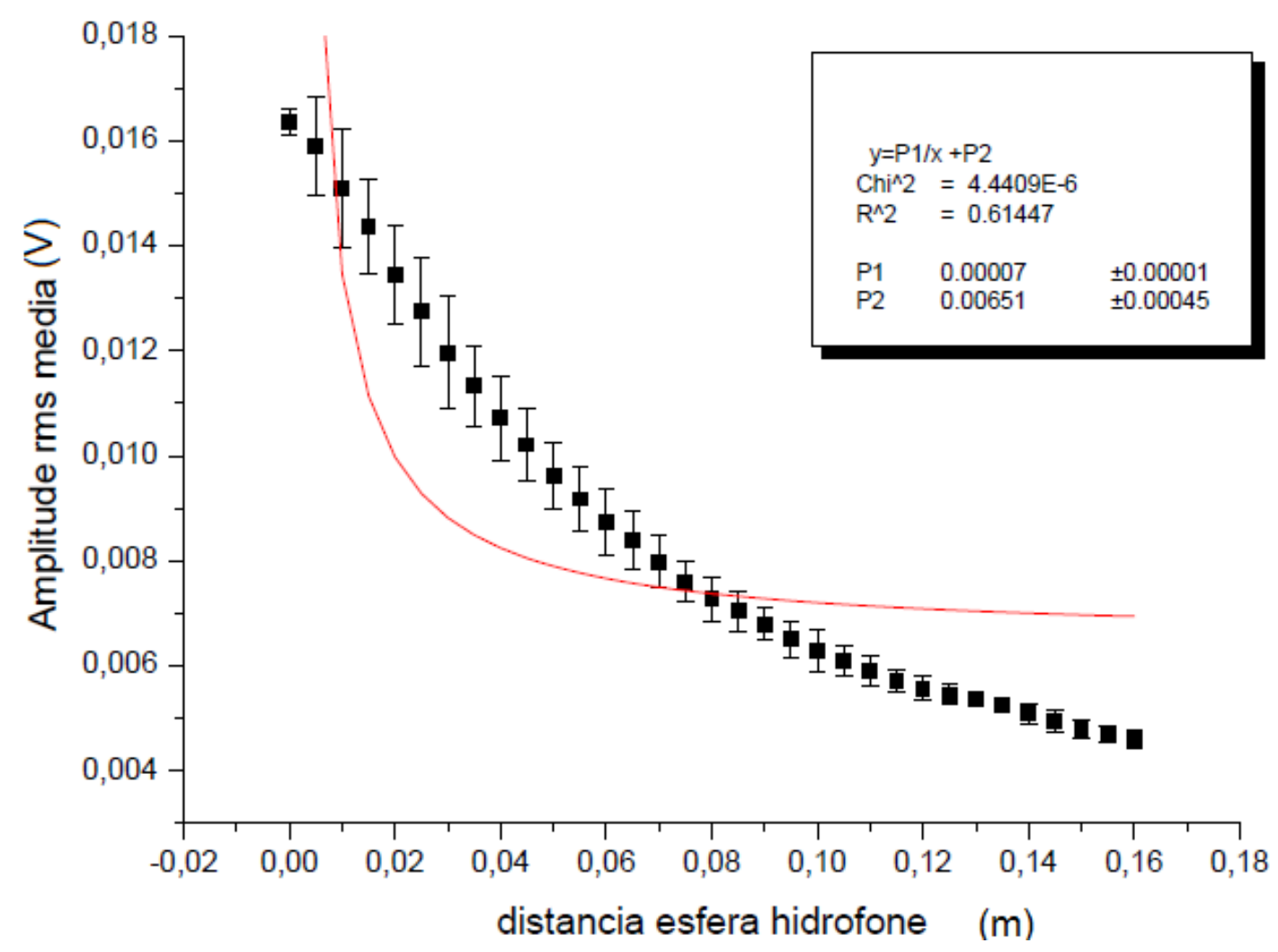

Figura 4.9: Ajuste para decaimento $1 / R$ 
Modelo $\ln (x) / x$

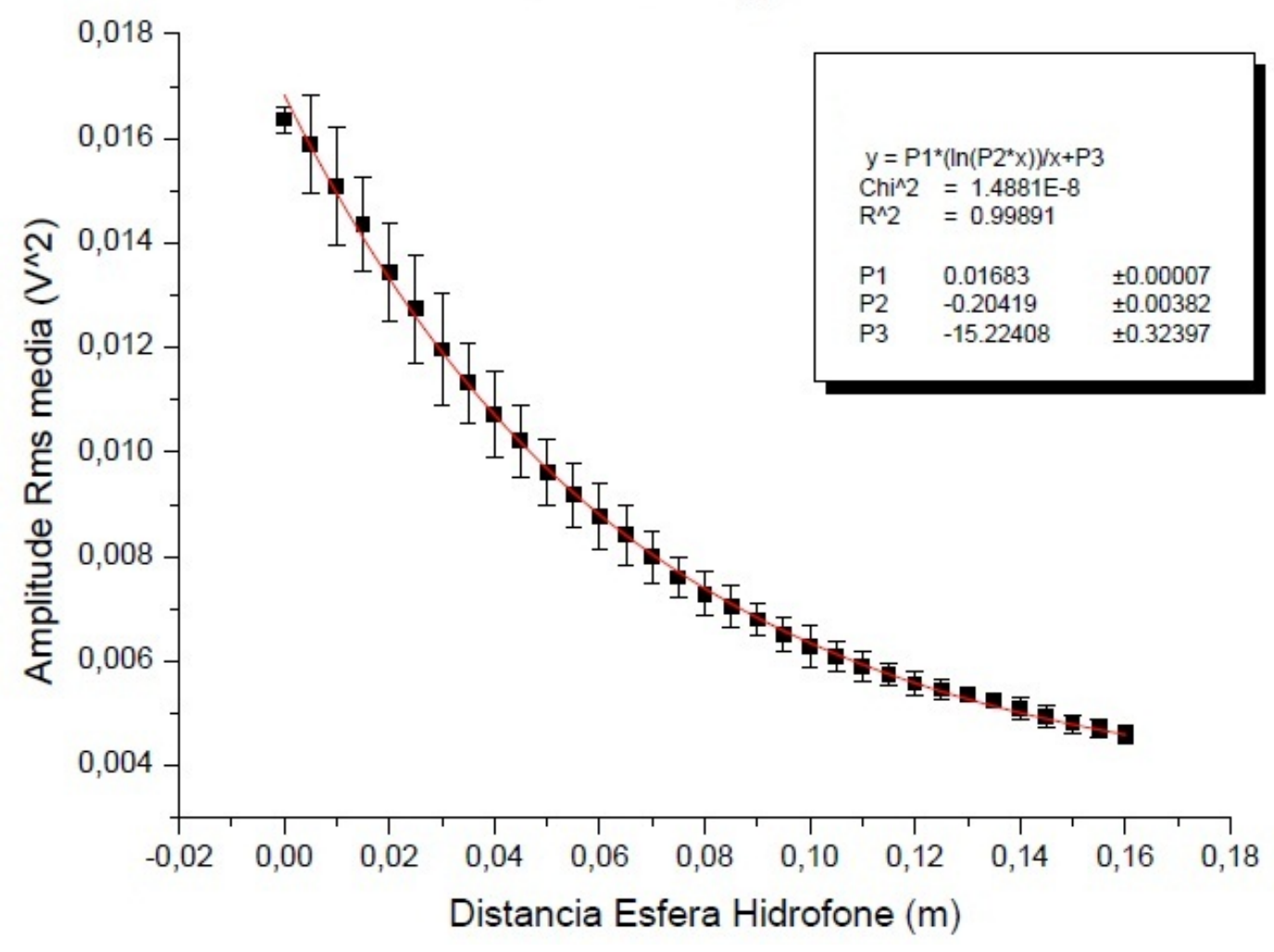

Figura 4.10: Amplitude RMS do sinal de baixa frequência captado com o hidrofone em distâncias diferentes da esfera sob o foco 


\section{Capítulo}

\section{Resultados e discussão}

$O$ capítulo 5 apresenta os resultados e as discussões referentes aos sinais produzidos pela técnica APE e os fenômenos envolvidos nas componentes de frequência do sinal detectado. Um estudo comparativo entre os sinais espectrais obtidos pela nova técnica (APE) e pela VA TB foi realizado de modo a observar as diferenças nos sinais captados pelo hidrofone quando cada uma destas técnicas é utilizada. Lembrando que na APE não há a modulação na frequência de batimento, mas sim uma auto-demodulação do feixe acústico, já na VA o feixe é modulado na frequência de batimento $\Delta \omega$. Uma imagem de uma fantoma com inclusões mais rígidas, mostra a sensibilidade da técnica e alguns gráficos demonstram o contraste da imagem em função dos parâmetros de aquisição. Além disso, imagens geradas pela APE e VA para uma esfera de aço inserida em um fantoma, mostram o potencial da técnica APE em produzir contrastes e resoluções equivalentes a VA em ambas as suas modalidades.

\subsection{Justificativa da técnica de APE}

Quando Fatemi e Greenleaf [11] propuseram a VA, na realidade eles estavam propondo uma forma de definir a função envelope do pulso de excitação, ou em outras palavras, eles propuseram a modulação da força de radiação acústica através do fenômeno de batimento, de forma que a força de radiação acústica sobre um alvo seria definida 
como harmônica com frequência $\Delta \omega$. No entanto, já se sabia, e foi melhor explorado, nos trabalhos de G.T. Silva e M. Fatemi[63],S. Callé et al. [64][16], S. Chen [65] et al. entre outros, que os termos nãolineares resultantes da interação dos feixes acústicos, não deveriam ser desprezados. Como pode-se observar no gráfico da figura 5.1, os dois espectros correspondentes a técnica VA TB, não são compostos puramente pela frequência de modulação da VA ("batimento"), a presença de outros picos de frequência no espectro pode ser atribuída a ao menos vários fenômenos, dentre estes destacam-se :

- Modulação da força de radiação (Efeito de Batimento

- Fenômeno não-linear de auto-demodulação dos feixes acústicos ultrassônicos $(\mathrm{MHz})$

- Susceptibilidade Mecânica da amostra

- Ativação dos modos vibracionais livres

- Reverberação da onda acústica de baixa frequência

O que observa-se é que quando a excitação é feita por VA no modo toneburst com uma frequência significativa obtida pela APE, o sinal adquirido para esta frequência ( $63 \mathrm{kHz}$ ) é notavelmente amplificado como pode ser visto na curva contínua e delgada (em vermelho). No entanto, se excitarmos com a VA toneburst mas na frequência de $45 \mathrm{kHz}$ o sinal é deteriorado como um todo, como pode ser visto na curva contínua e grossa (em verde). O que se pode concluir é que, evidentemente se soubermos a frequência que predomina, no caso $63 \mathrm{kHz}$ poderíamos utilizar a VA toneburst e obter um resultado satisfatório em relação ao sinal ruído para a formação de uma imagem.

No entanto convém destacar que, a metodologia proposta para a VA TB, prevê uma pré escolha do sinal de excitação e da frequência de filtragem do sinal adquirido de modo que, caso a frequência escolhida como batimento não seja a que produza uma grande relação 
sinal ruído, outra aquisição deverá ser realizada. Deve-se observar que mesmo que, a partir de um espectro de frequência seja adquirido anteriormente para a escolha da frequência de batimento, nem sempre os picos de maior intensidade serão os que oferecerão a melhor imagem, devido a padrões de reverberação na amostra. Com a nova técnica proposta ( $\mathrm{APE}$ ) não é necessária a escolha prévia de uma frequência específica de excitação, de modo que, não havendo oscilação forçada em uma determinada frequência, não acarretaria em deterioração das outras componentes vibracionais.

A figura 5.1 mostra três espectros de frequência obtidos pelas técnicas APE e VA TB para a excitação de uma esfera de diâmetro 2,34 mm presa em um filme plástico. A linha azul tracejada, corresponde a resposta acústica no domínio de frequência, da técnica APE, para um sinal adquirido em uma taxa de aquisição de $2,0 \mathrm{MHz}$ para uma janela de $150 \mu$ s e para uma excitação de 340 ciclos de 3,43 MHz e amplitude de $40 \mathrm{Vpp}$. A partir deste espectro, outros dois experimentos foram realizados envolvendo a vibroacustografia em seu modo pulsado (VA TB), um para uma excitação com frequência de batimento de $45,0 \mathrm{kHz}$ e outra em $63,0 \mathrm{kHz}$ para um burst de excitação correspondente a 5 ciclos da frequência de batimento (cerca de 340 ciclos completos de 3,43 MHz).

O espectro gerado pela VA TB, na frequência de excitação em $63,1 \mathrm{kHz}$, apresentou uma amplitude em torno de $63 \mathrm{kHz}$ pronunciada, quatro vezes maior que a amplitude detectada pela $A P E$, lembrando que na VA TB, dois feixes são utilizados, a potência é quadriplicada, explicando assim o ganho na amplitude. Observa-se também, que a amplitude dos demais picos é reduzida, característica esta, coerente com a excitação forçada promovida pelo pulso VA TB. Quando escolhida uma outra frequência para geração do espectro, $(45 \mathrm{kHz})$, praticamente todo os sinal obtido pelo VA TB foi deteriorado, mesmo na região da banda de $45 \mathrm{kHz}$. Este resultado demonstra que, uma escolha inadequada da frequência de excitação na técnica VA TB, pode 
não produzir um sinal significativo para a produção da imagem, acarretando em nova aquisição. Devido a aquisição multi-frequencial da APE, as imagens podem ser geradas em outras frequências, sem exigir uma nova aquisição, sendo esta uma das suas principais vantagens.

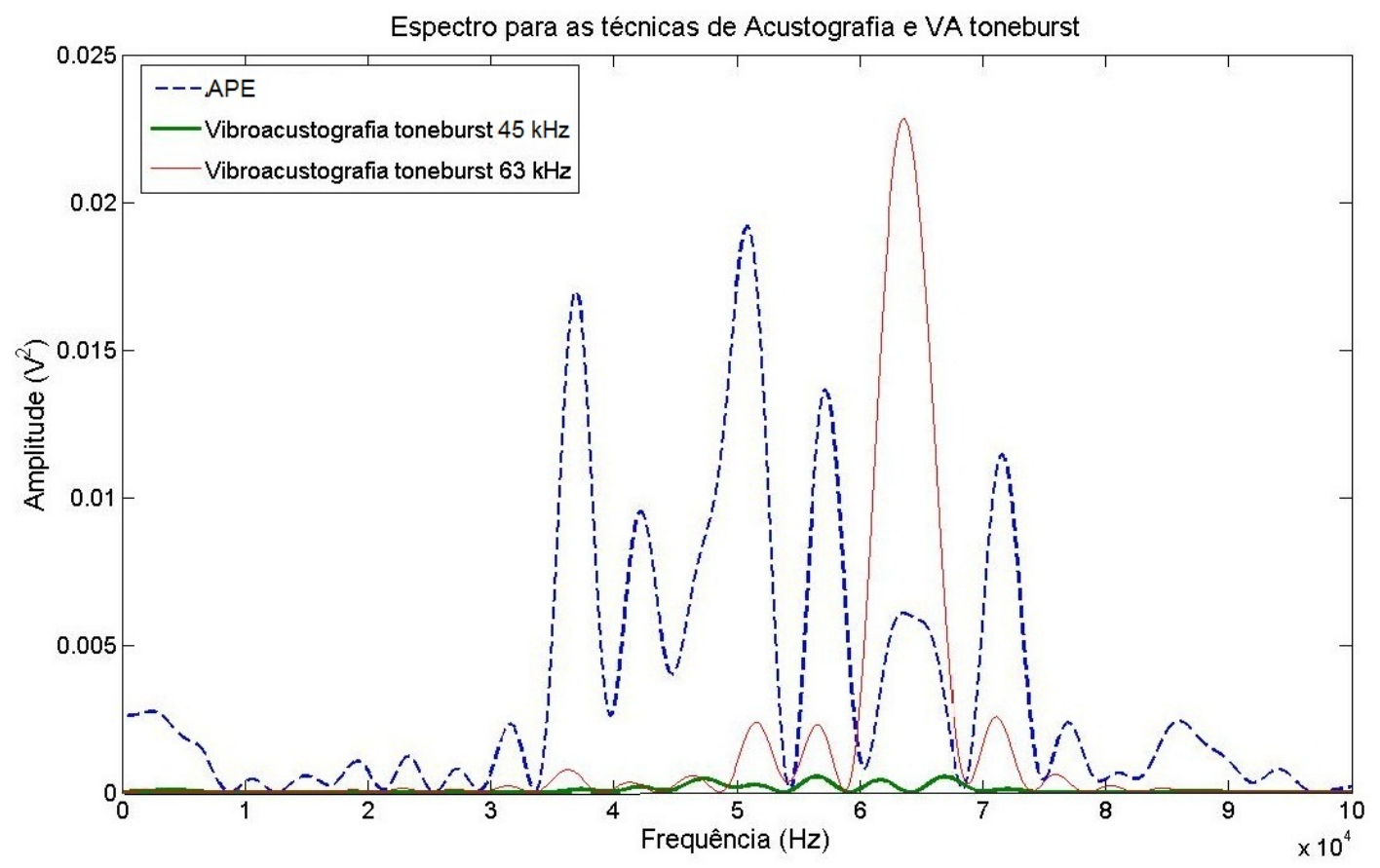

Figura 5.1: Comparação entre a APE e a VA em modo toneburst para duas frequências de excitação

\subsubsection{Formação de ondas de baixa frequência por auto-demodulação}

Como descrito no capítulo 2, as baixas frequências causadas pelo fenômeno de auto-demodulação tem seu espectro proporcional $\partial^{2} f / \partial t^{2}$, sendo $f(t)$ a função envelope do pulso ultrassônico. Nos gráficos da figura 5.2 pode-se observar a forma do pulso ultrassônico emitido pelo elemento central do transdutor de excitação quando excitado por um burst de 3 ciclos de 3,43 MHZ e amplitude de $40 \mathrm{Vpp}$ e seu correspondente envelope que foi obtido através da transformada de Hilbert do pulso conforme a equação 3.3. Extraindo a segunda derivada temporal 
da função $f(t)$ do envelope, e em seguida fazendo a FFT desta derivada, obteve-se o espectro representado na figura 5.3.

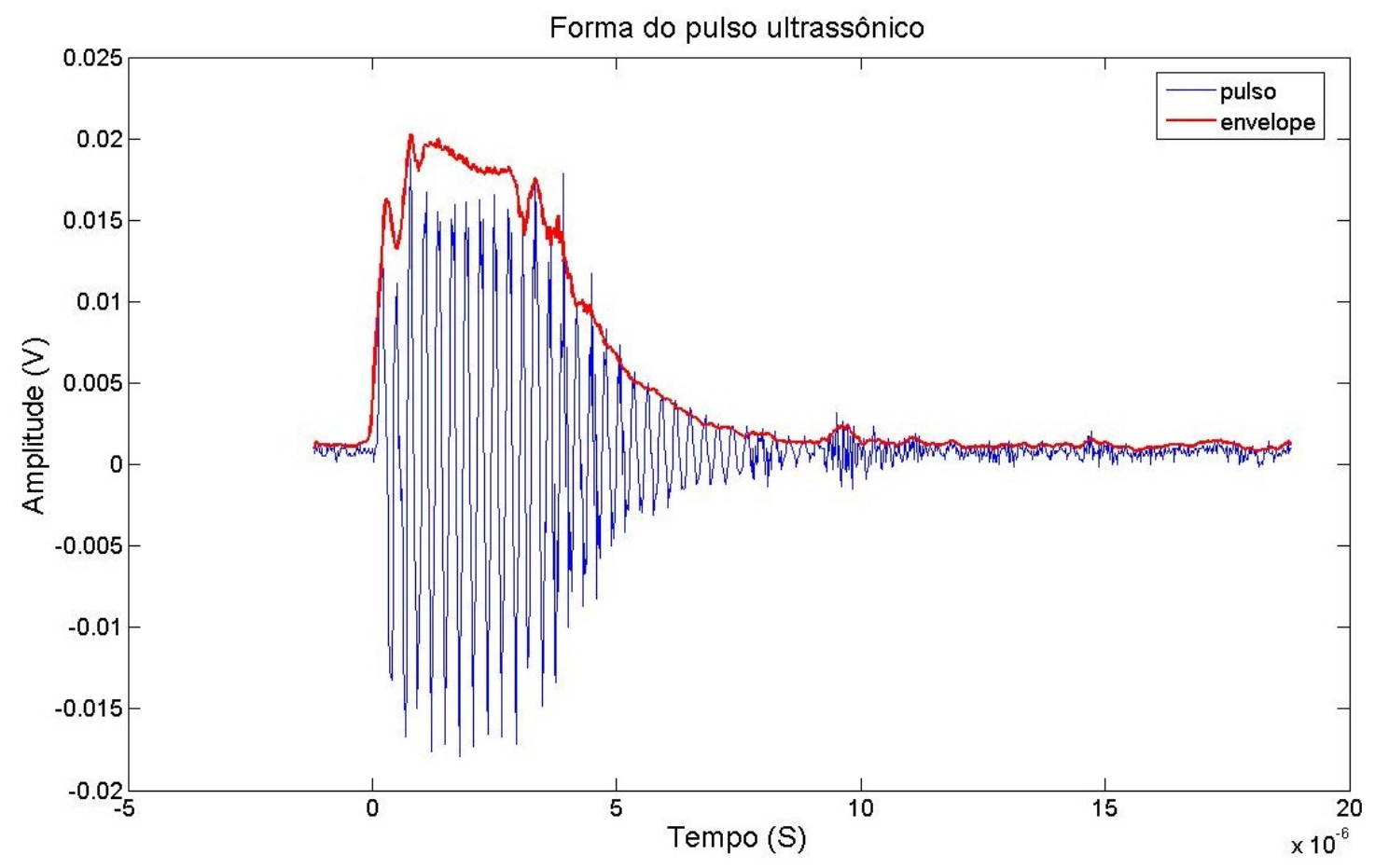

Figura 5.2: Pulso acústico emitido pelo transdutor e o respectivo envelope.

Observando os picos de frequência mais proeminentes da FFT do envelope, pode-se destacar as bandas em torno de 20, 40 e 60 e $70 \mathrm{kHz}$. As frequências em torno de $40 \mathrm{kHz}$ e $60 \mathrm{kHz}$ estão presentes na maioria dos espectros exibidos neste trabalho, as frequências em torno de $20 \mathrm{kHz}$ não aparecem em alguns espectros devido ao pequeno intervalo temporal da janela, que limita a condição de amostragem, que foi escolhido assim de modo a diminuir as distorções provocadas pelas ondas de reverberação. A banda em torno de $70 \mathrm{kHz}$ não se pronuncia em alguns nos espectros devido a baixa sensibilidade o hidrofone, como pode ser visto na caracterização do mesmo. 


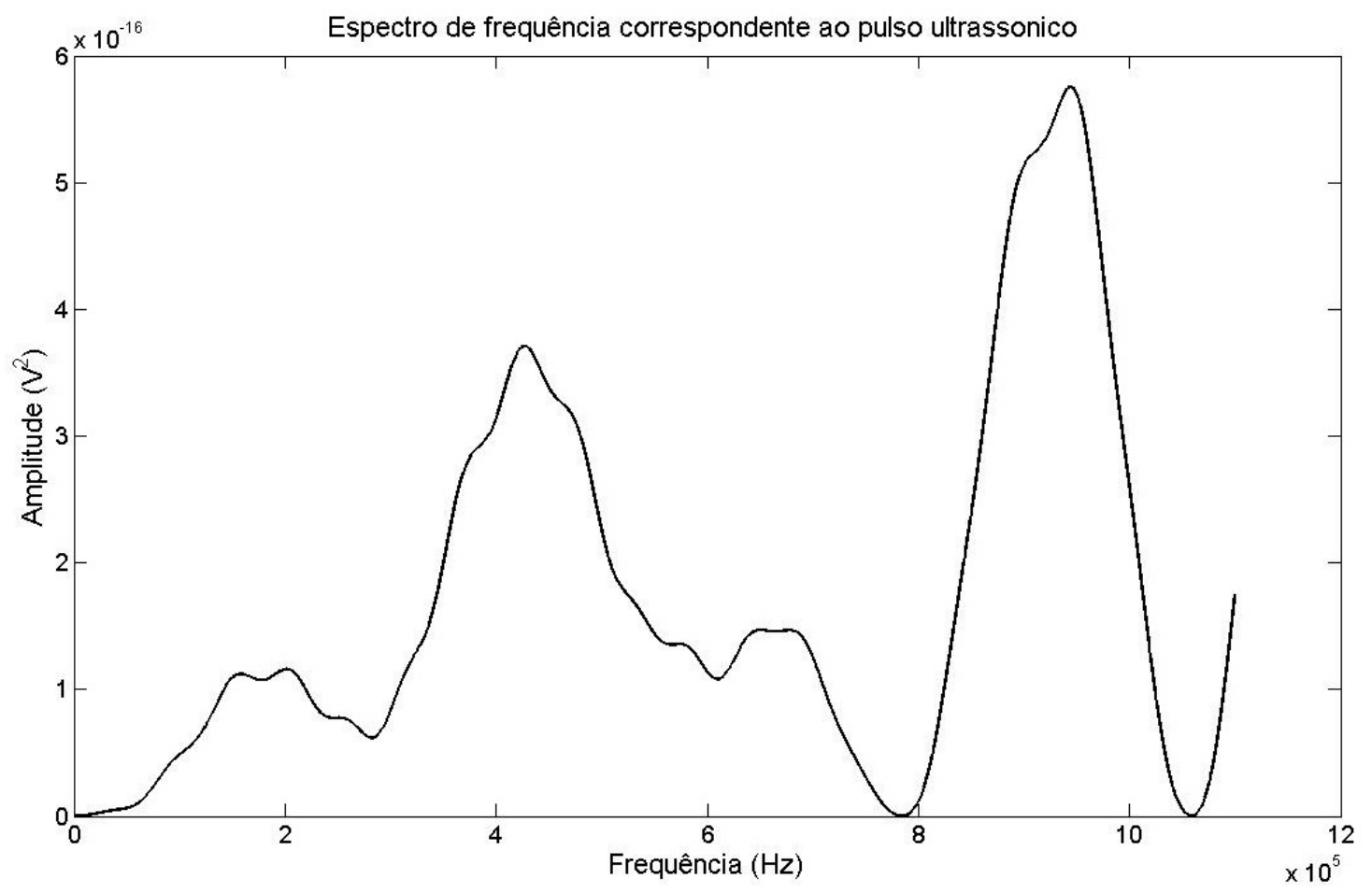

Figura 5.3: Espectro de frequência correspondente a segunda derivada temporal do envelope do pulso de excitação

\subsubsection{Contribuição da reverberação da onda acús- tica no sinal detectado}

Refazendo as transformadas de Fourier para o mesmo experimento de excitação na esfera de $2,34 \mathrm{~mm}$ porém para uma janela de processamento maior ( 3000 ciclos de 3,43 MHz), é possível observar o surgimento de picos de mais baixa frequência ( $5 \mathrm{kHz}$ e $15 \mathrm{kHz}$ ). Reverberações e formação de ondas estacionárias podem se formar tanto dentro da própria amostra, quanto entre as paredes do tanque acústico e entre os instrumentos. Estas reverberações são devido a reflexão das ondas emitidas que, ao encontrar interfaces com diferença de impedância acústica, sofrem reflexão parcial criando padrões de interferência destrutivos, ou construtivos dependendo da geometria e da frequência.

Ondas estacionárias podem ser formadas entre a amostra e diferentes estruturas de maneira similar a um tubo ressonante aberto (tubo 


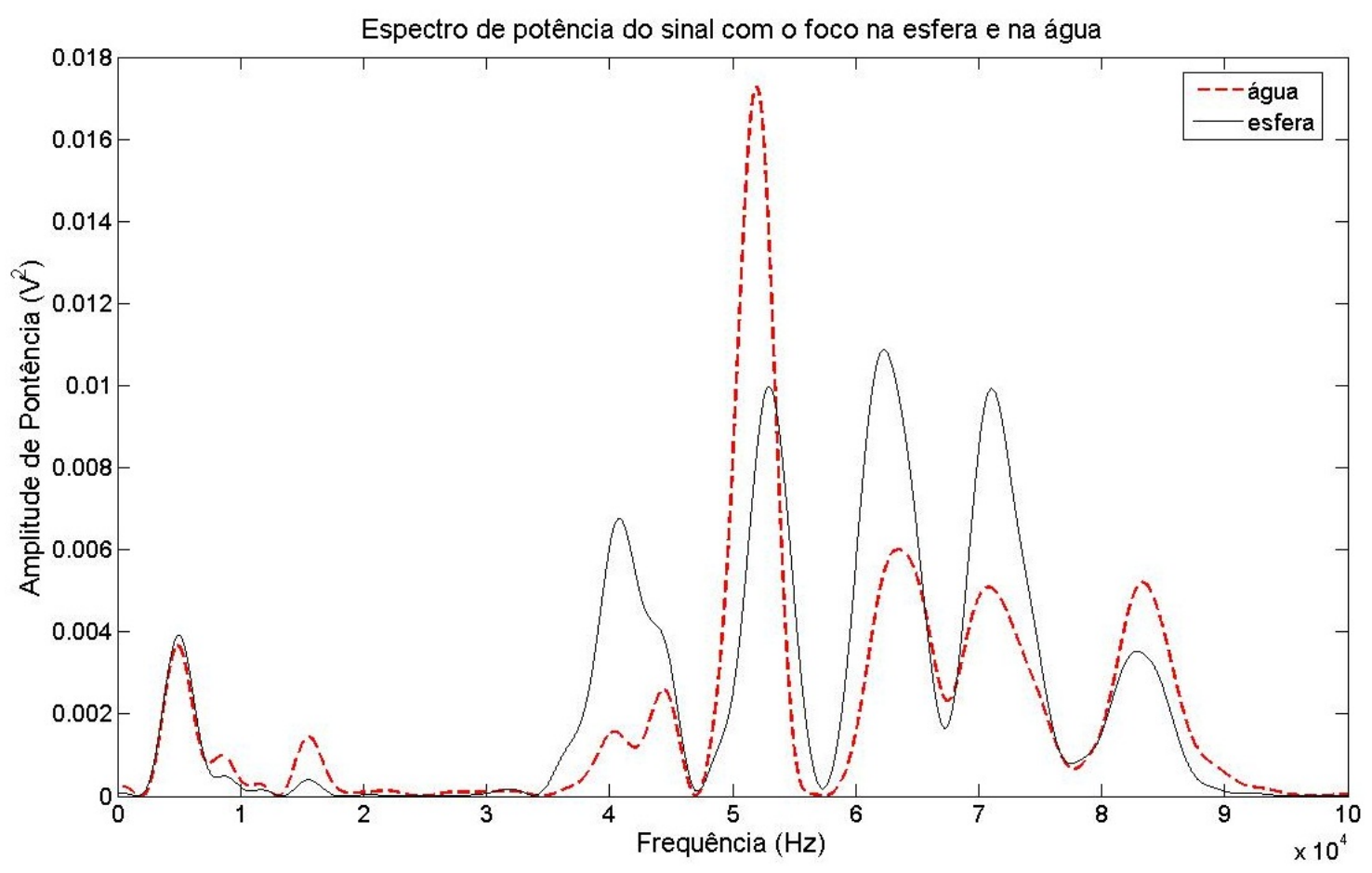

Figura 5.4: Resposta em frequência da amplitude de potência do sinal acústico adquirido em duas situações: com o foco centrado na esfera e diretamente na água

de Kundt [66]), por exemplo, uma onda estacionária formada entre o objeto presente no ponto focal e a cerâmica, o comprimento de onda $\lambda$ desta onda, é igual a $\lambda=2 L$ sendo $L=5 \mathrm{~cm}$ que é a distância focal. Calculando a frequência desta onda a partir de $C=\lambda f$, para $c=1497 \mathrm{~m} / \mathrm{s}$, encontra-se o valor de $f=14,97 \mathrm{kHz}$ que justificaria a presença de um pico em torno de $15 \mathrm{kHz}$ no espectro. Há também a formação de onda estacionária entre a amostra e o hidrofone que estava distante aproximadamente $15 \mathrm{~cm}$ da amostra, neste caso, calculando a frequência desta onda, encontramos o outro pico em torno de $5 \mathrm{kHz}$. Uma maneira imediata de reduzir estes fenômenos é diminuir o tamanho da janela de processamento porém, em detrimento da relação sinal ruído para frequências mais baixas devido a condição de Nyquist. Para o caso da VA $\mathrm{CW}$, ferramentas de pós processamento podem diminuir o artefato de onda estacionária. Uma outra solução encontrada nos experimentos desenvolvidos no laboratório GIIMUS sugere a varredura com foco fixo, 
ou seja quem se move é a amostra e tanto o transdutor de excitação quanto o hidrofone permanecem imóveis.

\subsection{Livre emissão acústica}

O gráfico da figura 5.5 ilustra o princípio de livre emissão acústica através da resposta da vibração de um diapasão devido a impulsos mecânicos gerados por diferentes formas. A primeira curva ( em vermelho tracejado) é a velocidade de vibração detectada por um vibrometro laser quando uma esfera atinge a extremidade do diapasão, a segunda curva (linha azul contínua) utiliza como forma de excitação um pulso de radiação acústica. No gráfico, os sinais têm amplitudes equivalentes, porém isto foi apenas um artifício para apresentação, pois a amplitude de vibração gerada pela força de radiação precisou ser amplificada cerca de $40 \mathrm{~dB}$ para que se igualasse a amplitude de vibração gerada pelo impacto da esfera. O interessante é observar que ambas as curvas possuem uma mesma frequência principal, que corresponde a frequência nominal do diapasão $(582 \mathrm{~Hz}$ ) corrigida para o caso de imersão em água. A detecção de modos vibracionais utilizando uma força impulsiva, como no caso da esfera atingindo uma haste, é uma forma de ensaio não destrutivo utilizado na engenharia de materiais como forma de obter parâmetros viscoelásticos de amostras padronizadas através do conceito de decaimento logaritmo. Uma possível substituição do método de força impulsiva tradicional pela utilização de força de radiação poderia diminuir a interferência dos modos vibracionais da esfera na vibração da amostra, já que a força de radiação pode ser considerada, neste caso, com uma forma de "não contato". Comparando as amplitudes de velocidade de vibração foi possível estimar também a força de radiação gerada pela onda ultrassônica produzida pelo transdutor focal.

O gráfico da figura 5.6 demonstra valores de contraste entre o sinal obtido no centro de uma esfera de aço pelo sinal obtido na água para 


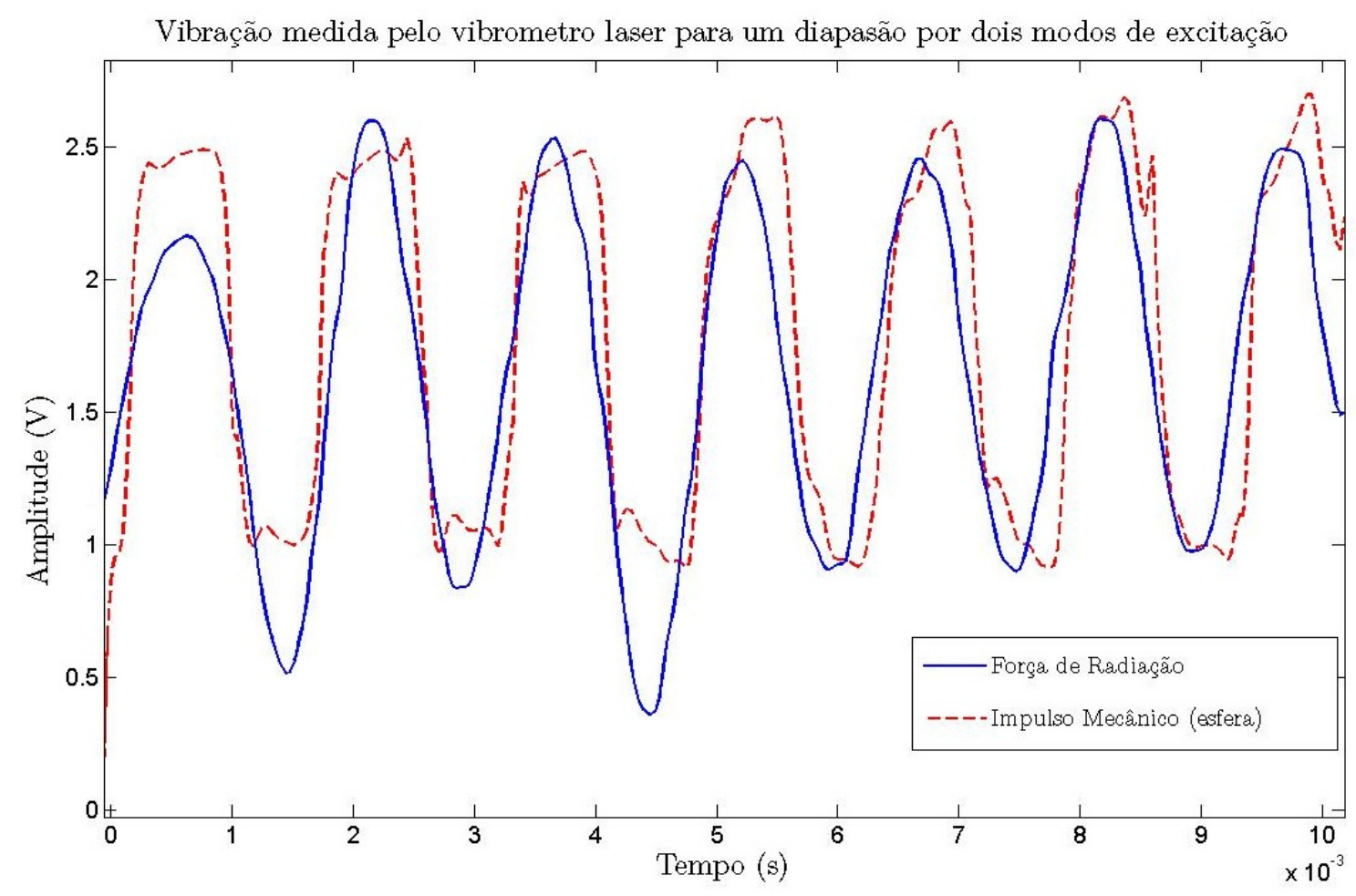

Figura 5.5: Imagem ilustrando a os sinais adquiridos, através de um vibrometro laser, de um diapasão vibrando, para os dois tipos de excitação: em vermelho tracejado a excitação pela esfera e em azul pela força de radiação acústica

dois diferentes parâmetros do pulso ultrassônico de excitação (voltagem e número de ciclos do pacote- burst). Para esta configuração o gráfico permite afirmar que o contraste entre esfera/água é maior quanto maior for a voltagem aplicada, ou seja quanto mais intenso for sinal, e também quanto mais curto for o pacote, isto deve-se ao fato de que quanto menor o pacote, maior a amplitude das componentes de baixas frequências geradas pelo fenômeno de auto-demodulação.

A figura 5.7 mostra o contraste em função da voltagem de excitação e a distância entre a fonte e o hidrofone. O maior contraste é obtido para um alto valor de excitação e para o hidrofone próximo a amostra. Pois neste caso os efeitos não lineares tem amplitudes significativas como visto nos resultados de emissão acústica de uma pequena esfera. 


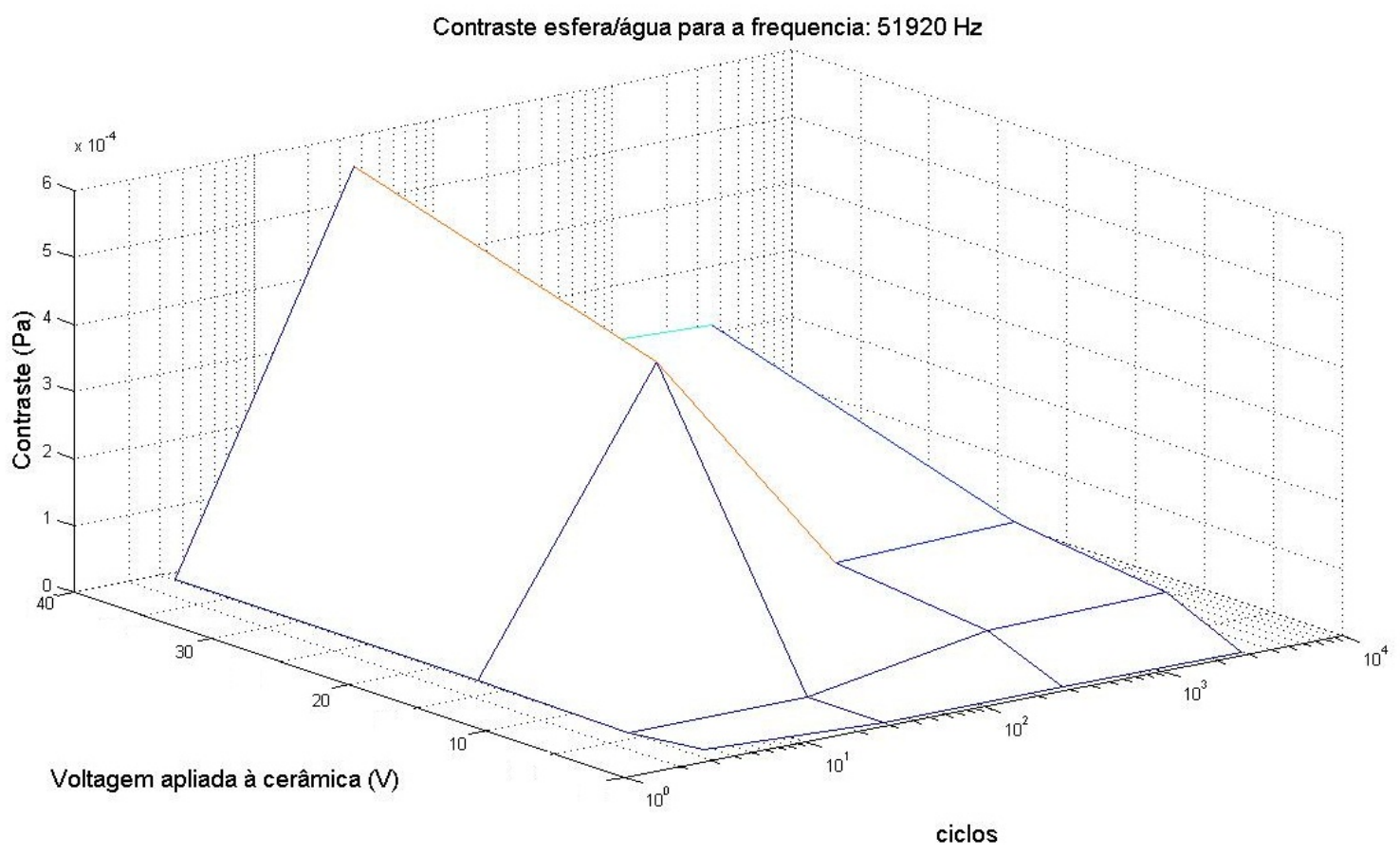

Figura 5.6: Contraste em amplitude de pressão acústica em função da voltagem de excitação e número de ciclos do pulso. A barra de cores é uma informação redundante ao eixo $Z$ apenas com o intuito de diminuir os efeitos de perspectiva do gráfico

Contraste esfera/água para a frequência de : $51920 \mathrm{~Hz}$

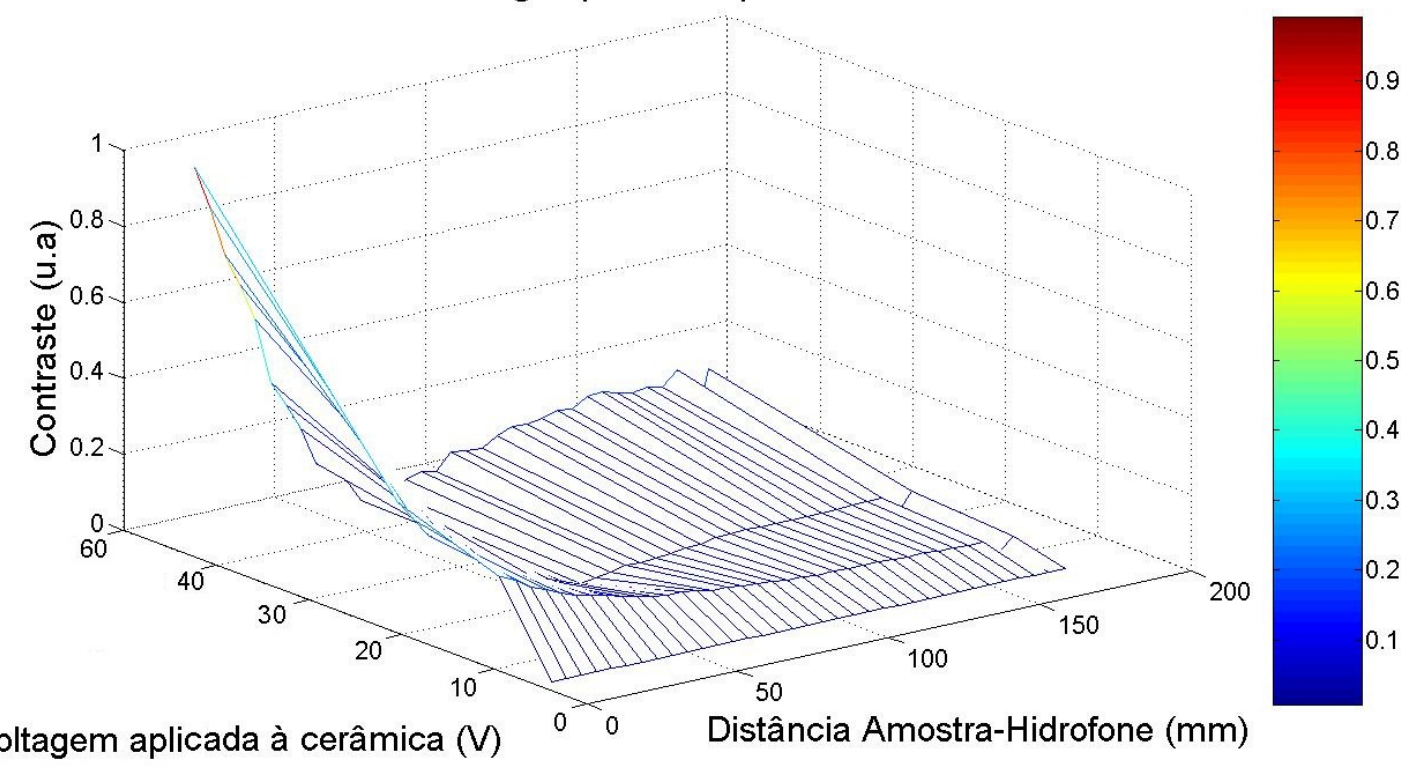

Figura 5.7: Contraste em amplitude de pressão acústica entre a esfera e o meio para diferentes valores de voltagem e distância amostrahidrofone 


\subsection{Formação de imagens pela técnica APE e pela VA}

As imagens da figura 5.8 ilustram os resultados do imageamento de uma esfera de aço de 2,34 $\mathrm{mm}$ de diâmetro, geradas a partir de três métodos. A primeira $(5.8$ a) foi produzida pela técnica APE, As outras duas (5.8 c) e d)) são produzidas a partir da técnica de VA em seus modos CW e TB respectivamente. As três imagens apresentam característica similares e fortemente dependentes do tamanho do foco do campo ultrassônico. Nos três casos, o fenômeno predominante responsável pelo contraste da imagem é o espalhamento do feixe acústico uma vez que as diferenças de impedância acústica entre o gel e o aço são muito grandes.

\subsection{Mudança de rigidez}

Para avaliar a sensibilidade da técnica de APE em simuladores de tecidos biológicos moles, com diferenças de rigidez, uma imagem foi obtida em um fantoma contendo cinco inclusões de diferentes valores de rigidez, utilizando a metodologia descrita em 3.6. O módulo de Young do material de base e das inclusões, foram obtidos usando a metodologia descrita em 3.7 e apresentados na tabela 5.1.

$\mathrm{Na}$ figura 5.10 é ilustrada a distribuição morfológica do fantoma (5.10(a)); a imagem obtida pela técnica APE 5.10(b) e a imagem obtida por ultrassonografia modo $B$.

A figura 5.9 ilustra o sinal obtido pela APE em função da frequência para as três diferentes gelatinas que compõem o fantoma ilustrado na figura 5.10(b). Neste espectro fica nítido um alargamento do pico em torno de $50 \mathrm{kHz}$ pelo aumento da rigidez. Por conta deste alargamento no pico de frequência, a imagem pode oferecer um bom contraste na frequência de 53,5 kHz, como indicado pela linha vertical na figura 5.9.

A imagem da figura ?? demonstra a imagem gerada pela técnica 
a)
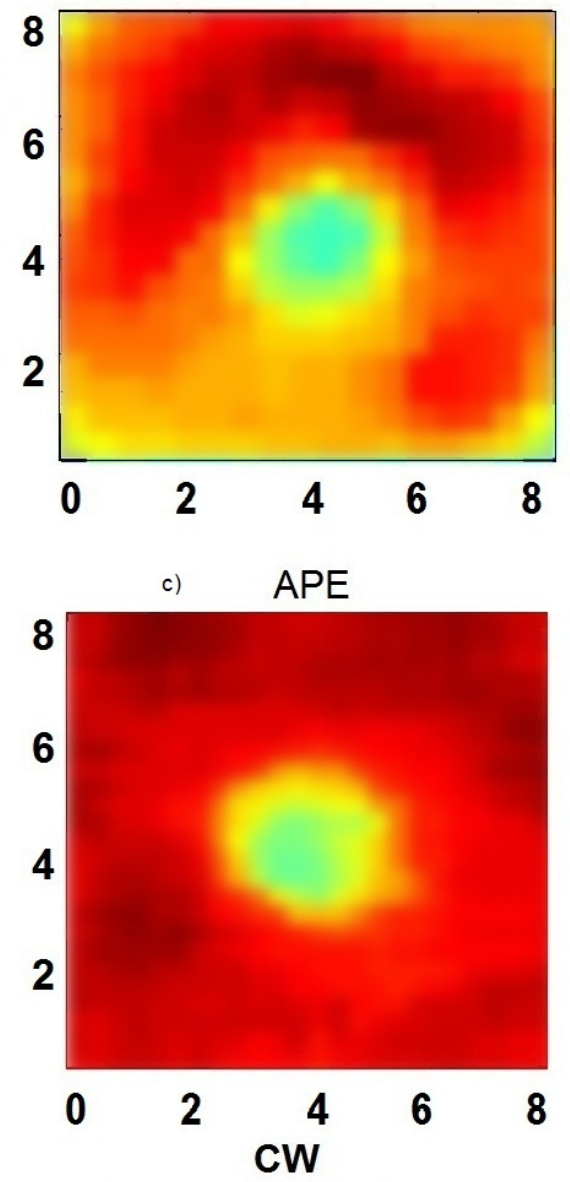

b)
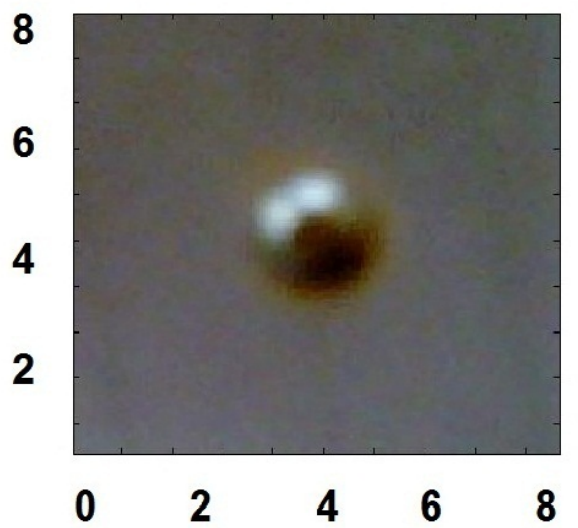

d) FOTOGRAFIA

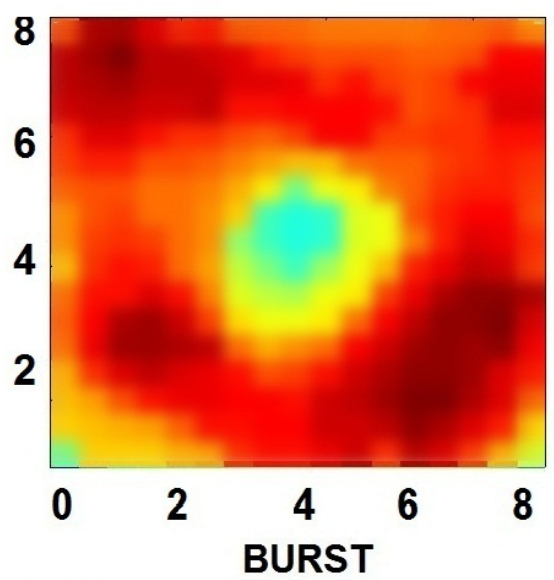

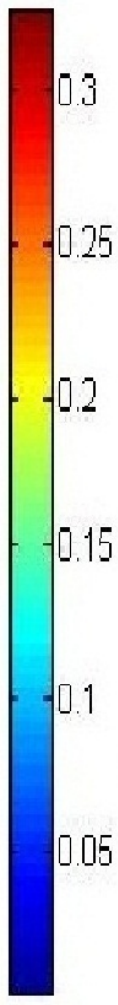

Figura 5.8: Imagens obtidas pelas técnicas APE e VA para um fantoma contendo uma esfera de aço: a) corresponde a uma imagem adquirida utilizando a nova técnica $A P E ; b)$ corresponde a uma fotografia do fantoma de gelatina ( $8 \%$ ) contendo uma esfera de aço de 2,34 mm;

c) corresponde a uma imagem produzida utilizando a VA em modo CW

; d) corresponde a uma imagem também de VA mas em modo TB

APE, nesta imagem é possível observar um maior contraste nas inclusões mais rígidas (números 2 e 3) e um baixo contraste para a esfera 5 que têm a mesma concentração de ágar. Os valores de contrastes $C$, entre os módulos de Young, obtidos pelo método quase estático, e a relação sinal ruído RSR, obtidos pela APE, são apresentados na tabela 5.2. 


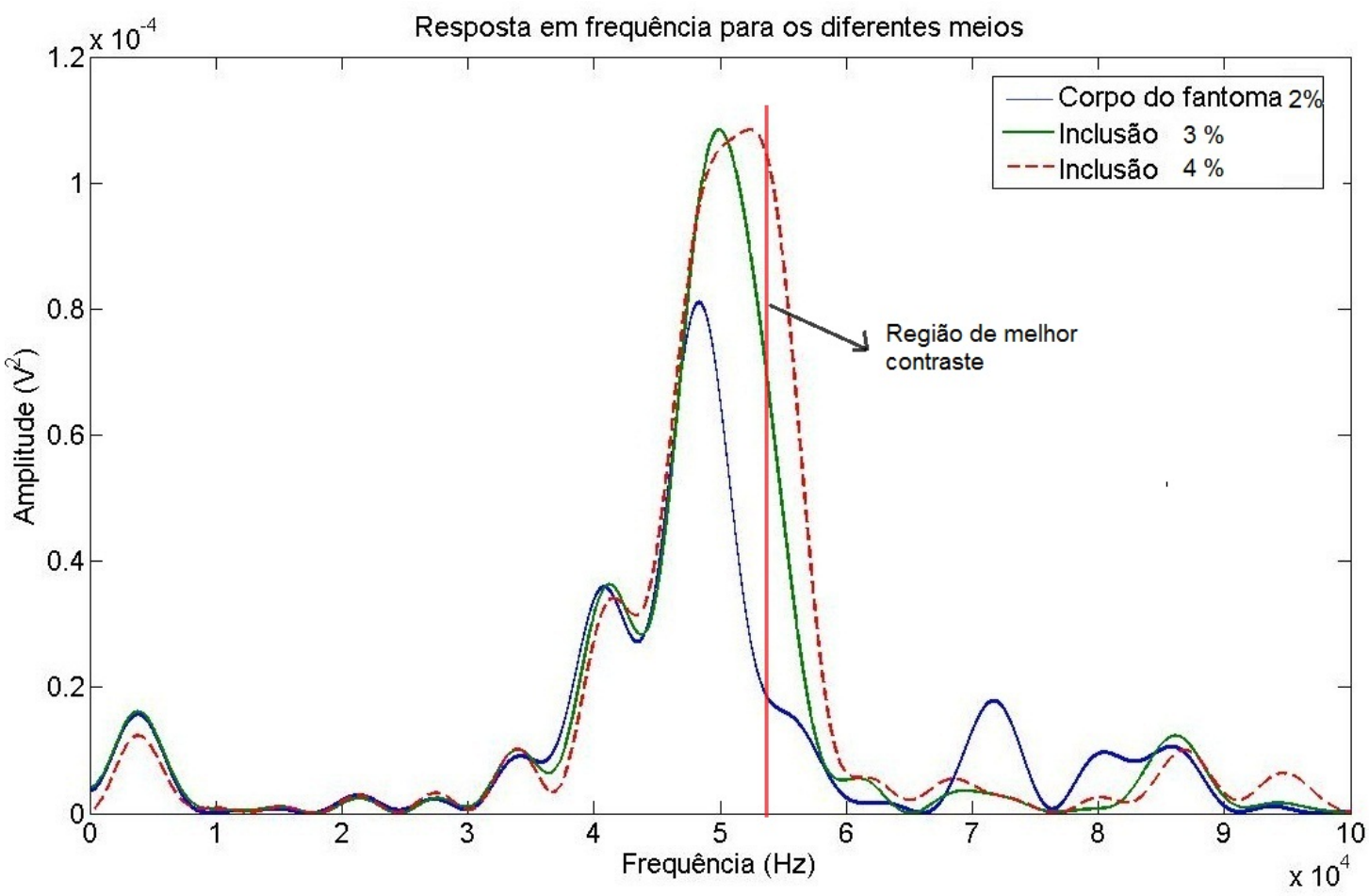

Figura 5.9: Resposta em frequência para o corpo do fantoma devido a um impulso ultrassônico

Tabela 5.1: Módulos de Young obtidos pelos ensaios quase-estáticos para as inclusões e para o corpo do fantoma.

\begin{tabular}{lcc}
\hline \hline Amostra & Concentração de Ágar & Módulo de Young \\
\hline Corpo do fantoma & $2,0 \%$ & 65,3 \\
Esferas 1 e 4 & $4,0 \%$ & 165,7 \\
Esferas 2 e 3 & $3,0 \%$ & 128,1 \\
Esfera 5 & $2,0 \%$ & 65,6 \\
\hline
\end{tabular}

\subsection{Variações na frequência de excitação do pulso ultrassônico}

A figura 5.11, ilustra os espectros de potência do sinal acústico no foco de excitação, por pulsos de diferentes frequências centrais, notamos para frequências bem baixas na ordem de $0,5 \mathrm{kHz}$ a amplitude mais elevada ocorre para a frequência de excitação de 3,43 $\mathrm{MHz}$ que é a frequência que ofereceu maior intensidade de pressão acústica na 


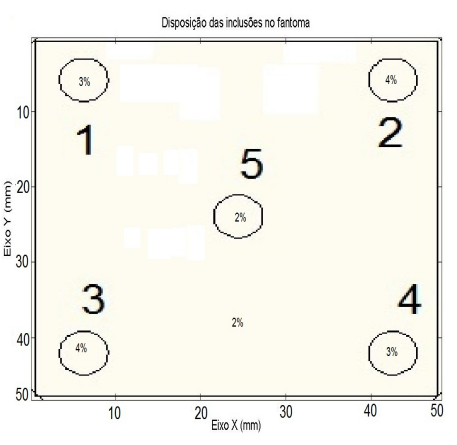

(a) Disposição das Inclusões

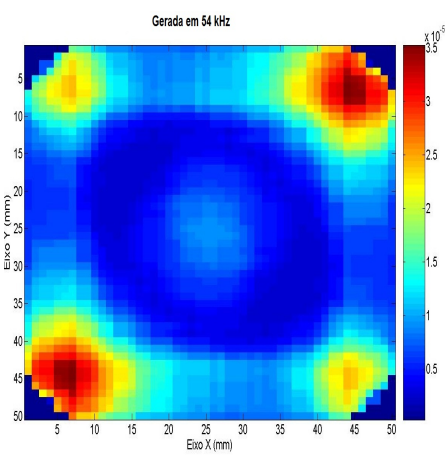

(b) Imagem APE

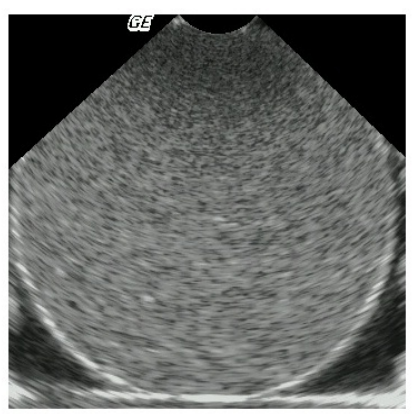

(c) Imagem ultrassom

Figura 5.10: Imagem de um fantoma contendo inclusões mais rígidas. a) diagrama representado a disposição morfológica das inclusões com diferenças de rigidez; b) Imagem produzida a partir da técnica APE; c) Imagem produzida por ultrassonografia no modo brilho

Tabela 5.2: Relação sinal ruído e contraste para o fantoma com inclusões mais rígidas.

\begin{tabular}{lcc}
\hline \hline Amostra & Contraste (módulos de Young) & Contraste (imagem) \\
\hline Esfera 1 & $1,9 \pm 0,2$ & $2,5 \pm 0,5$ \\
Esfera 2 & $2,5 \pm 0,2$ & $3,5 \pm 0,3$ \\
Esfera 3 & $2,5 \pm 0,2$ & $3,0 \pm 0,2$ \\
Esfera 4 & $1,9 \pm 0,2$ & $2,7 \pm 0,4$ \\
\hline
\end{tabular}

calibração com a balança,

\subsection{Discussão geral sobre a técnica APE}

Um sinal acústico, como os produzidos na APE, é o resultado de um conjunto muito rico de interações das ondas acústicas com o meio material, seja pela propagação da onda de forma linear, pela qual a onda viaja através de um meio atenuante, ou seja pelas interações nãolineares entre as ondas espalhadas, como propunha Westevelt [34]. Além disso, de forma similar ao que ocorre com radiação eletromagnética, as interfaces com diferença de impedância, promovem os fenômenos de espalhamento, dando origem a reverberações e ondas esta- 


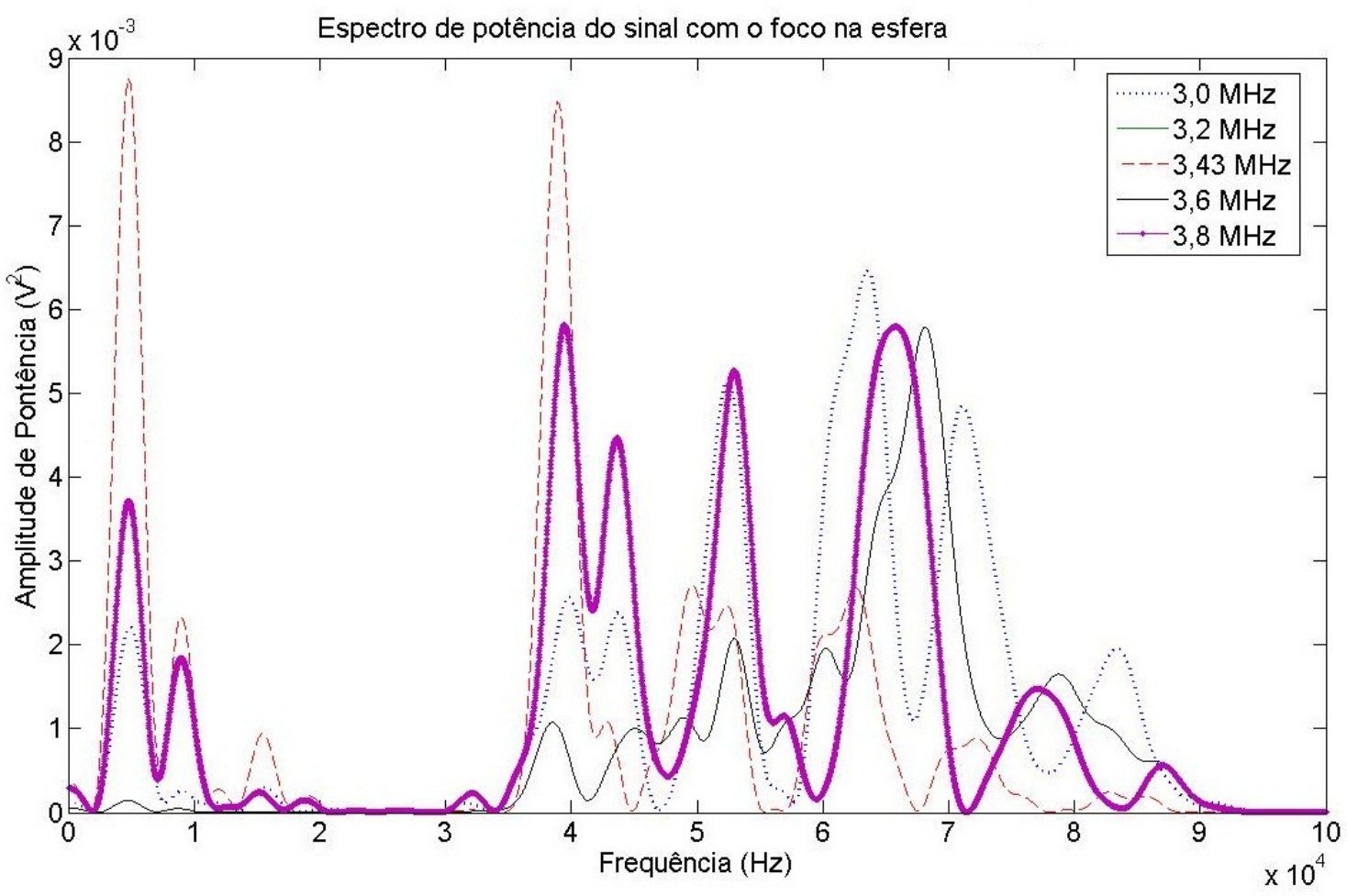

Figura 5.11: Espectro do sinal adquirido em baixas frequências para diferentes frequências de excitação de uma esfera de 0,664 $\mathrm{mm}$ de diâmetro

cionárias ( como é comum na VA CW) [13]. Estes artefatos foram, por muito tempo, rejeitados no processo de formação de imagens convencionais de ultrassonografia. No entanto, hoje estes mesmos artefatos são peças fundamentais no auxilio ao diagnóstico [67]. A técnica APE utiliza destas propriedades de propagação acústica e das características vibracionais provenientes da morfologia das estruturas como base da formação de imagem. Evidentemente, o padrão de reverberação é diferenciado ao longo da amostra, mas esta propriedade é dependente da frequência da onda que se propaga, de modo que é possível contornar ou acentuar este artefato de modo a ser útil ao destacar uma determinada estrutura. O sinal obtido no hidrofone, a final, é a soma de todos estes efeitos sobrepostos e modulados. A escolha da frequência de filtragem do sinal e janela temporal são artifícios válidos para reduzir os artefatos de reverberação, principalmente em frequências mais 
baixas.

Como toda onda mecânica, o som está sujeito às propriedades do meio, temperatura, pressão externa, densidade etc. O espectro das ondas sonoras se modifica com a variação destes parâmetros, de modo que o inverso, ou seja, definir a variação destes parâmetros a parir da mudança do sinal acústico é um desafio que vale a pena ser explorado. Neste contexto, muito ainda pode ser explorado a partir dos sinais acústicos produzidos pela APE e também pela VA, entender e criar mecanismos para separar as variáveis deste sinal complexo, tem sido o maior desafio para que se chegasse a imagens como o exemplo da imagem do osso.

Sequências diferenciadas de pulsos de excitação, tem sido apresentadas para a VA TB, com objetivo de reduzir artefatos que estão presentes também nesta técnica. Uma vertente importante a ser explorada é a criação de sequências de pulsos de modo a produzir imagens ponderadas nos diferentes fenômenos observados. Como apresentado na teoria, a contribuição das parcelas não-lineares da propagação acústica e consequentemente, o espectro produzido pelo fenômeno de autodemodulação é dependente da forma do pulso de excitação e das características de propagação do som. Criar pulsos que permitam intensificar uma certa banda do espectro de frequências terá significante impacto na técnica APE. 


\section{Capítulo}

\section{Estudos de aplicação da técnica APE}

Este capítulo apresenta exemplos de aplicação da técnica APE em E três aplicações distintas. A primeira secção apresenta uma imagem gerada a partir da técnica, para uma amostra "in vitro"de um osso inserido em um fantoma de gelatina. Dois outros experimentos preliminares, demonstram a potencial aplicação da técnica para avaliação da variação da temperatura local, muito importante nos tratamentos envolvendo HIFU* e também como ferramenta para ensaios não destrutivos(END), como por exemplo no acompanhamento da integridade de tubos de extração de petróleo etc. Estes estudos piloto visam mostrar o potencial da técnica APE seja no processo de formação de imagens, ou pela utilização das variações do sinal acústico como forma de obter-se outros parâmetros físicos.

\subsection{Aplicação da técnica APE na geração de imagens de tecido ósseo "in vitro"}

Neste experimento é apresentado um exemplo de imagem formada pela técnica APE. Um pequeno osso de galinha foi inserido dentro de um fantoma a base de gelatina e escaneado de modo a produzir uma imagem correspondente as características do osso.

\footnotetext{
${ }^{*}$ HIFU (do inglês High Intensity Focused Ultrasound)
} 


\subsubsection{Materiais e métodos}

Para demostrar a aplicação da APE na geração de imagens de ossos, um úmero de galinha "in vitro" foi inserido em gelatina seguindo a fórmula da tabela 3.1, conforme os procedimentos de preparação padrão, com o objetivo de simular o tecido adjacente ao osso, como mostrado na fotografia da figura 6.1. A imagem foi gerada em intervalos de $0,5 \mathrm{~mm}$ em uma região de interesse de $40 \times 50 \mathrm{~mm}$. A excitação foi configurada para um burst de 3 ciclos de 3,43 $\mathrm{MHz}$ em amplitude 40,0 Volts. A aquisição foi realizada a uma taxa de $2,0 \mathrm{MHz}$. A janela de processamento tinha largura temporal de $150 \mu$ s e a filtragem de cada sinal ocorreu na frequência de $\omega_{f}=63,1 \mathrm{kHz}$ com banda de filtragem em $1,0 \mathrm{kHz}$.

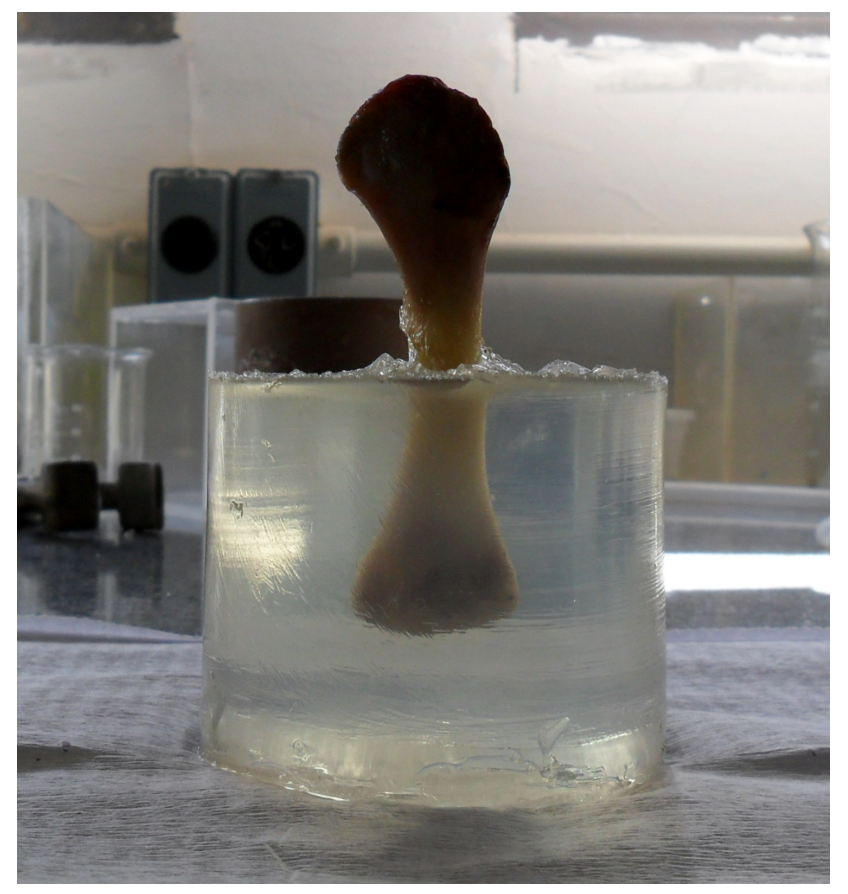

Figura 6.1: Fotografia do fantoma constituido por um úmero de galinha inserido em gelatina.

\subsubsection{Resultados}

As imagens apresentadas na figura 6.2 ilustram os resultados da aplicação da técnica APE na formação de uma imagem de um úmero 
de galinha. A primeira figura 6.2 a) é o resultado da imagem gerada a partir da matriz de valores RMS dos sinais filtrados por um filtro do tipo passabanda Butterworth de 3 polos centrado na frequência de $63,1 \mathrm{kHz}$ e largura de banda de $5 \%$. Um filtro de mediana (janela=4×4) foi aplicado sobre esta matriz de modo a eliminar valores espúrios. A figura b) demosntra a PSF do sistema de imagem. Em c) tem-se a mesma imagem de a) porém corrigida pela aplicação da deconvolução pela função espalhamento e em seguida por um filtro Fourier (parâmetros=3-40). d) é a fotografia da região imageada do osso.
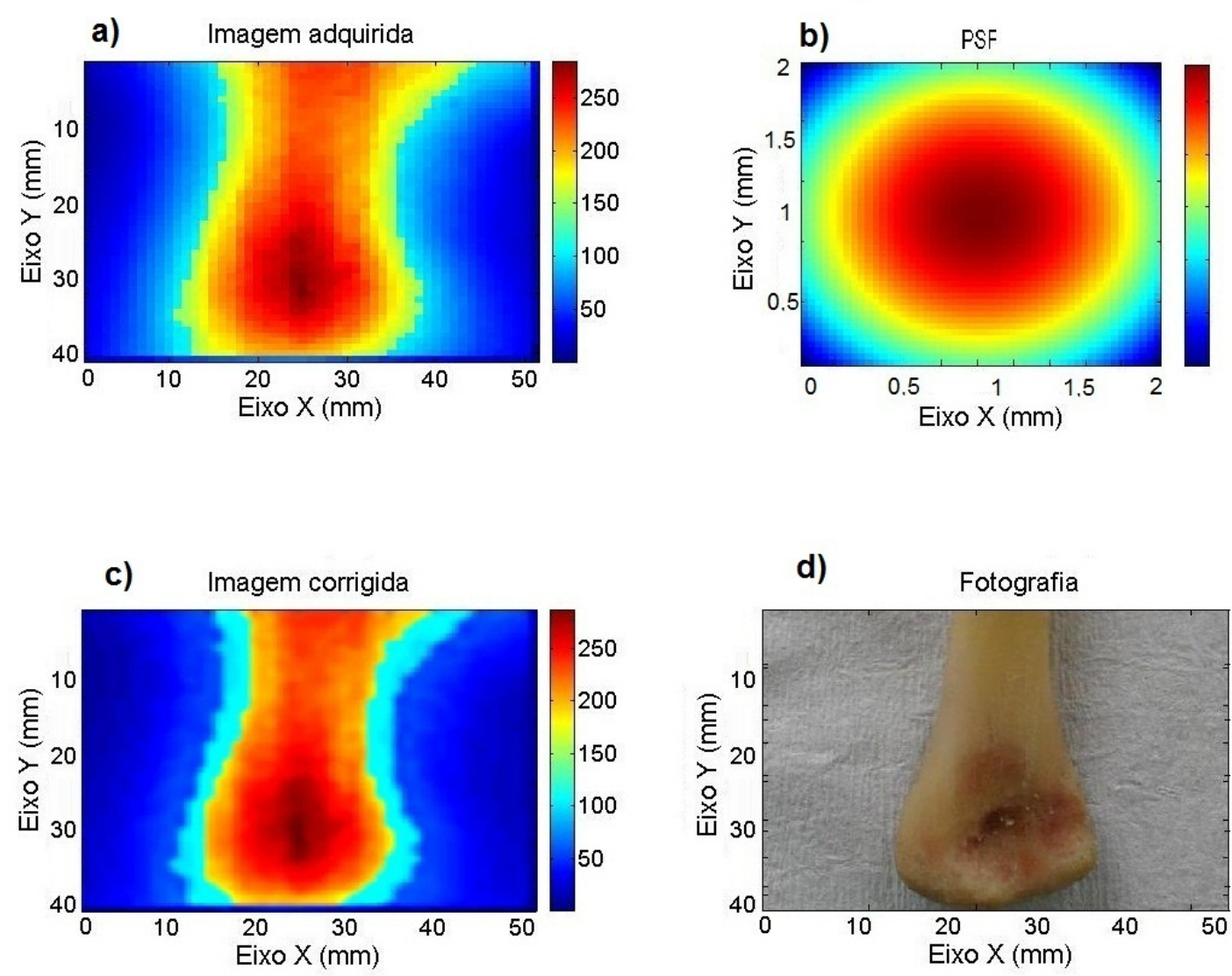

Figura 6.2: Imagem de um osso (úmero de galinha) produzida pela técnica APE. a) Imagem adquirida, b) PSF do sistema, c) Imagem Corrigida a partir da deconvolução da função objeto e PSF, d) Fotografia do osso fora da gelatina.

Observando a imagem $6.2 \mathrm{c}$ ), é possível notar que a imagem produzida é livre de speakles, com contornos definidos e oferece ainda, 
um contraste diferenciado na região central da cabeça do úmero que corresponde a uma reentrância do osso (equivalente a fossa do olécrano [68]). Esta estrutura dificilmente seria observada em uma ultrassonografia convencional (modo-B) devido aos artefatos de reverberação e a alta diretividade das ondas ultrassônicas de alta frequência. Já na APE, a imagem é formada com frequências muito menores (cerca de 50 a 100 vezes), com características de baixa direcionabilidade, permitindo assim, um maior detalhamento da imagem.

Os ossos, de modo geral, tem impedâncias acústicas muito superiores aos tecidos moles, o que resulta em índices de reflexão da onda acústica muito elevados [69] [70]. Devido a esta alta reflexão, a imagem gerada pela APE, neste caso, é fortemente ponderada pelas diferenças nos padrões de espalhamento da água e do osso.

\subsection{Utilização da técnica APE na avaliação da temperatura local}

Em alguns tratamentos que utilizam feixes ultrassônicos de alta potência, como acontece nas cirurgias utilizando HIFU, a avaliação da temperatura local é uma variável importante, principalmente devido a grande diferença entre tecidos e grau de vascularização, a verificação do sucesso do tratamento em um determinado ponto do tecido, dá-se de maneira indireta através da medição da variação da temperatura local. Atualmente, a técnica mais utilizada para monitorar a temperatura é feita utilizando sequências apropriadas de ressonância magnética nuclear (RMN) [71]. O inconveniente deste método é a necessidade da execução do procedimento cirúrgico dentro do tomógrafo de RMN. A proposta deste trabalho é verificar a possibilidade da utilização da técnica APE na monitoração da temperatura local. O interessante em utilizar a APE, é a possibilidade de utilizar o próprio transdutor da terapia como elemento excitador da técnica de monitoração, com a vantagem de se manter o corregistro entre o ponto que está sendo tratado como 
o ponto onde está sendo mensurada a temperatura.

\subsubsection{Materiais e Métodos}

\subsubsection{Preparação dos fantomas}

Para realizar os experimentos envolvendo variação de temperatura, dois fantomas foram confeccionados seguindo os procedimentos da secção 3.6. Um primeiro foi moldado em uma forma de acrílico no formato cilíndrico com dimensões de $25 \mathrm{~mm}$ de diâmetro por $10 \mathrm{~mm}$ de altura, para a estimativa do módulo de Young através do ensaio quase-estático. Um segundo fantoma foi preparado também na forma cilíndrica nas dimensões de $70 \mathrm{~mm}$ de diâmetro por $25 \mathrm{~mm}$ de espessura com a inclusão de uma liga termopar (cobre/constatan), $10 \mathrm{~mm}$ distante do centro do cilindro, de modo a aferir a temperatura, sem interferir consideravelmente na região focal dos ensaios. Para ambos os testes, os fantomas foram refrigerados à uma temperatura de $4,0^{\circ} \mathrm{C}$ e as medições foram realizadas a medida que a temperatura se elevava a cada $2,0^{\circ} \mathrm{C} \pm 0,5^{\circ} \mathrm{C}$.

\subsubsection{Aplicação da técnica APE}

Para cada intervalo de temperatura, um sinal foi adquirido seguindo os procedimentos padrão da APE, para uma excitação de 300 ciclos de 3,43 Mhz e amplitude de $40 \mathrm{Vpp}$. O sinal foi filtrado utilizando o filtro digital Butterworth de 4 polos na frequência de $1,53 \mathrm{kHz}$ e largura de banda em $5 \%$, para uma janela de processamento de $150 \mu \mathrm{s}$. A amplitude RMS do sinal foi associada a cada valor de temperatura aferido pelo termopar.

\subsubsection{Ensaios quase-estáticos}

Para os ensaios quase- estáticos, no mesmo intervalo de temperatura utilizado na técnica APE a amostra foi submetida aos ensaios quase 
estáticos e os valores obtidos de rigidez foram associados a cada intervalo de temperatura.

\subsubsection{Simulação da amplitude do sinal esperada devido a mudanças na rigidez}

Como foi descrito no capítulo 2 a amplitude de vibração emitida pela amostra quando a frequência de excitação aproxima-se de umas das frequências dos modos vibracionais naturais do sistema é regida pela função modal, que por sua vez é composta por uma função $(\Gamma)_{p}$ eq. (2.16) que é um fator de magnificação dependente das frequências dos modos vibracionais em relação a frequência de excitação. Considerando a variação de frequência $\omega$ em função da variação da rigidez, é possível estimar a variação no fator de magnificação em função da rigidez que, consequentemente influenciaria linearmente a amplitude de pressão. Se considerarmos o modelo de voigt[72] como uma primeira aproximação, uma pertubação no valor da constante elástica $k$ resultaria em uma pertubação em $\omega$ seguindo a equação diferencial:

$$
d \omega(k)=\frac{d k}{2 \sqrt{m k}}
$$

então, $\omega(k)=\omega_{p}-d \omega(k)$ pode ser aplicado a equação 2.16 de fator de magnificação para estimar a amplitude de pressão de modo que:

$$
H_{n}=\frac{e^{-i \phi_{n}}}{\left\{\left[1-\left(\omega / \omega_{n}\right)^{2}\right]^{2}+\left(2 \zeta \omega / \omega_{n}\right)^{2}\right\}^{1 / 2}}
$$

A equação 6.2 expressa a variação da amplitude de pressão em função do fator $H_{n}$ que por sua vez, depende da frequência $\omega$. A relação entre frequência de ressonância de um sistema e o módulo $d$ e Young ( $k$ ) é descrita pela equação 2.43. A dependência entre $k$ e a temperatura foi obtida empiricamente através de ensaios quase-estáticos, como descritos na secção 3.7. O resultado dos valores de $k$ em função da temperatura são demonstrados no gráfico da figura 6.3. a partir dos 
valores empiricos de $k(T)$, foi possível simular a amplitude normalizada da pressão acústica em função de $\omega(k)$, no intervalo de valores de $k$.

\subsubsection{Resultados}

A figura 6.3 demonstra o pefil de variação de rigidez de um fantoma de gelatina quando submetido a variação térmica. a partir destes valores obtidos foi possível simular a amplitude de vibração em função da temperatura. O resultado da simulação é comparado com o perfil da curva obtida pela técnica APE, como mostra a figura 6.4.

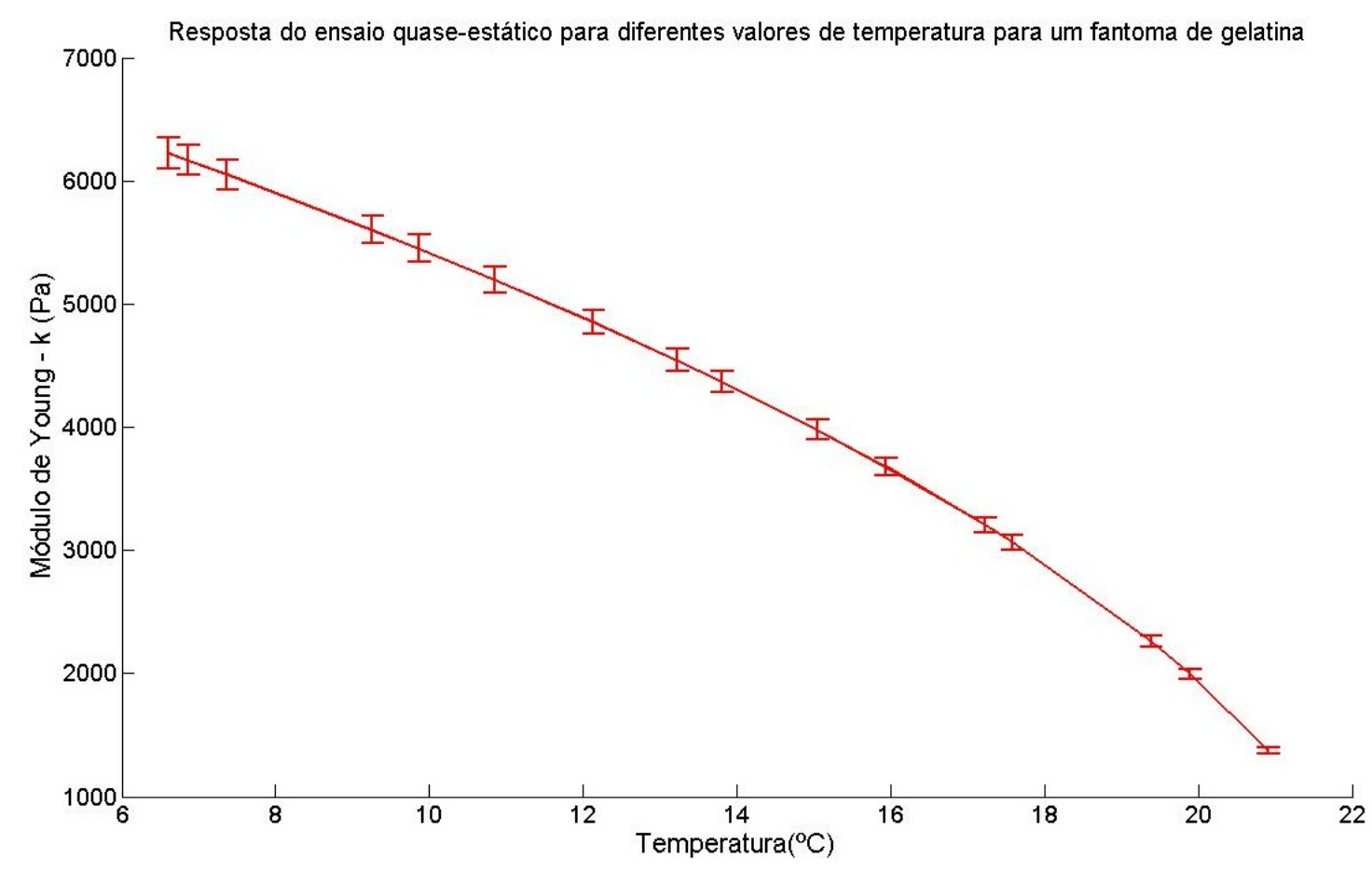

Figura 6.3: Módulo de Young de um fantoma de gelatina a 8\% para diferentes valores de temperatura utilizando o método de ensaio quaseestático

A figura 6.4 mostra os gráficos correspondentes aos resultados obtidos pela simulação, pela amplitude RMS do sinal adquirido pela técnica APE e pelos ensaios. 


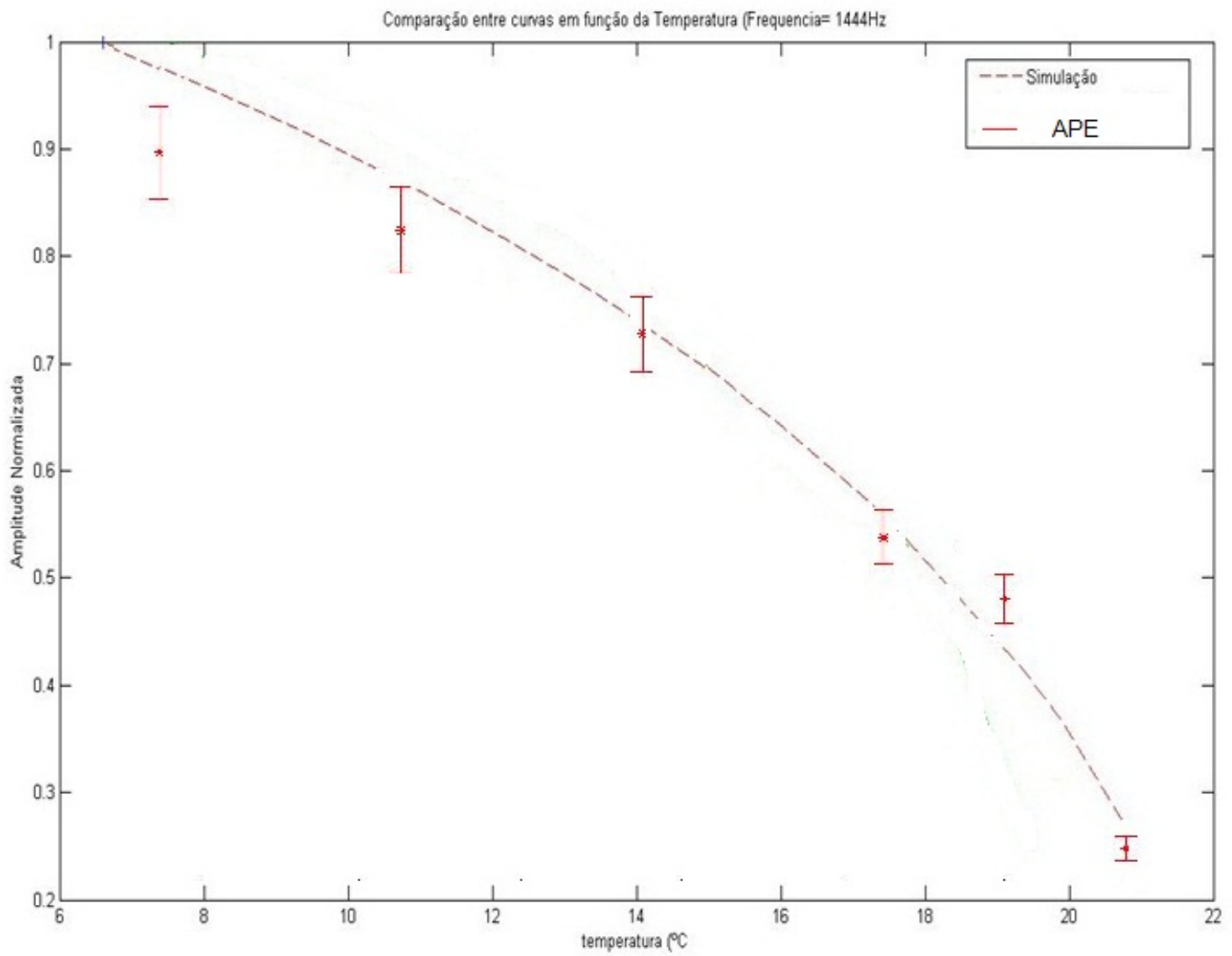

Figura 6.4: Relação entre o módulo de young em função da temperatura para um fantoma com $8 \%$ de gelatina.

\subsection{Experimento tubo ressonante}

A corrosão de tubos metálicos é um processo contínuo e variável de liberação de íons de ferro da tubulação para a água. Sobre certas condições ambientais, canos de metal podem tornar-se corroídos com base nas propriedades do metal, do solo ao redor do tubo, e da água [73]. Cabos submarinos e umbilicais, utilizados na exploração de petróleo, são um exemplo de aplicação, porque precisam ser examinados e substituídos, sempre que há uma suspeita de corrosão.

A presença de falhas, rachaduras, buracos e fadigas, em uma estrutura, causam distúrbios nos modos de vibracionais, diminuindo suas amplitudes ou alterando suas frequências [74]. Após a identificação do perfil do espectro de frequências, de uma estrutura instalada, em 
condições normais (sem falhas), é possível acompanhar, através da variação do sinal acústico, uma possível falha mecânica na estrutura [75].

Com o objetivo de demonstrar a viabilidade da técnica APE em uma aplicação de ensaios não destrutivos, um experimento foi montado utilizando a APE para observar as variações no modo vibracional de um objeto metálico diante de uma falha na estrutura. Um tubo de aço foi submetido a pulsos de ultrassom em diferentes pontos de modo que fosse possível identificar as variações no espectro de frequência devido a posição de excitação, de modo a observar a sensibilidade da técnica APE quanto a posição de excitação. Em seguida, o tubo foi submetido a um processo de corrosão, utilizando ácido Clorídrico a 2 molar, cobrindo uma região isolada do tubo de aproximadamente $6 \mathrm{~cm}^{2}$ de área corroída.

\subsubsection{Materiais e métodos}

O arranjo experimental é mostrado na figura 6.5, que consiste basicamente na excitação por impulso ultrassônico em diferentes pontos do tubo. As dimensões do tubo eram comprimento: $300 \mathrm{~mm}, 25,4 \mathrm{~mm}$ de diâmetro externo e $2,1 \mathrm{~mm}$ de espessura da parede do tubo. 0 foco de excitação foi posicionado em diferentes distâncias do ponto de apoio do tubo de modo a avaliar a amplitude de vibração. Os parâmetros utilizados na APE foram: pulso de excitação na forma de um burst de 3000 ciclos de 3,43 MHz com amplitude $40 \mathrm{Vpp}$, a janela de processamento foi de $1,5 \mathrm{~ms}$. Os espectros de frequência foram discretizados em $20 \mathrm{~Hz}$ utilizando o algoritmo de FFT.

\subsubsection{Resultados com o tubo ressonante}

O gráfico da figura 6.6 demonstra o espectro de frequências para um tubo metálico excitado pela técnica, para cada curva, o ponto onde o tubo foi excitado era diferente, de modo que a distância longitudinal entre o ponto de excitação e o ponto de apoio por onde o tubo foi preso 


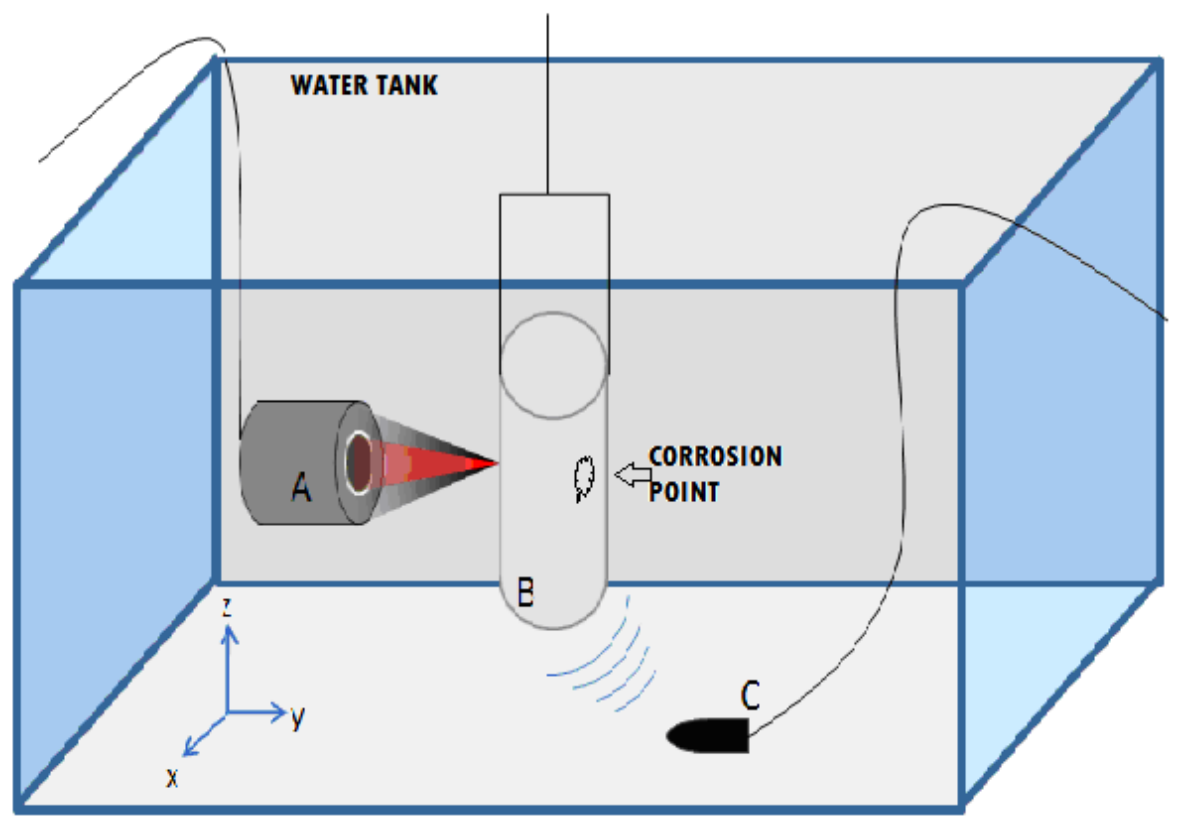

Figura 6.5: Configuração para avaliação da técnica em um tubo ressonante

era diferente. Observando as amplitudes dos sinais em torno da frequência de $7,0 \mathrm{kHz}$, notamos um decaimento do valor a medida que o ponto de excitação se aproxima do ponto de apoio, fazendo uma correção pelo torque, ou seja, fazendo uma compensação pelo tamanho da alavanca, é possível justificar o decaimento do sinal. Mas o mais importante deste gráfico na verdade, é mostrar que, para as três diferentes posições de excitação, o material era o mesmo e o padrão de espalhamento era o mesmo, isto nos permite concluir que a frequência de $7,0 \mathrm{kHz}$ esta relacionada a um modo vibracional do tubo. Deste modo, se agora, provocarmos uma falha na estrutura do tudo, então este modo deveria ser alterado. De fato, ao excitarmos em um mesmo ponto um tubo que foi submetido a uma pertubação em sua estrutura, como no caso uma corrosão ou um furo, notamos uma variação no espectro como observado na figura 6.7.

Especificamente na frequência de $7 \mathrm{kHz}$, houve uma significativa degradação do sinal para a corrosão provocada, mostrando assim que 


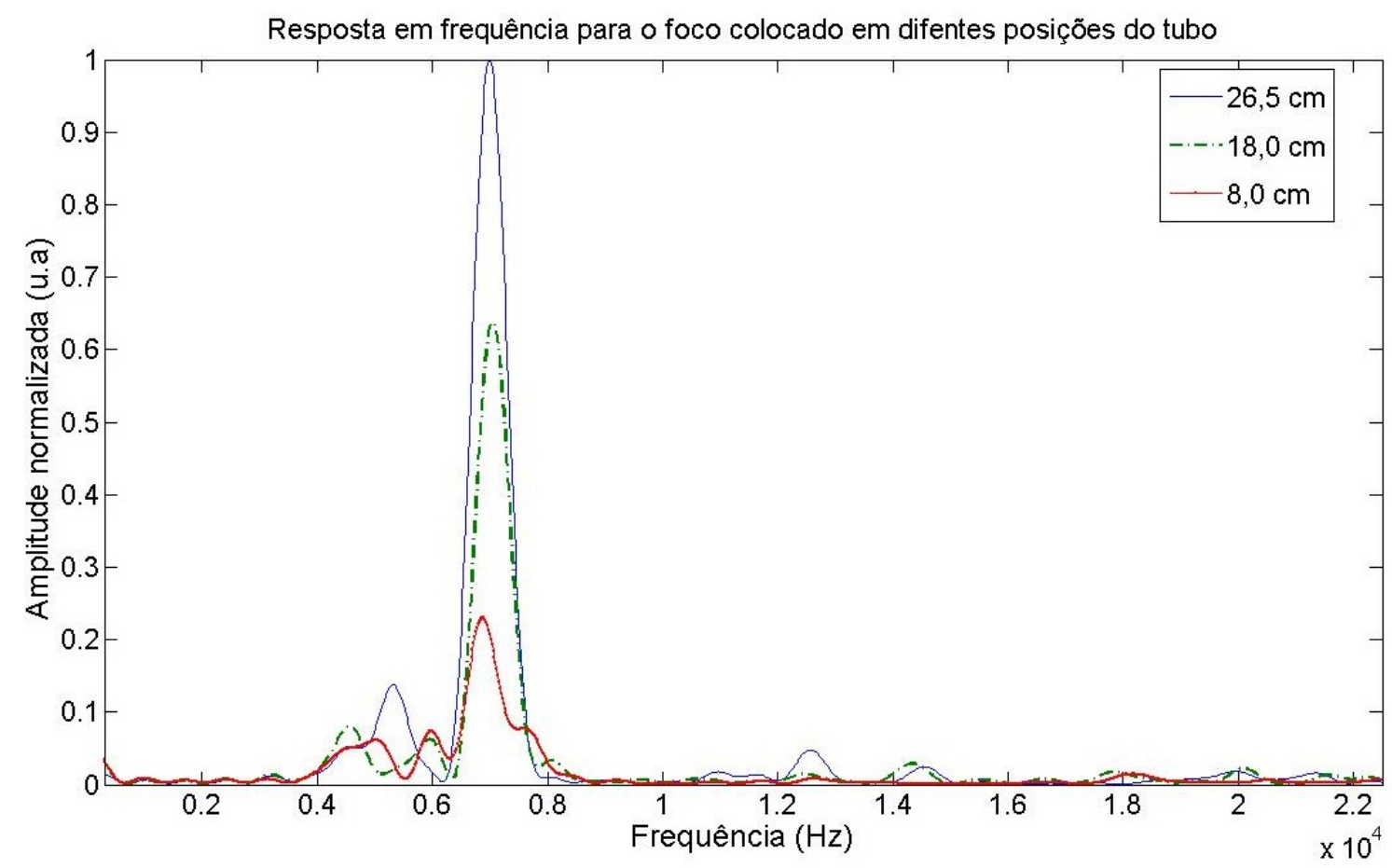

Figura 6.6: Resposta em frequência para diferentes pontos de excitação em um tubo metálico. (os valores na legenda correspondem à distância do ponto de excitação ao ponto de fixação do tubo)

há viabilidade de utilização da técnica neste tipo de ensaio[61] [62]. 


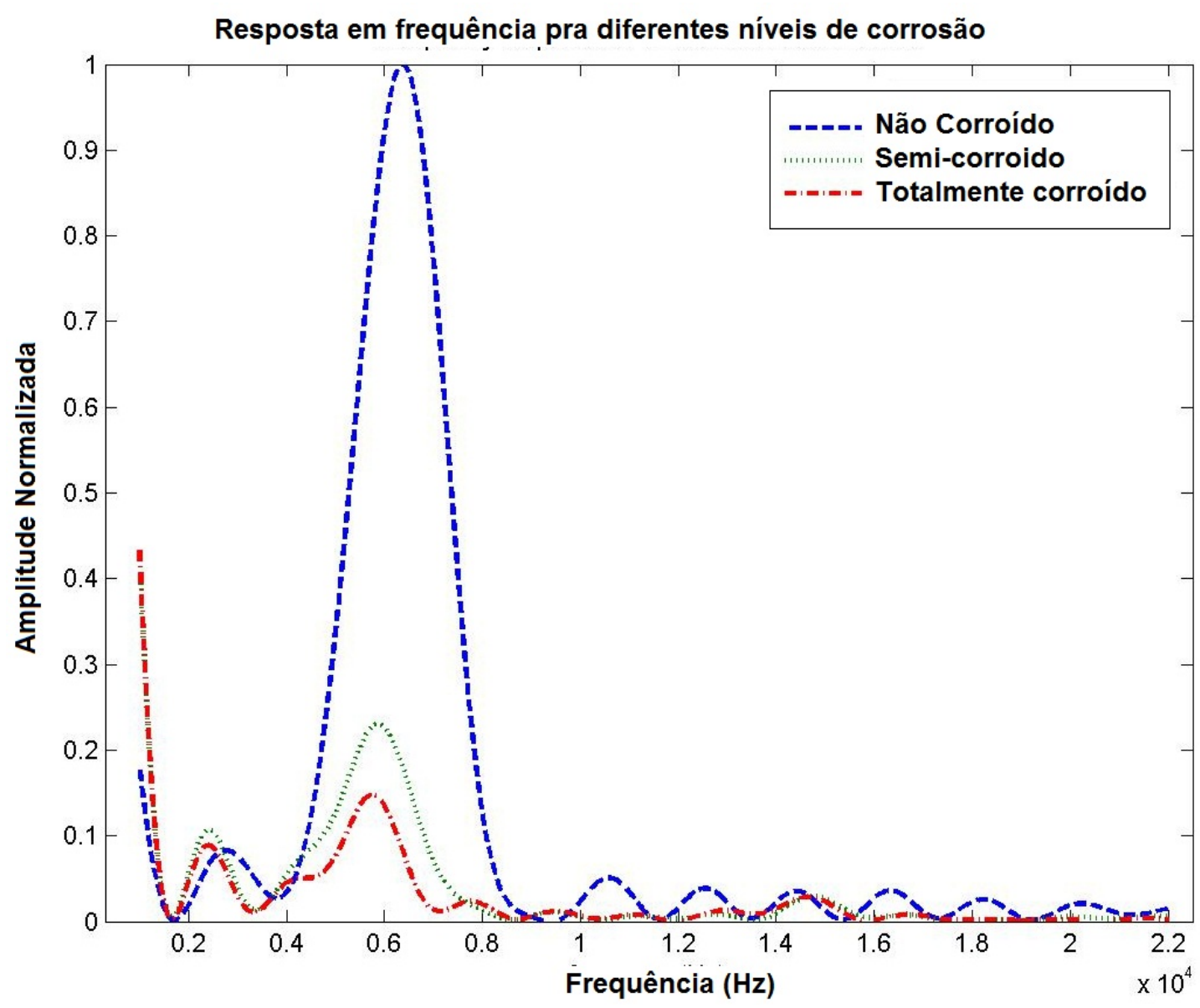

Figura 6.7: Espectros de frequência para diferentes condições de corrosão de uma pequena região do tubo $\left(6 \mathrm{~cm}^{2}\right)$ 


\section{Capítulo}

\section{Considerações finais}

A nova modalidade de imagem proposta nesta trabalho mostrou resultados promissores no processo de geração de imagens baseadas na interação da onda acústica com o meio material. Os resultados mostraram que as características vibracionais do objeto, os efeitos não lineares de propagação acústica e o padrão de espalhamento do alvo estão presentes no sinal acústico detectado e podem ser utilizados no processo de formação da imagem. A resolução espacial das imagens é semelhante aos valores encontrados nas modalidades de vibroacustografia. Um dos fatores que mostrou maior influência na qualidade das imagens foi a definição do tamanho da janela temporal de processamento do sinal adquirido, isto se justifica pela influência dos sinais reverberados presentes em intervalos maiores de aquisição.

\subsection{Vantagens da Técnica APE}

Entre as vantagens da técnica APE, pode-se destacar:

- Ausência de speakles devido as baixas frequências utilizadas na formação das imagens.

- Baixa diretividade do feixe emitido, facilitando a produção de imagens irregulares como a de ossos 
- Aparato instrumental simplificado, quando comparado com a vibroacustografia.

- Permitir a geração de imagens multi-frequenciais em uma única aquisição.

- Pode ser facilmente implantado em equipamentos de diagnóstico por imagem.

Uma das principais limitações da técnica é o acoplamento do sistema de detecção do sinal (hidrofone) em arranjos experimentais envolvendo medições "in vivo", que, acreditamos poderá ser resolvido em um futuro próximo, com a utilização de hidrofones especiais que podem ser colados ao corpo. A resolução espacial é fortemente ligada ao perfil do campo acústico do transdutor de excitação, trabalhos envolvendo transdutores matriciais reconfiguráveis, estão sendo estudados de modo a redefinir um campo acústico com foco reduzido, que, muito provavelmente aumentariam a resolução espacial da APE.

\subsection{Trabalhos Futuros}

- Mapear a influência da característica do pulso gerado para diferentes cerâmicas PZT no sinal da APE.

- Expandir a aplicação da técnica em estudos "in vitro" e "in vivo".

- Explorar a sensibilidade da técnica com o efeito não-linear devido a interação da onda ultrassônica com o meio, com o objetivo de localizar micro-calcificações.

- Implantar a técnica APE em equipamentos de ultrassom diagnóstico por imagem. 


\section{Referências Bibliográficas}

[1] FATEMI, M.; GREENLEAF, J. F. Vibro-acoustography: An imaging modality based on ultrasound-stimulated acoustic emission. Proc. Nat. Acad. of Sci. USA, Washington, v. 96, n. 12, p. 6603-6608, jun. 1999. xxiii, 4, 6, 24, 28

[2] LAUGIER, P.; HAÏATI, G. Bone Quantitative Ultrasound. New York: Springer, USA, 2011. xxvii, 8

[3] ACKERKNECHT, E. A short history of medicine. Johns Hopkins Univ Pr, 1982. 1

[4] GEN. Encyclopedia britannica @ONLINE, June 2011. 1, 2

[5] THORWALD, J. O segredo dos médicos antigos. São Paulo: Melhoramentos. VITÓRIA DA CONQUISTA (BA), p. 221-230, 2001. 1

[6] SCHAPIRA, D.; LEVINE, R. Breast cancer screening and compliance and evaluation of lesions. The Medical clinics of North America, $\mathrm{v}$. 80, n. 1 , p. $15,1996.2$

[7] OPHIR, J.; CESPEDES, I.; PONNEKANTI, H.; YAZDI, Y.; LI, X. Elastography: a quantitative method for imaging the elasticity of biological tissues. Ultrasonic imaging, v. 13, n. 2, p. 111-134, 1991. 3

[8] VIEIRA, S.; MARIAPPAN, Y.; FERNANDES, J.; EHMAN, R.; FATEMI, M.; CARNEIRO, A. Magnetic resonance elastography of gel dosimeters: Preliminary study. 3 
[9] GAO, L.; PARKER, K.; LERNER, R.; LEVINSON, S. Imaging of the elastic properties of tissue-a review. Ultrasound in medicine \& biology, v. 22, n. 8, p. 959-977, 1996. 3

[10] SUGIMOTO, T.; UEHA, S.; ITOH, K. Tissue hardness measurement using the radiation force of focused ultrasound. In: . c1990. p. 1377-1380. 3

[11] FATEMI, M.; GREENLEAF, J. F. Ultrasound-stimulated vibro-acoustic spectrography. Science, Washington, v. 280, n. 5360 , p. 82-85, abr. 1998. 4, 6, 27, 28, 73

[12] NIGHTINGALE, K.; SOO, M.; NIGHTINGALE, R.; TRAHEY, G. Acoustic radiation force impulse imaging: in vivo demonstration of clinical feasibility. Ultrasound in medicine \& biology, v. 28 , n. 2, p. 227235, 2002. 4

[13] MITRI, F.; GREENLEAF, J.; FATEMI, M. Chirp imaging vibroacoustography for removing the ultrasound standing wave artifact. Medical Imaging, IEEE Transactions on, v. 24, n. 10, p. 12491255, 2005. 5, 87

[14] MITRI, F.; SILVA, G.; GREENLEAF, J.; FATEMI, M. Simultaneous sum-frequency and vibro-acoustography imaging for nondestructive evaluation and testing applications. Journal of Applied Physics, Woodbury, v. 102, p. 114911, 2007. 5

[15] SILVA, G.; URBAN, M.; FATEMI, M. Multifrequency radiation force of acoustic waves in fluids. Physica D: Nonlinear Phenomena, v. 232, n. 1 , p. $48-53,2007.5$

[16] CALLE, S.; REMENIERAS, J.; BOU MATAR, O.; PATAT, F. Presence of nonlinear interference effects as a source of low frequency excitation force in vibro-acoustography. Ultrasonics, v. 40, n. 1-8, p. 873-878, 2002. 6, 74 
[17] ALIZAD, A.; FATEMI, M.; WOLD, L. E.; GREENLEAF, J. F. Performance of vibro-acoustography in detecting microcalcifications in excised human breast tissue: A study of 74 tissue samples. IEEE Trans. Med. Imag., lowa City, v. 23, n. 3, p. 307-312, mar. 2004. 7

[18] MITRI, F. G.; TROMPETTE, P.; CHAPELON, J. Y. Improving the use of vibro-acoustography for brachytherapy metal seed imaging: $A$ feasibility study. IEEE Trans. Med. Imag., lowa City, v. 23, n. 1, p. 1-6, jan. 2004. 7

[19] MITRI, F.; DAVIS, B.; URBAN, M.; ALIZAD, A.; GREENLEAF, J.; LISCHER, G.; WILSON, T.; FATEMI, M. Vibro-acoustography imaging of permanent prostate brachytherapy seeds in an excised human prostate-preliminary results and technical feasibility. Ultrasonics, v. 49, n. 3, p. $389-394,2009.7$

[20] ZHANG, X.; KINNICK, R.; FATEMI, M.; GREENLEAF, J. Noninvasive method for estimation of complex elastic modulus of arterial vessels. Ultrasonics, Ferroelectrics and Frequency Control, IEEE Transactions on, v. 52 , n. 4 , p. 642-652, 2005. 7

[21] ZHANG, X.; FATEMI, M.; GREENLEAF, J. Vibro-acoustography for modal analysis of arterial vessels. In: . c2002. p. 513-516. 7

[22] VIEIRA, S.; KINNICK, R.; BAGGIO, A.; NICOLUCCI, P.; FATEMI, M.; CARNEIRO, A. Evaluation of vibro-acoustography techniques to map absorbed dose distribution in irradiated phantoms. In: . c2009. p. 796-799. 7

[23] MOUSSATOV, A.; CASTAGNĖDE, B.; GUSEV, V. Observation of nonlinear interaction of acoustic waves in granular materials: demodulation process. Physics Letters A, Amsterdam, v. 283, n. 3-4, p. 216-223, 2001. 9

[24] ALLARD, J.; HENRY, M.; TIZIANEL, J.; KELDERS, L.; LAURIKS, W. Sound propagation in air-saturated random packings of beads. The 
Journal of the Acoustical Society of America, v. 104, p. 2004, 1998. 9

[25] TOURNAT, V.; CASTAGNÈDE, B.; GUSEV, V.; BÉQUIN, P. Selfdemodulation acoustic signatures for nonlinear propagation in glass beads. Comptes Rendus Mecanique, v. 331, n. 2, p. 119125, 2003. 9

[26] CASTAGNĖDE, B.; SAEID, M.; MOUSSATOV, A.; GUSEV, V.; TOURNAT, V. Reflection and transmission at normal incidence onto airsaturated porous materials and direct measurements based on parametric demodulated ultrasonic waves. Ultrasonics, v. 44, n. 2, p. 221-229, 2006. 9

[27] WeSTERVELT, P. Parametric end-fire array. The Journal of the Acoustical Society of America, v. 32, p. 934, 1960. 13, 15

[28] BERKTAY, H. Possible exploitation of non-linear acoustics in underwater transmitting applications. Journal of Sound and Vibration, v. 2, n. 4, p. 435-461, 1965. 14, 15, 17, 18

[29] SINGHAL, S.; ZORNIG, J. Synthesis of arbitrary broadband signals for a parametric array, July 29 1986. US Patent 4,603,408. 14

[30] AVERKIOU, M.; LEE, Y.; HAMILTON, M. Self-demodulation of amplitude-and frequency-modulated pulses in a thermoviscous fluid. The Journal of the Acoustical Society of America, v. 94, p. 2876, 1993. 14, 67

[31] CERVENKA, P.; ALAIS, P. Fourier formalism for describing nonlinear self-demodulation of a primary narrow ultrasonic beam. The Journal of the Acoustical Society of America, v. 88, p. 473, 1990. 14

[32] BARNES JR, R.; BEYER, R. Ultrasonic absorption in water at finite amplitudes. The Journal of the Acoustical Society of America, $\mathrm{v}$. 36 , p. $1371,1964.15$ 
[33] NUSSENZVEIG, H. Curso de física básica: ótica, relatividade, física quântica. Edgard Blucher, 2000. 15

[34] WESTERVELT, P. Scattering of sound by sound. The Journal of the Acoustical Society of America, v. 29, p. 199, 1957. 16, 18, 86

[35] REIF, F.; REIF, F. Fundamentals of statistical and thermal physics. McGraw-Hill New York, 1965. v. 148. 17

[36] MEIROVITCH, L. Analytical methods in vibration. New York, NY.: The Mcmillan Company, 1967. 19

[37] ZHANG, X.; FATEMI, M.; KINNICK, R.; GREENLEAF, J. Modal analysis of a mechanical heart valve by vibro-acoustography. In: . c2003. v. 2. p. $1392-1395$ Vol.2. 20

[38] MORSE, P.; INGARD, U. Theoretical acoustic. McGraw-Hill, 1968. 21,28

[39] ANTONIOU, A. Digital filters: analysis and design. McGraw-Hill, 1979. 22

[40] CHEN, X.; SCHWARZ, K.; PARKER, K. Radiation pattern of a focused transducer: A numerically convergent solution. JOURNALACOUSTICAL SOCIETY OF AMERICA, v. 94, p. 2979-2979, 1993. 24

[41] RAYLEIGH, L. On the pressure of vibrations. Philosophical magazine, v. 3, p. 338-346, 1902. 26, 28

[42] TORR, G. The acoustic radiation force. American Journal of Physics, Woodbury, v. 52, p. 402, 1984. 26

[43] CHU, B.; APFEL, R. Acoustic radiation pressure produced by a beam of sound. The Journal of the Acoustical Society of America, v. 72, p. $1673,1982.26$ 
[44] BEYER, R. Radiation pressure-the history of a mislabeled tensor. J. Acoust. Soc. Am, v. 63, n. 4, p. 4, 1978. 26

[45] RUDENKO, O.; SARVAZYAN, A.; EMELIANOV, S. Acoustic radiation force and streaming induced by focused nonlinear ultrasound in a dissipative medium. The Journal of the Acoustical Society of America, v. 99, p. 2791, 1996. 27

[46] JIANG, Z.; GREENLEAF, J. The nonlinear interaction of two plane waves in a viscous medium. The Journal of the Acoustical Society of America, v. 99, p. 2783, 1996. 27

[47] WESTERVELT, P. The theory of steady forces caused by sound waves. The Journal of the Acoustical Society of America, v. 23, p. $312,1951.27$

[48] DOEBELIN, E. System dynamics modeling and response. Merrill (Columbus, Ohio), 1972. 30

[49] OPPENHEIM, A.; SCHAFER, R.; BUCK, J. et al. Discrete-time signal processing. Prentice hall Englewood Cliffs, NJ:, 1989. v. 1999. 38

[50] MARPLE JR, L. Computing the discrete-time analytic signal via fft. Signal Processing, IEEE Transactions on, v. 47, n. 9, p. 2600-2603, 1999. 39, 40

[51] HALL, T.; BILGEN, M.; INSANA, M.; KROUSKOP, T. Phantom materials for elastography. Ultrasonics, Ferroelectrics and Frequency Control, IEEE Transactions on, v. 44, n. 6, p. 1355-1365, 1997. 47

[52] MADSEN, E.; HOBSON, M.; SHI, H.; VARGHESE, T.; FRANK, G. Tissue-mimicking agar/gelatin materials for use in heterogeneous elastography phantoms. Physics in Medicine and Biology, v. 50, p. 5597, 2005. 47, 50 
[53] SAMBUICHI, M.; NAKAKURA, H.; NISHIGAKI, F.; OSASA, K. Dewatering of gels by constant pressure expression. Journal of chemical engineering of Japan, v. 27, n. 5, p. 616-620, 1994. 47

[54] MADSEN, E.; FRANK, G.; HOBSON, M.; SHI, H.; JIANG, J.; VARGHESE, T.; HALL, T. Spherical lesion phantoms for testing the performance of elastography systems. Physics in Medicine and Biology, v. 50, p. $5983,2005.49$

[55] ASTM, E. 756: Standard test method for measuring vibrationdamping properties of materials. In: . c2004. 53

[56] HODNETT, M.; ZEQIRI, B. A strategy for the development and standardisation of measurement methods for high power/cavitating ultrasonic fields: review of high power field measurement techniques. Ultrasonics sonochemistry, v. 4, n. 4, p. 273-288, 1997. 57

[57] CARDONA, M.; A.V., A.; COSTA-FÉLIX, R. Implantação da Medição Primária de Potência Ultrassônica do Laboratório de Ultrassom do INMETRO. Simpósio de Metrologia na Área da Saúde Rede Metrológica do Estado de São Paulo - REMESP, v. 1, p. 1-6, 2005. 57, 59

[58] KAMIMURA, H. A. S.; PAVAN, T. Z.; ALMEIDA, T. W. J.; PÁDUA, M. L. A.; BAGGIO, A. L.; FATEMI, M.; CARNEIRO, A. A. O. Pressure transducer for measuring acoustic radiation force based on a magnetic sensor. Measurement Science and Technology, Philadelphia, v. 22, p. 015101, jan. 2011. 57

[59] JENSEN, J. Simulation of advanced ultrasound systems using field ii. In: . c2004. p. 636-639. 64

[60] NAYFEH, A.; MOOK, D. Nonlinear oscillations. Wiley Online Library, 1979. v. 31.67 
[61] SILVA, G. T. ; MITRI, F. Difference-frequency generation in vibroacoustography. Physics in Medicine and Biology (print), 2011. 68, 99

[62] BANDEIRA, A.; SILVA, G. Difference-frequency generation in nonlinear rayleigh scattering of acoustic beams. Journal of the Acoustical Society of America (print), 2011. 68, 99

[63] SILVA, G.; CHEN, S.; GREENLEAF, J.; FATEMI, M. Dynamic ultrasound radiation force in fluids. Physical Review E, v. 71, n. 5, p. 056617, 2005. 74

[64] CALLE, S.; REMENIERAS, J. P.; MATAR, O. B.; DEFONTAINE, M.; PATAT, F. Application of nonlinear phenomena induced by focused ultrasound to bone imaging. Ultr. Med. Biol., v. 29, n. 3, p. 465472, abr. 2003. 74

[65] CHEN, S.; KINNICK, R.; GREENLCAF, J.; FATEMI, M. Harmonic vibroacoustography. Ultrasonics, Ferroelectrics and Frequency Control, IEEE Transactions on, v. 54, n. 7, p. 1346-1351, 2007. 74

[66] FOLEY, A. The speed of sound pulses in pipes. Physical Review, New York, v. 14, n. 2, p. 143, 1919. 79

[67] RUMACK, C.; WILSON, S.; CHARBONEAU, J.; LEVINE, D. Diagnostic ultrasound, 2-volume set. Mosby, Philadelphia, PA, 2005. 87

[68] BRYAN, G.; BRYAN, G. Skeletal anatomy. Churchill Livingstone, 1996. 92

[69] COBBOLD, R. S. C. Foundations of biomedical ultrasound. New York: Oxford University Press, USA, 2007. 92

[70] ANTICH, P.; PAK, C.; GONZALES, J.; ANDERSON, J.; SAKHAEE, K.; RUBIN, C. Measurement of intrinsic bone quality in vivo by reflection ultrasound: Correction of impaired quality with slow-release 
sodium fluoride and calcium citrate. Journal of Bone and Mineral Research, v. 8, n. 3, p. 301-311, 1993. 92

[71] BOHRIS, C.; SCHREIBER, W.; JENNE, J. et al. Quantitative mr temperature monitoring of high-intensity focused ultrasound therapy. Magnetic resonance imaging, v. 17, n. 4, p. 603-610, 1999. 92

[72] MEIROVITCH, L. Fundamentals of Vibrations. WAVELAND PRESS, INC., 2010. 94

[73] ASSOCIATION, A. W. W. The External corrosion; introduction to chemistry and control. AWWA manual of water supply practices, M27, 1987. 96

[74] K.S, M. L. The Ultrasonic Non Destructive Testing. VVIET,Mysore, 1987. 96

[75] F.G. MITRI, Z.E.A. FELLAH, E. C. P. T. J. C. Determination of object resonances by vibro-acoustography and their associated modes. Ultrasonics, v. 42 , n. 1 , p. $537-543,2004.97$

1

\footnotetext{
${ }^{1}$ Citação de referências normalizada de acordo com a Associação Brasileira de Normas Técnicas (ABNT) - NBR 6023.
} 